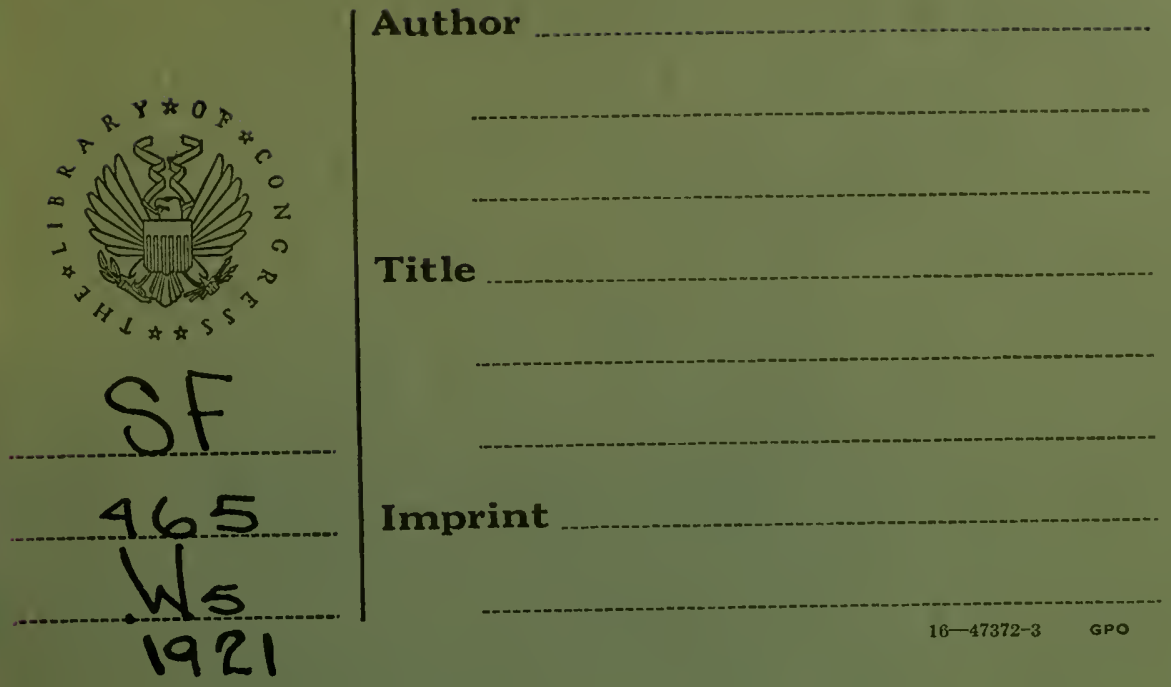





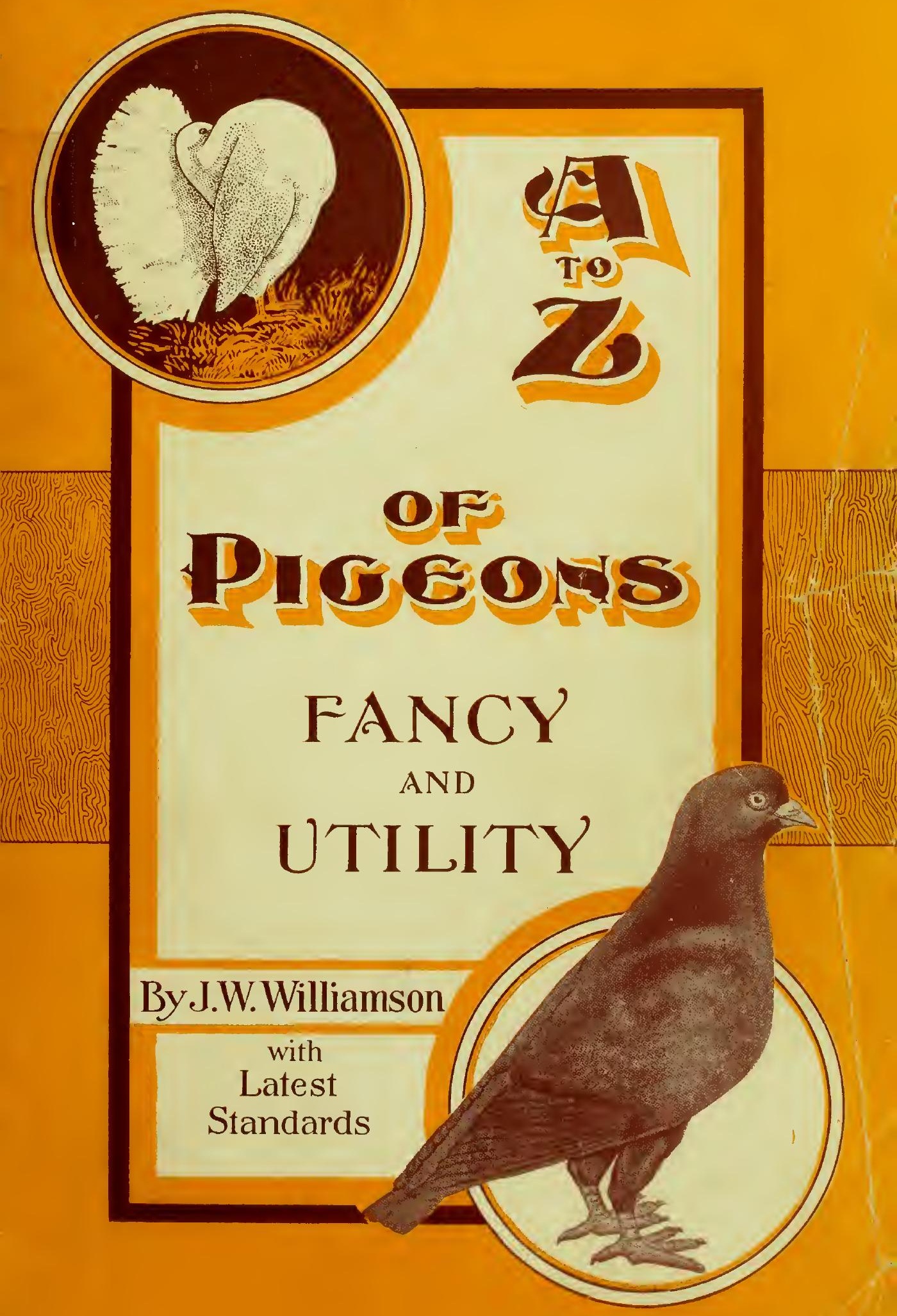





\section{A to Z $\mathrm{QF}$ \\ Pigeons Fancy and Utility}

With Latest Standards

By J. W. Williamson

New Edition

1921

_ Illustrated

\section{Published by the \\ Item Publishing Company}

Publishers of

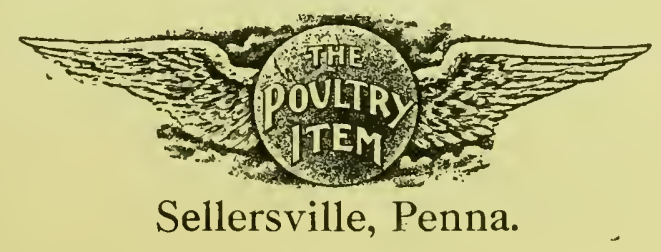




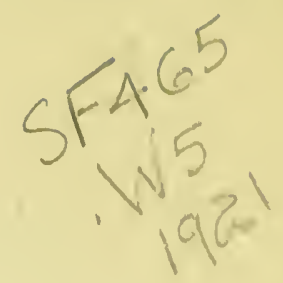

Copyrighted by the

Item Publishing Company

I92I

(C) ClA620398

Prices

l'aper Cover ... \$0.75

J,eather ..... \$i.25

JUL 281921 


\section{Index}

Page

Introductory

Wheat Screenings ......... 64

Origin and History of Pigeons .. 5

The Characteristies of Pigeons 6

Classification of Pigeons .... 8

Favorite Varieties ......... 9

Pigeon Questions and Answers ... 10

The Fancy Varieties ......... 11

Blue Pied Pouters .......... 11

English Carriers .......... 13

Flying Homers ............ 14

The Show Homer .......... 16

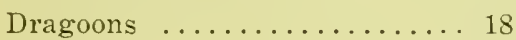

Tumblers .............. 18

English Turbits .......... 22

Magpies .............. 23

Satinettes and Blondinettes ... 24

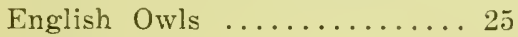

Trumpeters .............25

Jacobins .............. 27

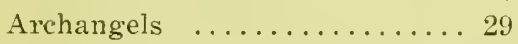

Fantails ....................... 31

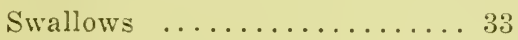

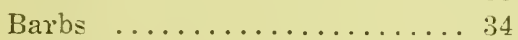

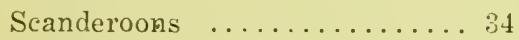

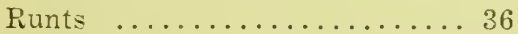

Utility Pigeons ........... 38

Squab Raisers ........... 38

Squab Raising as a Business ... 23

A Few Points on Squab Raising 39

Thorobred Squab Raising Homers 41

Carneaux ....................... 41

Maltese ............. 47

Hungarians .................... 48

White Kings ............ 52

Mondaines ................. 54

Duchesse .............. 56

Squabs ............... 57

Their Rapid Growth ........ 57

Raising Squabs .......... 58

Feeding ............... 61

How to Feed ............6 61

Automatic Feeders .........6 62

Time to Feed ...........6 62

What to Feed ............6 62

Kafir Corn .............6 63

Indian Corn ............. 64

Wheat ..............6. 64

Scorched Wheat .......... 65

Stale Bread ............6 65

Peas ................6. 65

Rice ..................6. 65

Hulled Oats ............6 65

Barley ................66 66

Buckwheat ............66 66

Hemp ................66 66

Sunflower Seed ..........66 66

Millet ..............66 66

Rape ................66 66

Lentils and Vetches .......66 66

Salt ........................ 67

Grit ................67 67

Charcoal ..............6. 68

Sanitation and Health ........69 69

Sickness ................ 69

Water .............. 69

Water System ........... 70

Whitewashing ............ 70

A Good Whitewash ......... 71

The Proper Way to Clean ..... 71

Cleaning Houses .......... 71

Training Cats to Catch Mice ... 72

Shifting Nests ...........73

From Egg to Market ....... 73

Diseases and Their Remedies .... 74

Canker ............... 74

Pigeon Pox .............. 74

Going Light ........... 75

Leg Weakness .......... 75

Pigeon Houses and Equipment ... 76

Standard Nesting Equipment 76

Old Style Nesting Equipment 79

Irating ............... 80

The Register Card ......... 81

Color Bands ............. 81

How to Tell the Sex ........ 82

Marketing Squabs .......... 83

How to Tell When Squabs are Ready for Market ........ 83

Prepare Squabs for Market .... 84

How Squabs are Picked ...... 84

Packing .............. 85

4 Recipes ............. 86

4 Index to Illustrations ........ 88 


\section{Introductory}

\section{Publishers' Preface}

We take pleasure in presenting this work on fancy and utility pigeons by J. WT. Williamson to the pigeon fraternity.

The Standards of the several varieties thruout the book are the very latest; some of them Mr. Williamson assisted in drafting for the specialty clubs and the U. S. Government.

The subject matter is well taken care of in the practical manner for which the author is noted. He has had long years of experience: is a well known authority, having written extensively and bred a great variety of fancy birds and marketing squab breeders since 1880 .

His judging at the leading shows has always been favorably commented on. His articles to the various pigeon papers have been read with pleasure and profit. Pigeon fanciers have often spoken of lnim as "knowing the pigeon inside and out." One of his lectures on "The Inside of a Pigeon" is both instructive and amusing.

He is a member of the Board of Managers of the National Piweon Association, member of the American Pigeon Club, Secretary of the International Carneau Club and an active member of other $\because$ lubs.

ITEM PUBLISHING COMPANY.

\section{Author's Preface}

In presenting "A to $Z$ of Pigeons" to the public the author realizes the task it would be to mention even in the condensed form in which the book is written all of the $A$ to $Z$ of pigeons or "From Egg. to Market", "All about Pigeons" and the various titles under which hooks on pigeons have been written. No living man can tell all, but as this is a revision of the book known as "A to $Z$ of Pigeons and Bantams," it was thot well to hold the "A to Z" title in this new edition and substitute utility pigeons in place of Bantams. So "A to Z" now is strictly a pigeon book of both fancy and utility breeds, that are the most popular in America.

In compiling the manuscript we have constantly had in mind the heginner with pigeons, the fancier and the marketing squab raiser. With this end in view, origin and history come first as an introduciory chapter. Some of the things, old fanciers have heard before, but not all. The amateur knows very little; hence we keep beginners, whom we desire to help, in mind, so they can in after years fill the ranks as the older ones drop out. Pigeon fanciers and keepers, like all men, do not forever stay in this world. So the first chapter is especially written for beginners.

At Glassboro, N. J.

J. W. WILLIAMSON. 


\section{Origin and History of Pigeons}

Everything has a beginning. Even the ring on a pigeon's leg, but where the beginning and where the ending? Who knows, and who knows the origin and history of the pigeon? The best that can be given is gleaned from historical works, including Sacred Writ.

The first we learn of it is when Noah let the dove fly out of the ark to learn if the waters were abated from off the face of the ground. The bird finding no resting place returned unto Noah into the ark. In seven days the dove was sent forth again - this time returning with an olive branch; again in seven days he sent forth the dove but it failed "to home," so Noah must be given credlit as the first flying fancier.

If the bird had been a present day trained Homer it would have returned to the ark eventually, even from hundreds of miles, but that would not have been fulfilling the object Noah wished. Everything for its particular purpose! 'The dove fulfilled its mission by not rei.urning, proving the waters had abated sufficiently for living creatnres to again inhabit the earth and multiply. Noah, by selecting a love instead of a pigeon, showed his wisdom, for even the common pigeon has an infinite liking for the cote it has established as its home.

Pigeons and doves have different habits clearly evident when left to their natural manner of living-the pigeon living in clefts of rocks, caverns and buildings, while the dove builds its nest in trees. There are, however, a few exceptions, as the Passenger Pigeon builds in trees. The following scriptural quotations, stated here as a matter of history, give us the pigeon and dove as separate species, which were taken to the market places to sell as food.

Gen. I5-9: "And He said unto him, take an heifer of three years old and a she goat three years old and a Turtle Dove and a young pigeon."

St. John 2-4: "And found in the temple those that sold oxen, sheep and doves."

Some vegetarians object to eating all kinds of meat from sentimental reasons only, yet Solomon ate large numbers of young fat I:igeons (squabs) while some of the Patriarchs offered them with other meats as sacrifices.

Of the pigeons of the old world the most interesting is dottbtless the Blue Rock pigeon, (Columbae livia) the "biset" of the French; a bird of extensive geographical range, breeding in crevices of rocks and within caverns that open on the sea.

Charles Darwin, in the "Origin of Species," claims that all our domestic breeds of pigeons are descendant from it or Columbae livia with its sub-species. 
Wild Pigeons or Passenger Pigeons are the only birds we can lay clain to as an American pigeon. All the other breeds, even our rommon barn pigeons, have been imported.

The last survivor of the wild pigeons died in the Zoological Garden at Cincinnati, Ohio, in the summer of I9I4. It was a large slender bird with small head, short strong legs and feet free from feathers, a long acuminate tail and was frequently spoken of as a "Bird of Passage."

They were quite plentiful in Ohio, Indiana, Illinois and a few Southern States until i860. When a boy, living in Ohio, I observed them building in trees and the peculiar way of feeding their young. Some of the old farmers stated that from 1835 to 1855 they were so plentiful as to be very destructive to crops of wheat, or any like seed, during planting time, that when a flock alighted upon a field they would settle so thickly upon the shocks that they would cover them entirely, and would also break the limbs of trees in the woods.

When startled, the sound was like that of thunder and the sky darkened as tho a dark cloud were passing. They were caught in great numbers in large nets by day and were easily caught in the hand at night. The squalos were always so heavy they could not fly well, and boys gathered them by the basketful to sell for 2 or 3 cents per dozen. Quite a contrast to our present pound squabs sell11ng for $\$ 1.25$ each!

Toothsome squabs (young pigeons) have always been considered a staple article of food for ages, but raising them in great quantities in a commercial way has been carried on only of late years. The eating of squabs has increased greatly; so much so, that the supply is never equal to the demand.

\section{The Characteristics of Pigeons}

Pigeons are a great deal like human beings and the better a person becomes acquainted with them the more their various characteristics are revealed. Most of them are found to be very loving to each other and will attend to their duties as two careful parents shouldrearing their young with all the care that good parents can possibly bestow upon them, feeding and keeping them in robust health. Such breeders can be lifted from their nest and they will at once return, but wee to the unruly bird that flies to such nests. The dutiful breeders seem to say, "This is our home, and we will fight before giving it up to ruffians." There are a few black sheep in the pigeon family, among both cocks and hens, who flirt with each other's mates and get into all sorts of trouble, but there are not many of this kind and they are soon noticed by any pigeon keeper. For instance, a cock bird will want to be "cock of the walk," and will fight everything that crosses his path, hasn't a civil word for anyone and abuses his mate. The best thing to do with such fellows is to get them ont of the way. Several years ago I had one of these tyrants. I knew that in house number six was a "grand old man," as I called him. who always attended to his own business and his family, but a great fighter if others tried to bully him. Into this house I placed 
the tyrant and his mate, and he began in his dominecring way to walk over everyone. The "old man" flew at him like an eagle, and buffeted him about the house most unmercifully. Personally, I detest fighting, but this one I did enjoy. We kept the tyrant Billy for a number of years and he and Teddy R, as I called the "old man," got along nicely, and Billy became the tamest bird in house number six. He and his mate became as peaceful as the others and raised excellent squabs.

No matter how many thousands of pigeons a man may have, he will always find time to show his appreciation for those that fly to him when he enters the house. He should cultivate the habit of noticing the wild ones, and tame them by tossing a few peas to them, talking to them, and handling them while on the nest. Teach them that you will not do them any harm; it will pay you a hundred-fold to do so. 'This is why I believe in flies not over six and one half feet high, low alighting boards, and the alleyways in front of the houses instead of the rear, so as to be always near the birds.

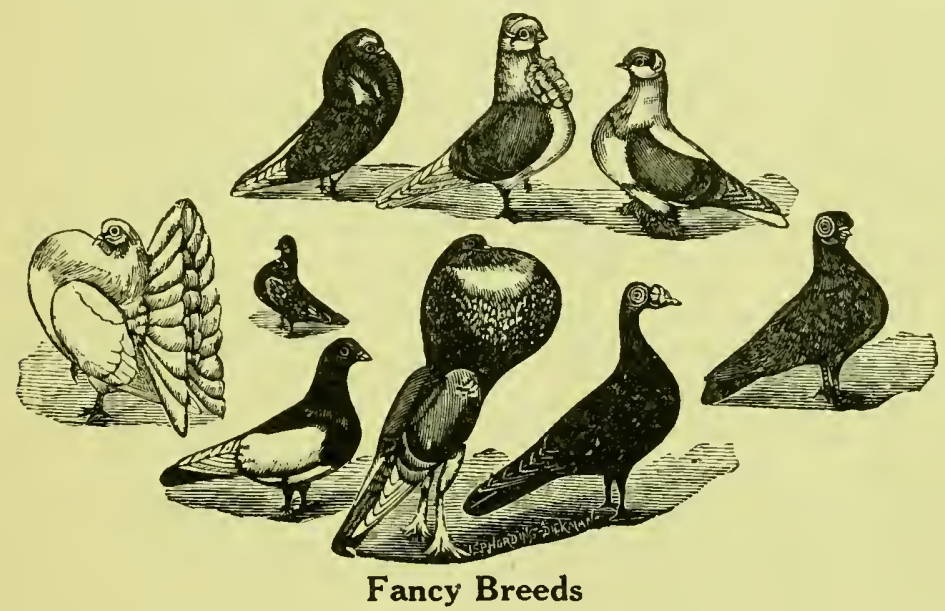

Cultivate the spirit of love toward them, and you will be paid for all such trouble, no matter how many birds you have. Two thousand can be kept tame and quiet as well as one hundred and they will work better.

Other Habits-The coo of some birds is different from others. 1 do not mean to the extent that some will make a trumpeting sound like the Trumpeter pigeon, but there will be some little peculiarity in the voice which an attentive pigeon fancier will quickly notice. Some will build a nest with only a few stems while others will build very high. Some birds will mate in three minutes after being together, while others will be two or three weeks, and possibly six months, when a lot of unmated birds are together. Sometimes a roung cock bird will run from a hen he has been flirting with, like a bashful youth, just as she is about to take his bill.

A cock bird is a very bashful fellow at times if there happen to 
be two odd hens trying to mate to him. He seems all bewildered, and does not know which to take. When eggs are laid in such cases, there are usually three or four but the continued fights between the two hens causes the eggs to chill so that they will not hatch. The greatest trouble in a breeding house is when two cock birds want the same hen, or the same nest. Pigeons are not doves, and in order that they may be peaceful, nothing but mated birds should be in an established breeding house.

\section{Classification of Pigeons}

To better understand the subject of pigeons they should be classified in order that the good points in each breed may be easily distinguished and should be divided into classes that the fancy may be more properly displayed and judged. Some of the I 50 varieties will be mentioned in the following pages.

Some varieties possess points and properties in which color and markings play no part in making them distinct breeds. They should therefore be separated from those which differ in color and markings from common street pigeons. The specially distinguished pigeons have always been considered the lords of the fancy and when classification became necessary they were placed at the head of the list as High Class Fancy Pigeons. In classifying, some place one breed to head the list while others place another breed. I will head the list with the Pouter, the dude of pigeondom, a large bird standing more erect than all others, sporting a large globe. In blacks the feather marking is similar to a man dressed in a cut-away coat with white trousers; when on parade he is like a tall drum major leading a band. Among this first division may be added The Carrier, Short-face Tumbler and Barb.

Second-Pigeons with distinctive properties where color is not an important factor, but with a strong tendency to impress their characteristics on their progeny, namely the Show Homer, Jacobin, Ow. Oriental Frill, Long-face Tumbler, Turbit, Scanderoon, Fantail, Priest, I'igmy Pouter, Mookee, Duchesse, Brunswick, Swift, Nahomet.

Third-Pigeons, which are dependent for quality almost entirely on color and markings, come under a group known as Toys including many sub-varieties-The Archangel, Helmet, Swallow, Nun, Spot, Crescent, Polish Silver Tail, Polish Black Tail, Suabian, Fire Back, Shield, Magpie, Breaster, Lahore, Ice, Starling, Quaker, Stork. Damascene, Fairy, Hyacinth, Porcelain, Moorcap.

Fourth-Utility pigeons used for the production of squabs for table use as well as show purposes. Homer, (Antwerp) Carneau, White King, Polish Lynx, Mondaines, Maltese, Hungarian, Austrian Strassers, 'l'cal and Runt.

Some of the second class that are large and good breeders of light skinned squabs also make good utility breeders.

The foregoing is a fair list of the best known breeds and varieties from which the novice may chcose to suit his fancy for pleasure or profit. Before purchasing birds he should first acquaint himself 
with some good fancier and also subscribe to a good pigeon nuagazine in which will be noted the various breeds and prices of birds of many varieties for sale.

\section{Favorite Varieties}

Pigeons, like poultry, dogs and other domestic creatures have their seasons of popularity. The old American Dominique fowl used to be seen on most all American farms; now we see more Leghorns. With dogs it used to be the Black and Tan, Pug, and Buston Terrier; now it is the Airedale. With pigeons, the Carrier and Pouter used to be supreme; now it is the Pigmy Pouter and Fantail at some shows while at others the Homer takes the lead. In utility classes the Carneau has the largest entry. At the National Show at Indianapolis, Indiana there were 224 entered.

A favorite pastime with many is keeping Flying Homers. Homing pigeons used for record flying are usually termed, "Working Homers." During wars they are used for carrying messages and always render excellent service as they fly very rapidly and make from 500 to 600 miles in a day. Other interesting breeds are Performing Tumblers of many varieties. The Parlor Tumbler can be taken into the house and it will rise a few inches from the floor and turn a somersault like an acrobat. Others classed as Rollers will repeatedly and rapidly turn somersaults, scarcely rising from the floor and the closer they stay to the floor the better. Outside performing Tunnblers will make a series of flights high in the air and work in a roll.

Keeping a kit of what are known as High-Flyers, is great sport for some people. It is a pleasure to keep them and a displeasure to lose them as they are a gamble. My first introduction was as follows: I was attracted by a kit of pigeons trying to alight on a tin roof on a red hot day in July. Sitting on the edge of a trap door I noticed a man waving a piece of cloth, tied to the end of a pole, to keep the birds away. I said to a friend "Is that man crazy?" $\mathrm{He}$ answered, "No, he is a pigeon crank." He will keep those birds up trying to get a greater number into the kit. His birds will attract them from a neighbor's loft. By the band number he can tell who owns every bird he gets in. He then takes them to the owner and receives a dollar or two as agreed. If his birds are attracted to his neiglibor's kit, he is out the same amount of cash. It's a great sport on a red hot roof on a red hot day.

The latest style of American High Flyer is very racy and attractive in appearance. Because some Racing Homers have a tendency to throw white flights in breeding, it would appear that at some time in the past this High Flyer had been used to put additional stamina in the Racing Pigeon. 


\section{Pigeon Questions and Answers}

Have you seen a Tippler flying in the sky?

A liglit and silver glimmer gliding by?

If not, then for you, is a pleasure rich and new, For the Tippler is a soarer, long and high.

Have you seen the Roller tumbling in the sky? A long and rapid roll, and wonder why?

If not, then for you, is a sight oft seen by few, For the Roller likes to tumble as well as fly.

Have you seen a Homer coming from the sky?

First a speck, then a pigeon to the eye?

If 110 , then for you, is a mystery ever new :

How the Homer reaches home, none knows why.

Have you heard a pigeon cooing in a cage?

The coo of love, of vigor, hate and rage?

If not, then for you, is a sound both old and new, For the pigeon's been a pet thru every age.

Have you seen a Fantail strutting in its pen? With a walk something like some prond men? If not, then for you, is a sight from any riew, When you see a Fantail strutting with its hen.

Have you seen a Pouter pouting in the sun?

Of this pouting, it would seem, he's never done.

If not, then for you, this stately "King of Doo(s)"

Shows you pride, and joy, and pleasure, all in one.

Have you seen the loyal Trumpeter calling Columbae far and near?

Walking with such a measured tread that all who see him ne'er forget,

His peculiar coo, 110 others have, yet all draw near

And never fear for he's kept it up for many a year.

Have you seen a pigeon fancier in the past?

Do you know that pigeon pleasures forever last?

If not, then for you, is a pleasure ever new,

Wher'er your home, or work or duty may be cast.

-E. J. W. D. in "American Pigeon Keeper." 


\section{The Fancy Varieties}

\section{Blue Pied Pouters}

The Pouter is one of the oldest varieties of fancy pigeons and has been a great favorite as far back as I735. In that year John Moore published his treatise on tame pigeons, which is thot to be the first book on the subject. He states that the Pouter was first bred in England and is, therefore, called the English Pouter. It was originally a mixed breed-between a Horseman and a Cropper-and it appears that this cross had been made very many years prior to Mr.

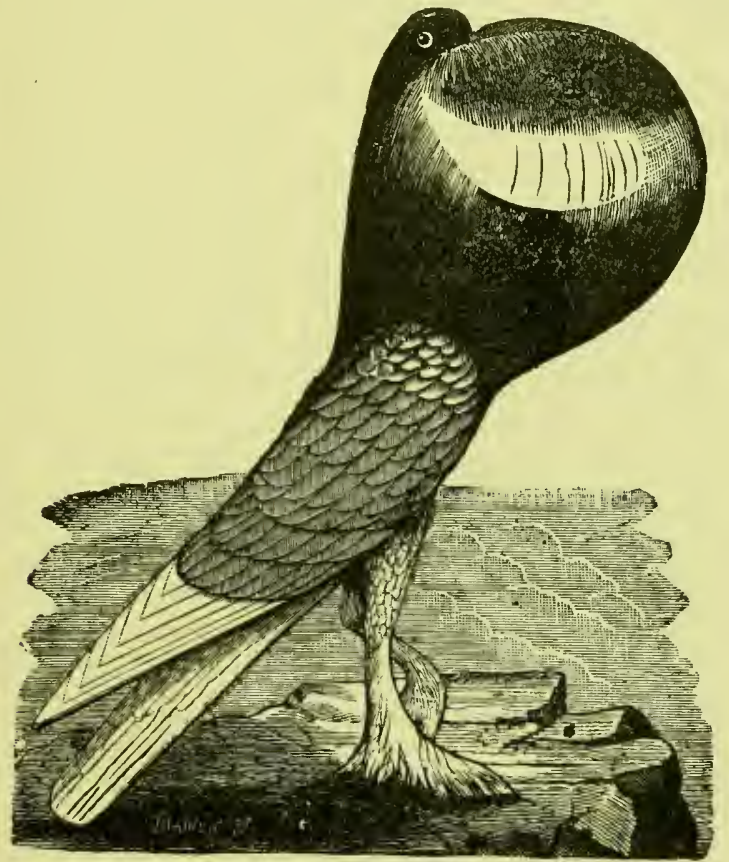

The Pride of the Show Room

Moore's remarks, judging from the description he gives. Of course, like all others of the older varieties, the Pouter has undergone many changes in fashion. Thirty years ago the great rage was size and length, somewhat irrespective of thickness of body, style and carriage. The shape of the limbs was not often what one would describe as elegant. I believe there are some few records that they measured seven and one half inches and over, but seldom, if ever, looked as long and more rarely were of the correct shape, position and closeness. Since that time the Pouter has grarlually been im- 
proved in general structure. 'The body has been greatly reduced in stoutness and the limbs no longer give the appearance of greater length on account of the careful breeding to get them placed further back in the body, closer inserted and finer in bone. Also length of feather has not been so much wanted, especially in tail. The shoulder has been considerably reduced, which all helps to give the bird a more slender appearance and, considering the foregoing points. the size of the crop of the present day Pouter is as large and as shapely as that of the old time clumsy birds.

There are many different varieties of Pouters. The Blue and Reds have always been the strongest, both in number and quality. 'The Blacks, altho they have improved in numbers, have made no material improvement, especially in color, excepting in a few cases. and these instances may be connted on the fingers. In Reds it has been quite the reverse, a great improvement having been made on them during the last several years, and there are plenty of good, first class specimens to be seen today. Yellows are quite popular and have improved much. These were the last to gain slenderness of girth, so much admired.

The Whites, unfortunately, have gone back very much during the past two or three years. I do not mean by this that there are no gond ones, but they are few indeed, in comparison with the others. In many sections of our Eastern States the Pouter is the most popular of the different varieties of fancy pigeons, and much enthusiasm is displayed by the fanciers, and in one instance the writer can relate having seen several hundred specimens in one show, nearly all of which were of exceptional quality.

\section{Pouter Standard}

Disqualifications-Trimming, plucking, coloring or any artificial alteration, out of condition from disease, any decided deformity, for whites; stained beak; colored feathers; or if eyes are not bull.

Length of Feather-i. e. the extreme distance when outstretched-from the point of the beak to the end of the tail, eighteen to nineteen inches is considered the proper length-the maximum figure to be preferred when the leg development is such as to admit of easy, lofty carriage.

Head-Small and narrow in proportion to the size of the bird, forming an elongated arch from the base of the beak, measuring about $15 / 8$ inches from the centre of eye to point of beak.

Crop-Should be globular in form, proportionately large and equally distended at all parts; to rise well up against the point of the beak, projecting prominently in front, and showing but a slight fullness back of the neck.

Girth-Slender, the greater the length from the lower part of the crop to the insertion of the thighs the better.

Back-Narrow and long appearing, slightly concave with a grooved line from base of neck towards rump, shoulders tucked close to body.

Breast-Narrow and convex, showing very little keel.

F'lights-Should be of sufficient length to reach nearly to the end of the tail, barely meeting at points directly over and close to the tail, to fold close and narrow.

Tail-Should be sufficiently long, and narrow enough to harmonize in the general taper of the bird, round ended and free from tendency to fork at extremity. 
Limbs-Generally lengthy, both in thigh and shank, measured from thigh. joint to tip of toe nail, constituting about three-eighths of the length of the bird. In referring to length, it is not necessarily meant the mere measurement by rule, but also a form and position that looks long to the eye ard at the same time enables the bird, when on a level floor, to stand tall and upright without being tilted forward by its tail. The thighs should be close together, and start from a position well back on the body, allowing room in front for the much desired long waist, the hock but slightly shown-almost straight, the entire limb well "stripped," showing to the fullest extent what length and form the bird may have. The feet stould incline slightly outward, and the knees in, toes spread, not doubled under or cramped.

Leg and Foot Feathering--The legs should be covered with short, soft feathers, fiting close and forming a complete mask for the entire limb, with only enough covering at the hock to hide the knuckles from view, called "Stocking-legged." The feet should have longer feathers, so thickly set as to leave no bare places exposed on the toes. The feathers should spread from the foot rather suddenly, forming what is denominated the "Slippe:"

Beal-Fine, mandibles straight, the upper showing slight curve at tip and slightiy over reaching the lower.

Beak Wattle-Small and fine in texture.

Eye Cere-Fine and thread like.

Cal'riage-Upright.

Movemerts-Majestic and proud, with head and crop aloft, gait opposite to straddling-graceful.

Colors-Pieds; black, blue, red and yellow. Plain color; white. Off colors; mealies, sandies, checquers, silvers and splashes.

Markings-Pieds; the head is colored, also the whole neck and back, including the wing coverts and crop, except a crescent shaped band of white passing around the front of the crop, the points or horns reaching within a short distance of the eye. The rib or colored patch coming down from the throat and forming the upper edge of the "Crescent" should be large and well defined. There should also be a few white feathers on the shoulders, which are desired, as nearly as may be, to fall separately one from the other in a small circular patch called the "Rose Pinion." These white feathers should be free from the edge of the wing butt. In blacks and blues the color extends to the end of the tail. Blues should have black bars across the wings and tail. In all colored varieties, the flights, thighs, legs and feet, also the entire under part of the body from the keel, or line across the breast, should be pure white. Whites-Plumage pure white thruout. The four representative colors, excepting blue, should be deep and rich in hue. The blue should be light, bright and even color. Color of Eyes-In the pied varieties, a bright red or orange; in whites, dark or bull.

\section{English Carriers}

The Carrier, during the World War, got mixed up in name with the Homer by many people-even by Government Officials. The Carrer is bred for show points only, not as a message carrier. The Norking Homer was the War Messenger bird.

The Carrier has often been termed the "King of Pigeons" but in tle United States of late years it has been losing its popularity as other breeds are outnumbering it in the Show Room. They are largely bred, not only in the United States but thruout civilization. They are bred in nearly all colors to a high state of perfection. It is a highly intelligent bird with bright eyes, alert and upright car- 
riage, large eye ceres and prominent wattles. In the past the different breeders seemed to give all their attention in perfecting the head points, thus sacrificing color and other qualities, but this folly seems to be past and now color and carriage are receiving attention with the result of a more uniform type as well as a more beautiful bird.

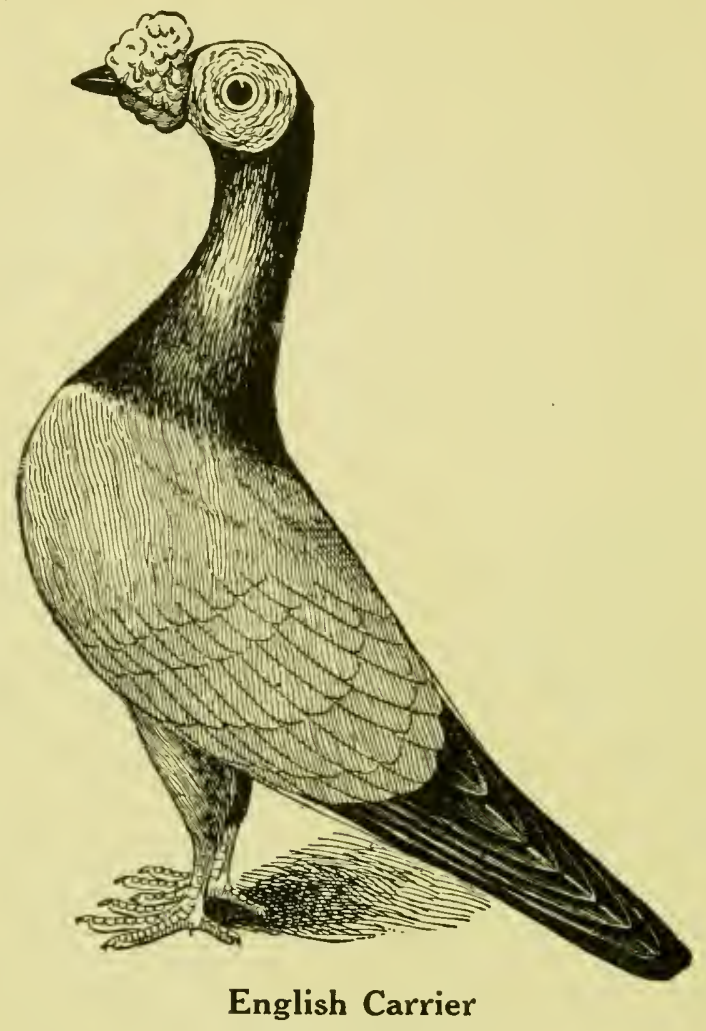

\section{Flying Homer}

\section{Working Homer or Racing Homer}

This variety has made rapid strides toward perfection, and when we sce a well bred, well trained Flying Homer it reminds us of a well trained athlete ready and willing to go into the contest. The requirements are a bird with a nice, even-shaped head of medium length set on a neck of medium thickness without any appearance of gullet, widening at the shoulders. The chest should be large and full but not too deep in keel; back short and flat, and broad across the shoulders, tapering off to the rump and tail; short and straight breast bone; wings to have graceful butts, flight to be broad. strong and closely overlapped; good secondary feather and covering: tail 
close fitting, having the appearance of one feather; carriage bold and alert, size medium and every point in proportion.

\section{Training the Flying or Racing Homer}

Nu variety of pigeons is so much attached to their home as the Homers, and such a thing as a Homer leaving his home loft and taking up his abode in another, as others sometimes do, never occurs. The home instinct is bred in them; indeed, so much of this instinct is impressed in their nature that well-bred ones rarely alight on any place but their own loft. Surrounding roofs of buildings are seldom used by them as a loafing place. The instinct for home in them makes them easily trained for long distance flights. No bird did such good service for humanity as these did during the World War both in the Army, Navy and Airplane service. When wires were down on land and boats were sinking at sea these trained messengers were

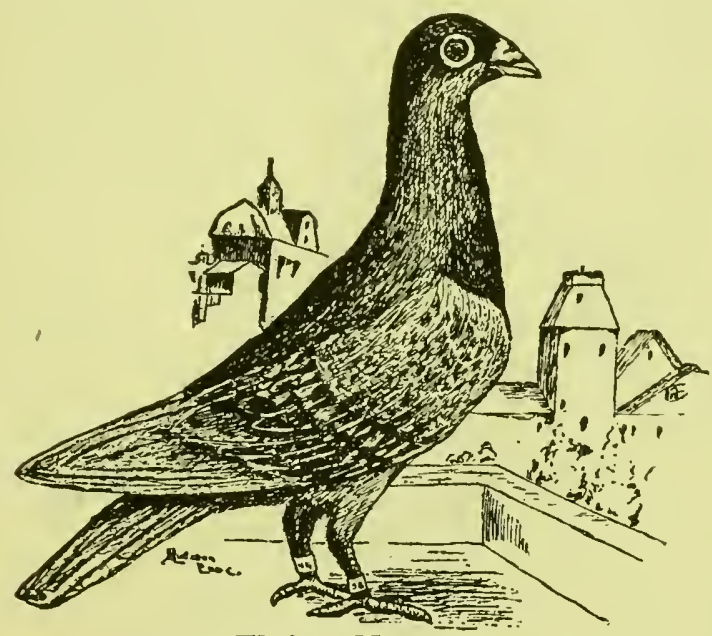

Flying Homer

used, the message was hurriedly written, placed in a small tube and fastened to its leg. If pains are taken in training and conditioning thenn, long and rapid flights are easily made by them, and the number of birds lost in long distance flights is very small if they have been carefully prepared.

In training old or young birds for homing races, the birds should be allowed to take daily exercise around the home loft. They should not be allowed unlimited liberty at all times, but the bob wires with which each loft should be equipped should be opened about three times a day and the birds allowed to exercise. In a short time they will become accustomed to being on the wing and make quite long flights from the loft and become thoroly acquainted with the surrounding country. Then they should be taken a few miles from the loft in a roomy basket or crate and liberated. They will at once circle and start for home. The next day they should be taken about 
five miles from home in the same direction as the previous day and liberated. The day following they should be taken ten miles from home in the same direction and allowed to fly home. Usually these preparatory flights are made from the east. After flying tein miles from the east, the birds are then taken over the same course from the west, and after they are thoroly acquainted with the surrounding country from ten to twenty miles from the loft in an easterly and westerly direction, they can then be started for their southern route. five miles from home for the first flight.

The day following they are taken ten miles from home; the following day twenty, after which they are given a rest for a day or two, with exercise around the home loft about a half hour each day. They can then be taken to the 50-mile station and liberated. After this they can be sent to the Ioo-mile station and then allowed one week's rest at home, with daily exercise of at least one hour. It the end of the week they can be shipped to the two-hundred-mile station and then allowed another week's rest at home with daily ex-

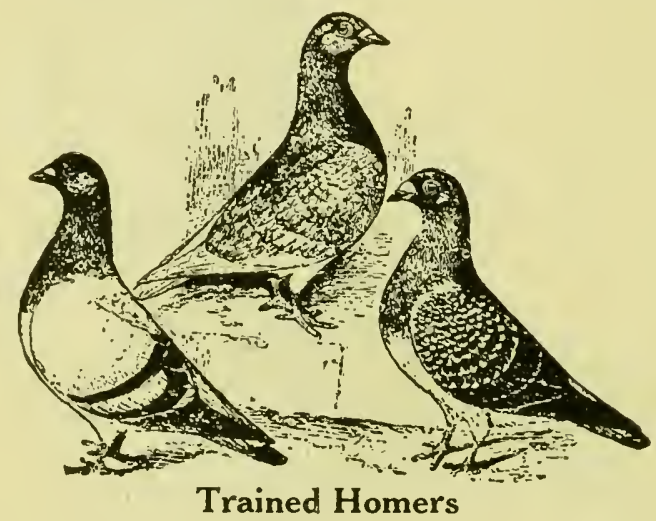

ercise of two hours. This system is continued by jumps of one hundred miles each week until the birds reach the five or six hundred mile station. After that, if extremely long distance flights are desired, they can be shipped to the station from which the long flight is desired.

By carefully following this system of training, Homers irequently fly five hundred and even six hundred miles in one day and cases are on record where birds have gone over eleven hundred miles. About the longest distance young birds should be trained is two hundred miles, altho they have been known to fly five hundred miles as youngsters, but we do not advise these long flights for them as they are rarely of any account as old birds. After they are thoroly matured they are ready for extreme distances.

\section{The Show Homer}

The interest taken in the Show Homer seems to increase as the years pass, thus giving its supporters abundant reason for claiming 
it one uf the most popular of all the different breeds of pigeons. 'Type is the strong point in the Show Homer. It matters not how perfect the eye, or color, the value is very much impaired if the specimen lacks type. Show Homers are bred in many different colorsCheguers, Blue, Black, Red, Dun, Silver and Yellow and in solid colors we have Blue, Silver, Mealy, Yellow, Grizzle and White.....

\section{Standard}

Disqualifications-Thin or horn colored beak, coarse or ill-shaped wattle, soft pale cere, red, gravel, lemon or hard eye, thick throat or gullet, frill or open feathered neck, long, swan neck, long shaped body, erooked breast bone, long soft feather, heavy or wry tail, white or pied rump or hocks, and other mismarkings, long, storky legs, web feet, crooked claws or toes. Birds when exhibited should be in perfectly natural condition. Io cut, trim, alter, or in any way improve by artificial means is altogether unallowable. Pied birds should be shown with their respective colors.

Head-The head is one of the most important features, and requires each part to be separately described. When looked at from a side view it should form a perfectly even and unbroken curve from the back of the skall to the tip of the beak. From the front or top each side of the face should be well filled, the front and top skull also forming an unbroken curve from side to side.

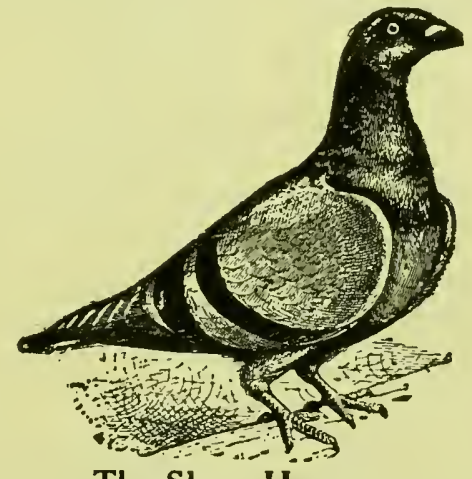

The Show Homer

Beak-The beak should be black, both mandibles stout, but not massive, and so set that it does not interfere with the perfect curve of the head. The edge of under mandible must be quite straight, and both fit closely together. From the tip of the beak to the corner of the eye it should measure about $13 / 8$ inches.

Wattles-These should be white, smooth and fine in texture, and shaped in the form of the letter $V$, the upper portion being clean cut out, and not filled in. With age there is a tendency to growth, but it should be only very slight, and for several years it should maintain naturally a fine and smooth appearance. No jewing should appear on the under mandible.

Eye-The eye should be set as nearly as possible in the centre of the head, should be pearly white in color, bright and sparkling, giving the bird a wild appearance, as if always on the alert.

Cere-This should be damson black, very fine and hard, having the appearance of a fine silk cord encircling the eye, and altho there is a slight tendency to growth, the cere should remain naturally fine and dark for several years. In the lighter colors, such as silvers and yellows, the beak and cere are mostly light in color; but it would be a great improvement if they could be gotten dark, as the mealies. 
Throat-The throat must be clean cut out and perfectly free from thickness or gullet.

Neck-The neck should be short, thick at the base, but gradually tapering to the point where it joins the head.

Body-The body should be short but strongly built, shoulders broad, chest well rounded, back broad, flat and straight, good depth of keel, the breast bone straight and vent bones close up, the whole body from the shoulders to the tail having a wedge-shaped appearance.

Feather-Firm and hard. The flights should be short, strong and broad, well overlapping each other to the end, and when standing should be carried close up to the body.

Tail-The tail should be short, thin and closely drawn together, straight and well carried.

Legs-The legs should be short, strong and well set, and quite free from feathers on the legs and toes.

Condition-The bird must be in perfect health, free from any deformity, and in a generally hard and firm condition.

Carriage-This should be of bold, upstanding appearance, showing a capability of great activity in all its movements.

Color-In Chequers the chief colors are blue, black, red, yellow, silver, dun. In all these the color should be sound thruout, and the chequering should be clear and distinct. The whole colors consist of blues, silvers, mealies and yellows, the color of each being sound thruout, with two broad and well-defined bars on the wings. There are also a few grizzles and plain whites.

\section{Dragoons}

Dragoons always command admiration wherever they are seen, whether it be in the show room or in the loft. Good quality in Dragoons comes high, and it is clamed the demand is greater than the supply. They are hardy and prolific breeders; stand confinement well. In many respects, as will be noticed by the illustration, they resemble the Antwerp, but have larger ceres and wattles. They are bred in Blues, Grizzles, Blacks, Whites, Duns, Silvers, Yellows and Chequers.

\section{Tumblers in General}

Pigeons have been kept both for fancy and utility for ages. The Romans were ardent fanciers of this beautiful bird, and the talk at the Forum as frequently dwelt upon the pigeon as it did upon the Senator.

Pigeon fanciers are like poets, "born, not made." This trait in an individual manifests itself early and persists late. It is a magic touch that places the urchin and the sage in the same class. Certainly no fancy holds out the temptation that this one does. The possibilities are so great. The whims of the most fastidious can find satisfaction in the pigeon. This bird is produced in most every conceivable shape and color. The delicate tints and penciling of their feathers seem hardly to be a part of a living bird. When one considers that these beautiful specimens of avian perfection evoluted from the aborigines, the Rock Doves, very evident is it then, what class of men labored to bring about this change. No other fancy can boast of so many artistic and intelligent sympathizers as this one. 
for the simple reason that intelligence is necessary to produce and maintain, and an artistic temperament is required to appreciate the elegance thereot.

Not only does the pigeon supply interesting combinations of color and shape, but action as well, viz., the lordly Pouter with his globe or the nervous Fantail with her toe-dance. But to me that sturdy little acrobat, the Tumbler, appeals most strongly. While this bird is produced in more colors and varied other morphological characteristics than we find in any other breed, his aerial gymnastics completely eclipse the tame demonstration of the Pouter, the Fan, or any other performing pigeon.

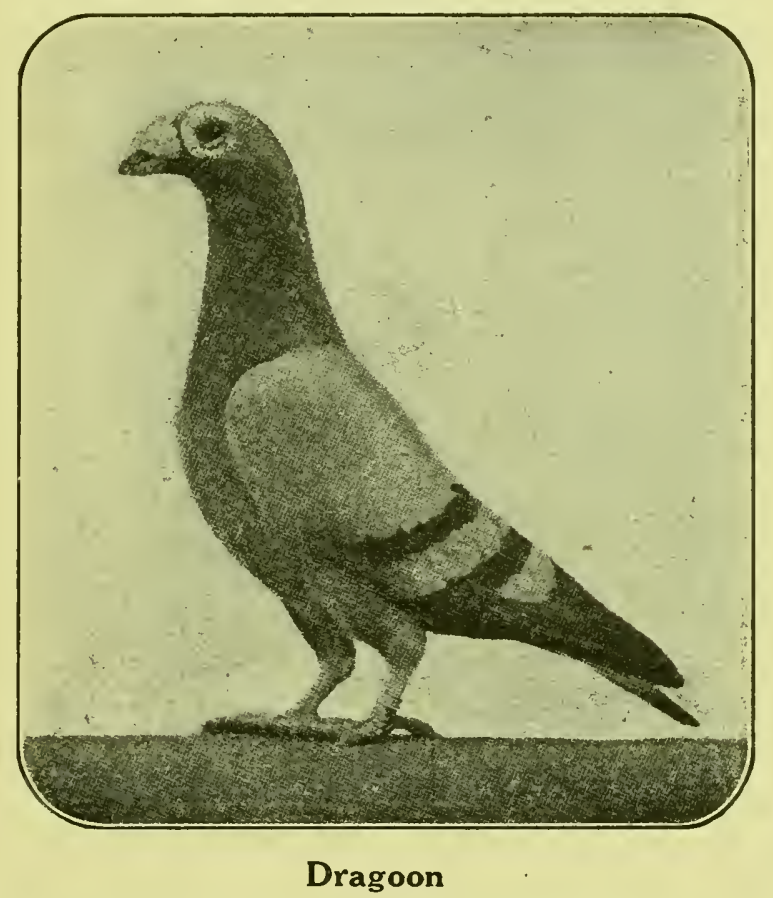

The Tumbler is bred in all the usual colors of pigeons, i. e., white, black, red, dun, silver, blue bar, saddle, also bald head, rosewing, white-side, badge, beard, etc. He may be either long-faced or of the short-beaked variety; clean-legged, stocking-legged, or muffed, and many pleasing conibinations of the foregoing colors and other characteristics. As a matter of fact, you are aware that this bird turns backward somersaults, hence the name Tumbler. The mode and surroundings in which he chooses to perform this feat divides his family into still further sub-divisions, i. e., outside and inside Tumblers. By outside Tumblers we refer to a bird that flies to some height before starting his daring performance. The inside Tumbler is a bird that will turn a somersault near the ground, thus 
making it possible to do so within the aviary. This bird is popularly known as the parlor 'Tumbler and was first trained in Plitadelplici, Penna.

Again the class is divided as to the number of somersaults, for instance, singles, as the word implies, a bird that turns a single somersault: dombles, the meaning of which is evident; roller, a performer that flies to a dizzy height and commences the roll, continuing same until he comes near to, or, as indeed is frequently the case, in actual contact with the ground or buildings, which in some instances makes it hazardous to allow sucl a specimen to perform. 'llhere are also inside Rollers.

This is by no means the limit of the classifications of this most interesting bird, but it will suffice to recall to the mind of the reader the truly wide possibilities in breeding a pigeon of so diverse characteristics. Another very strong point in tavor of the 'Tumbler is his remarkable vitality. In winters characterized by much snow, when it is necessary to house Bantams and indeed larger poultry, frequently for weeks at a time; this is quite smperfluous in the case of the Tumbler. A number of the clean-legged variety which the author allowed to fly at liberty during such times would, with impunity, walk about on the snow, the temperature near zero, flipping the dry snow first one way and then the other in search of feed tossed to them fur the purpose of observing their actions.

I have yet to see the first pair of 'Tumblers that are not good feeders, rearing their young without any trouble whatsuever. This is a very essential qualification which is frequently lacking in other fancy breeds. I know quite a few fanciers who make it al routine practice to shift certain of their fancy pigeon eggs to bircls of hnown feeding ability. This, to say the least, is contusing and expensive, necessitating the sustaining of a surplus amount of stock, and perhaps these foster parents are not so obliging as to set about the task of incubation at the proper time, another source of annoyance.

When a fancier has spent much time and money to produce a pair of birds which he thinks will breed just the progeny le wants, how eagerly he watches the eggs, and when pipped he knows there is a wimner in each shell. A few days later he fincls his winners mashed flat as a flitter-lead-starved. Then it is he realizes that the parents are no feeders, and if he expects any young from them they must be reared by other birds. With Jumblers this olojectionable feature is obviated.

Io summarize, the hardy characteristics and ample feeding proclivities of the 'lumbler recommend him and assure success to the amateur breeder as well as the veteran. His neat, compact bill, grand head and eye, dainty coloring and pleasing combinations of same and other bodily characteristics appeal to the artistic, while his marvelous acrobatic achievements champion him the prince of entertainers.

\section{Performing Tumblers}

The single performer should make but one turn, consisting of a straight backward somersault, (similar to the human acrobat.) 
The turn should be on a straight line backward (not sidewise) and at each turn the bird shonld land square on its feet. Performance shomld be noiseless and free from fluttering of wings. The single performer should clear the floor at each turn, but the closer the bette:

The Double performer should make two successive turns and as nuiseless and free from fluttering of wings as possible. 'The turns should be straight backward (not sidewise). The bird should clear the floor, but the closer the better, and land square on its feet.

The Roller performer should make a series.or number of straight backward turns: these turns or somersanlts to be on a straight line, backward (not sidewise) and as free from flutter of wings as possible. The performance of the Roller should be down on the floor, and at no time should the bird rise high enough to clear the floor while turning. Performance should be an actual roll on the floor. There are also outside 'Tumblers described under heading, "Favorite Varieties."

Colors-Selfs: black, yellow, dun and white. Nottles: red, black, yellow, dun and white. Black Self: Color deep) and sunnd showing a green metallic lustre. Beak black. Red Self: Color leep. red bronzy hackle showing free from green. Beak flesh color. Yellow Self: Color rich yellow, even thruout, pinkish bronze hackle showing free from green. Beak flesh color. Dun Self: Vary in hade, but must be clear and even thruont, either light, dark or medium. Beak, horn color. Mottles: Color sound and even thrnout. The pinion mottlings to be white and nearly circular, evenly distributed. Butts free from white. The back markings should be $\mathrm{V}$ shaped, well and evenly mottled. Beak as in solids. Splashes: IVell spangled with white, and color of the variety all over the body. IVing primaries and tail solid. Beak as in solids.

\section{Stanciarc.}

Disqualifications-Dark or broken eyes, or feathers below the hock.

Beak-Close fitting, straight, of medium length.

Wattle-Neat, fine in texture.

Skul!-Round, rather high in front.

Eyes-Pearl, centrally located.

Cere-Small, fine in texture.

Neck-Medium length, broad at base, tapering to thrcat.

Body-Short, stout and wedge shaped, prominent and wide in chest.

Flights-Closely set, short and carried on the tail.

Tail-Closely folded and wedge shape.

Legs-Stout and well set, medium length.

Carriage-Sprightly, upright, bold and jaunty.

Feather-Clean, close and tight fitting.

\section{Bald Head Tumblers}

The head, primary flights, tail and body color, downward from the breast-bone, should be white. The line of demarcation on the head should start from slightly under the lower mandible, pass close under the eye and rise gradually and evenly to the back of the head. Beak flesh color in all varieties. 


\section{English Turbits}

Tow much cannot be said of the English Turbit, the aristocrat of the pigeon family, which has always kept a strong hold on the fancier, who has an eye for the beautiful, for surely no other variety possesses so much real beauty as is combined in a thorobred Turbit. Their beautiful wing color, their large appealing eyes and haughty carriage are a delight to all lovers of birds, and for fondling, the Turbit has no equal among birds, for they are docile by nature, can be picked up anywhere in the loft if treated gently, and like to trass and strut and be played with. I have had birds so tame that they would light on me and follow me around the loft eating from my hand.

You may ask: "What are they good for?" If you do not like pets I will answer that they are good for nothing. They will get you out of bed a little earlier to give them a little attention, and

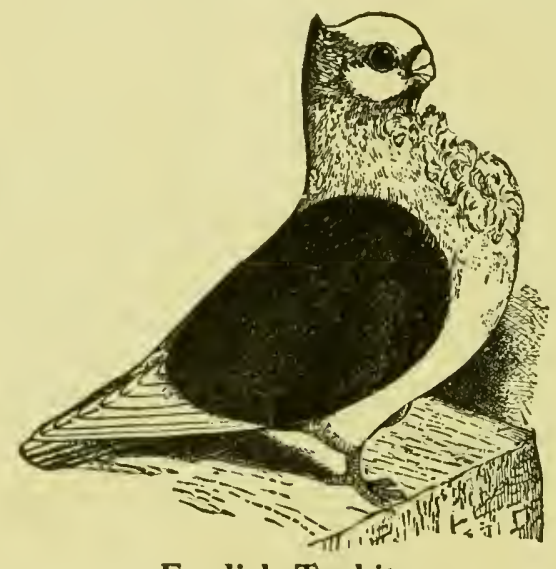

English Turbit

you will fuss with them noon and evening, which is just what you need to drive dull care away.

If you have never kept pigeons, I'd advise you to try it, but get the best pair you can. It will take you a season to learn the A. B. C. of Turbit breeding, and you want a good pair for there is as much difference in pigeons as there is in humans. And the better the breed the better results you will get-all things being equal.

The essentials are a dry place to keep them in, plenty of fresh air and fresh water, no draughts, good, clean food, a first class health grit and care as to lice and rats. Do not feed any more than the birds will eat up clean.

No variety of pigeons commands higher prices than a good thorobred Turbit, and winners at large shows have sold for, from $\$ 200.00$ to $\$ 300.00$ each. A pair of breeders that will not command $\$ 25.00$ are likely to be ordinary birds.

Learn first to fancy the Turbit, then learn to care for them successfully and raise the young, then buy one or two good pairs in 
preference to ten ordinary pairs, and with intelligent mating you will have good results and be successful.

The accompanying cut of an English Turbit hen will give you some idea of their beauty, and you may conclude for yourself whether you like the English or home-grown the better. England has years of advantage over us in breeding this handsome bird, but many a. good one has been brought here, and many good birds are raised in this comntry today. However Turbits are not so generally raised here as in England for some reason or other, and the breeders of

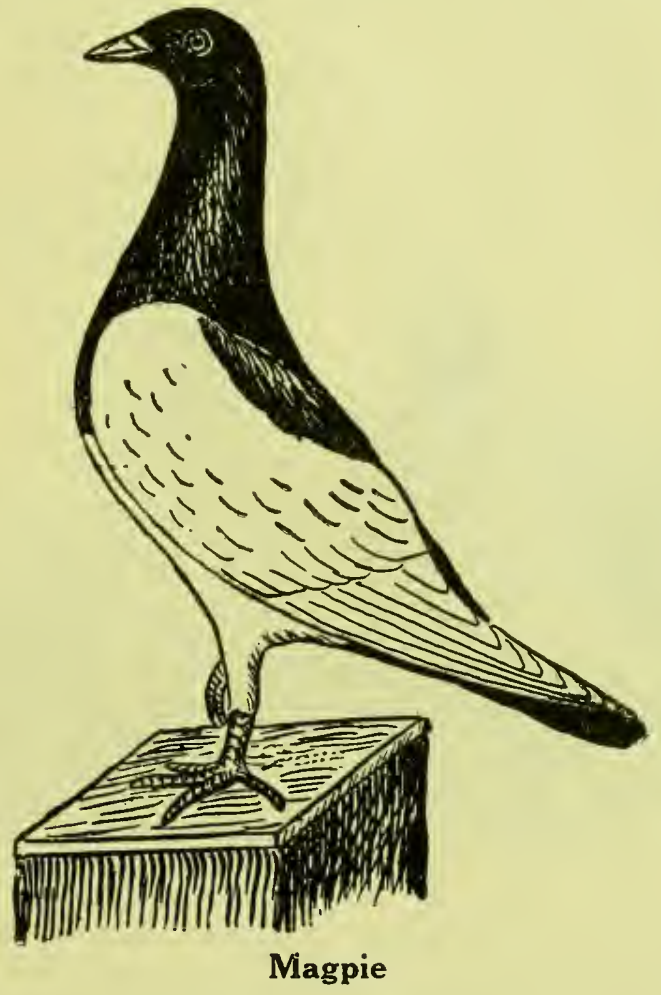

strictly high class blue-blood Turbits in this country today can be counted on your fingers.

The fancier who will take up the Turbit and hold to his oars until he reaches the headwaters of Turbit possibilities will make a name for himself. Men like Kline, Lenhart, Ulrich, Orr, Parson, Feather, Hart, McIntyre and others will go down in the history of the American advancement of this favorite bird.

\section{Magpies}

To keep Magpies is to love them. Their charming colors, alertness, delicate and symmetrical form and the manner in which they care for themselves and their young endear them to their owners. 
The sketch which appears with this article will convey to the reader who knows little or nothing about pigeons, the handsome outlines and lady-like form of the Magpie, which is oft times referred to as the "Oueen of Pigeons." The high class specimens are more slender in neck and body than the foregoing sketch.

They are bred in Black, Red, Yellow, Blue, Silver and Dun. 'The main points of the Magpie are so clearly defined in the sketch accompanying the article that it seems unnecessary to call any particular attention to them. The beautiful shape of skull, the fine texture of beak and wattle, the small bold eye, with fine choral cere, the long fine neck, the elegant outline of body, fine folded tails and game-like legs and feet are placed in front of the fancier in such a masterful way that to see them is to admire them.

\section{Satinettes and Blondinettes}

The Satinettes and Blondinettes are one of the oldest varieties of pigeons in existence, but just where they originated is a mystery,

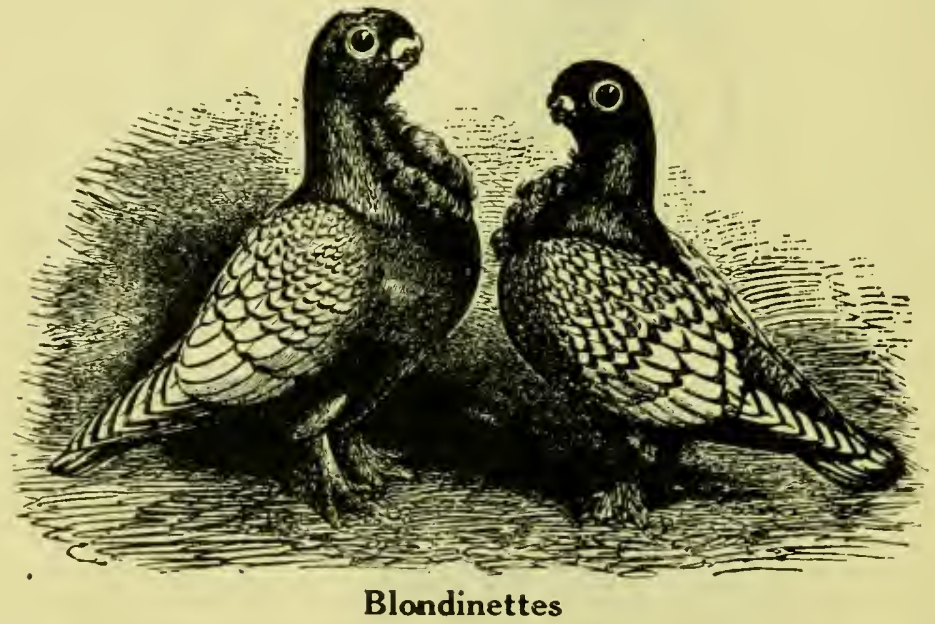

and they belong to that group of pigeons known as Oriental Frills. As their name implies, it is presumed they had their origin in the Far liast. 'The Satinettes and Blondinettes are very much alike. The Blondinette may be termed a dark-bodied bird and the Satinette a white-bodied bird, with only colored shoulders and tails. The Blondinette is laced over the entire body and the Satinette on the shoulders. 'The lacing should be regular and free from moss, the gromnd color being white. The Barred birds in both varieties should have spot tail with pure white boas, edged with a dark line with the distinction in the marking as in the laced birds.

\section{Black Blondinettes}

These are sub-varieties of the Oriental Frills. The lacing is more pronounced and conspicuous. Each feather is evenly edged with its respective colors varying from heavy to fine and from dark 
to light lacing. 'Tail and flights fairly edged thruout and neck also fairly variegated. Breast, back, under part, thighs and muffs also edged.

\section{English Owls}

The English Owls are not without a host of supporters, who claim them to be just as good, just as pretty as any variety. We find them most plentiful in blue, silver and dun, while occasionally we see a few blacks, chequers and creams. The good English Owl must have a fine dark eye cere, neat and shapely wattle, rich red eve, full gullet and abundance of frill. The head must be romnd, full and wide, have plenty of top skull and full frontal. The beak should be stout and well set and have a downward appearance, upper and low-

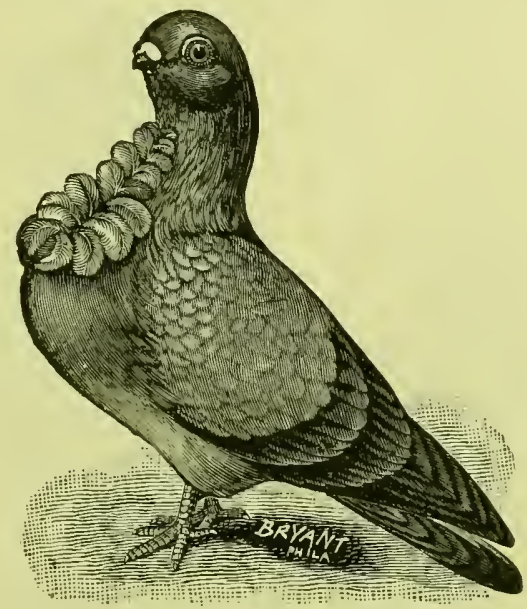

The English Owl

er mandibles close fitting with lividing line pointing to the center of the eye. The carriage is one of the main features, as is also shortness of feather.

\section{Trumpeters}

The Trumpeters are a most peculiar and interesting variety. They were first imported into the United States about 1875. They are natives of Asia, where they are bred in the Mosques by the priests. They are bred in Blacks, Whites, Chequers and Mottles. They should stand low in the legs, very heavily feathered, well spread clear to the toe nails. The main features are the rose and shell. The rose should be large, round, smooth and even, with a nice droop covering the beak and eyes, shell standing well up at back and curved forward, extending from eye to eye. One of the peculiarities of the Trumpeters is the coo, and if once heard it is seldom forgotten. It is possibly from this that they derived their name.

Trumpeters are described by Moore as well known in his time, and as deriving their name from the peculiar voice; the con being- 
very frequent, loud and abrupt. Their other properties are rose, crest, and foot-feather. 'The crest should resemble that of the shell crested Turbit, Nun and other pigeons, or otherwise the edge of a shell standing upright, and extending round the back of the head till nearly level with the eyes. It should not lie down, or fit close like the hood of a Jacobin, but stand upright, clear away from the head; and when it does this, the more developed it is the better. The rose is a circular top-knot or crest on the top of the head, spreading out as evenly as possible on all sides from a central point in the middle. The legs are heavily vulture-hocked, and the shanks themselves furnished with very long quill feathers.

The old style of English Trumpeters excelled in foot-feather, but rose and crest were poor. About i860, or soon after, however,

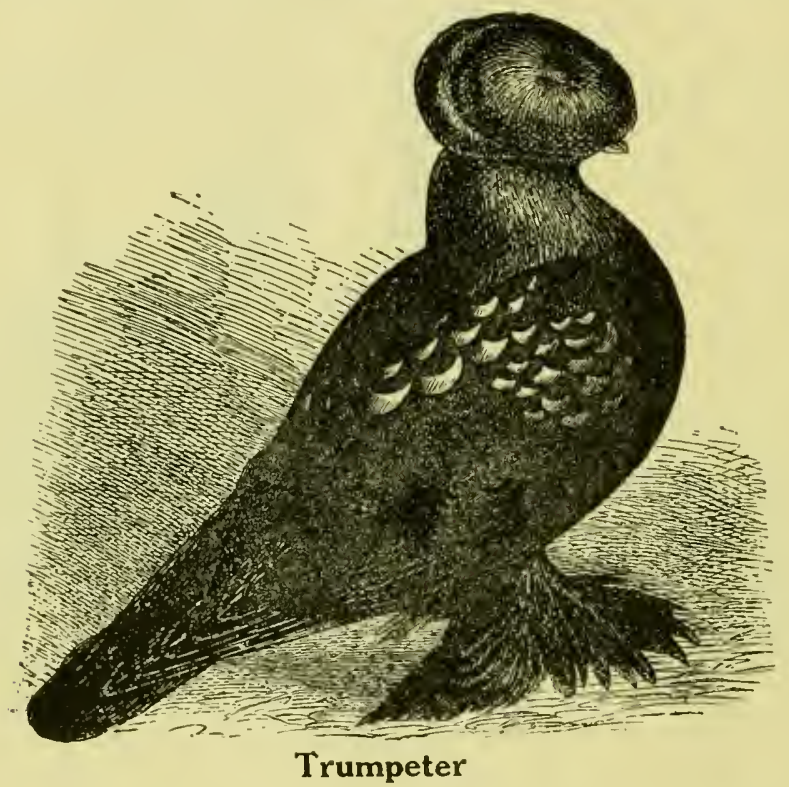

Messrs. John Baily and Son began to import birds from Russia, with enormous development of rose and crest, so far superior that they beat all the old stock. Their foot-feather was less developed; but this point has been improved, and the Russian Trumpeter is now the accepted standard. 'The eyes are pearl, and the colors black, white. black-mottled and splashed. It is a long feathered bird, loose in feather, and being also large in body, appears very large in size. Nothing can be more stately than the way the 'Trumpeter cock walks about when courting his hen.

Trumpeters deserve to be considered a very high class of pigeon, hut are not general favorites, being unfortmately very delicate. It is probably not the climate-since they come from Russia-but more likely the confinement in which they are kept, which is too much for them. Be the canse what it may, imported birds are peculiarly 
liable to consumption, for which it might be well to try small doses of hypophosplite of soda.

The lighter mottles and splashes do not look nearly so attractive as blacks and the orthodox mottle, or rather approach to it, for we have never yet seen a really good rose-mottled Trumpeter. The most likely plan of breeding such would be to go on matching blacks with better mottles.

In breeding for fancy properties the voice of the Trumpeter has been nearly lost, in many birds entirely so. It is never taken into consideration in judging. There is, however, a true laughing or trumpeting pigeon, with clean legs, not only described by Moore, but later by Brent; and in 1878 a pair of these birds was shown by Mr. Betty at a meeting of the National Peristeronic Society. They were blue-chequered, very small, dove-headed, and clean-legged.

\section{Jacobins}

The Jacobin, like the Fantail, depends on its attractiveness and wonderful formation of feather for its popularity and demand. The Fantail is possibly better known to the novice than the Jacobin on account of its wonderful formation of tail, which even the novice can distinguish and thus place the name to the bird. However, the Fantail can claim no greater army of enthusiasts than the Jacobin. The rivalry among the Jacobin breeders of the present is almost equal to that of any other variety, and rightly so, for there are reasons why it should be. The Jacobin is a hearty and prolific pigeon and requires but little assistance to rear its own young. In other words, they are considered to be fairly good workers. This latter point sliould be empliasized, for it is far too commonly assumed that a pair of feeders is necessary for each pair of Jacobins. Many of the Jacobin fanciers claim that they can successfully rear every bird they have, but that a few pairs of feeders will rear many a bird which gets a bad start from its parents or whose parents go to nest too soon.

The Jacobin is a peculiar variety and can never be improved, nor its characteristics increased by crossing with any other variety of pigeon. No small advantage is this, when one looks around and sees the evil results of such breaks in some favorite varieties of the day. The day has long passed when selection and perseverance on the part of the breeder will overcome every difficulty, however obstinate it may be, and the present day Jacobin is really a work of art, made so by years of careful mating and breeding to bring about the desired result and the truly wonderful feather formation that we see on nearly every specimen that adorns our exhibitions. No variety has a more high-bred appearance than the Jacobin when he is in full dress array. For the information of the novice, let $11 \mathrm{~s}$ briefly describe the chief point of this beautiful variety. By common consent the most important point in a good Jacobin is the hood. This should be smooth, and thick in substance of feather, fitting almost closely to the head, reaching forward as far as possible to the front of the head and merging without break into the mane behind 


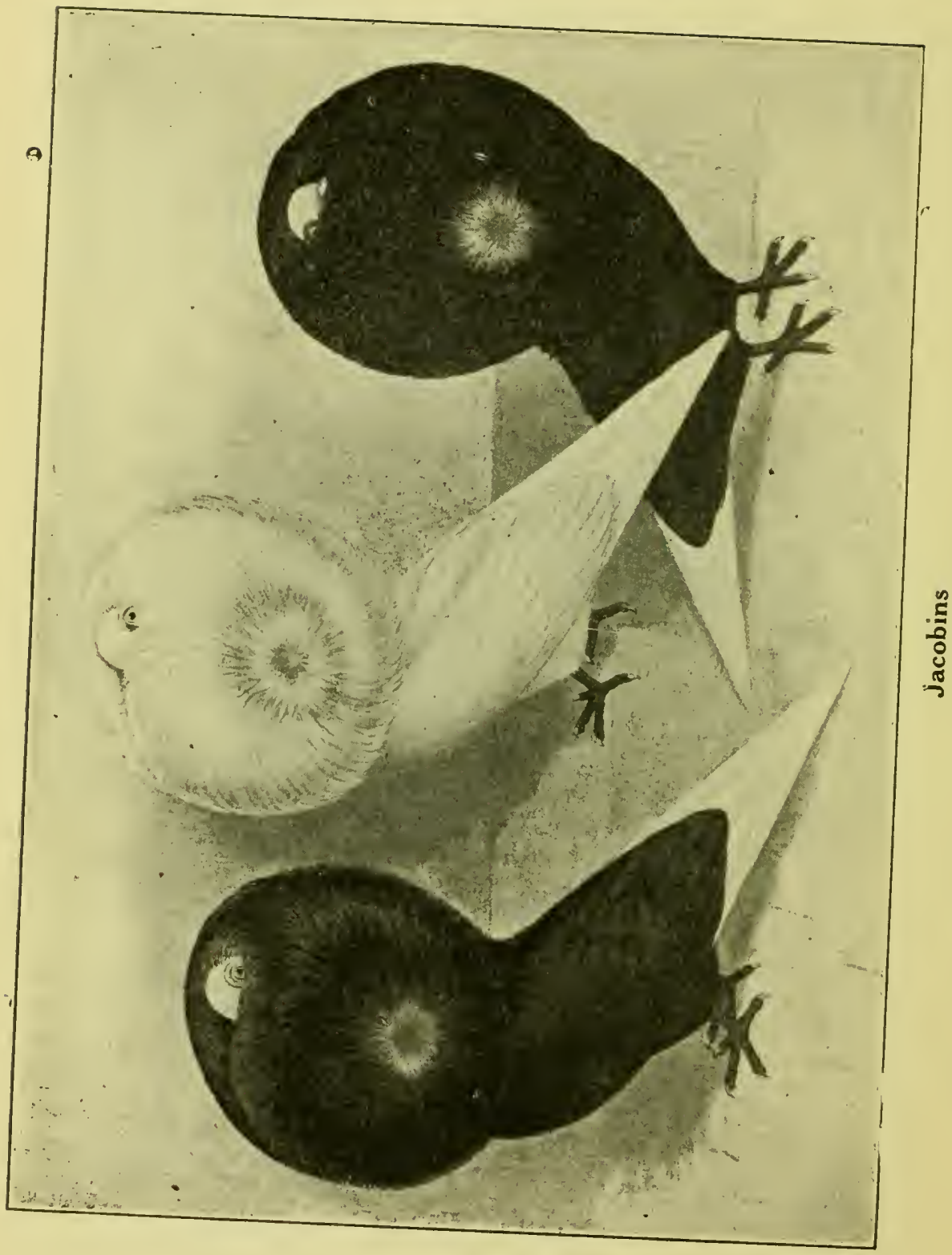


and the chain at either cheek. 'The chain should spring in a siveep)ing curve on either sicle from its junction with the hood, completely covering the big eyes and evenly meeting on both sicles, reaching as far lown the breast as possible. The mane should be well sprung int 1 an arch shape from its junction with the back of the hood. The feathers should be thick and smooth and meeting from either side in a graceful curved line without a break. The center from which the feathers radiate at the side of the neck to form the main chain is known as the rose. The tail and ten Hight ieathers on either side should be white; the remainder of the body in colored rarieties should be lustrous in color, whether red, black or yellow. IVhite or

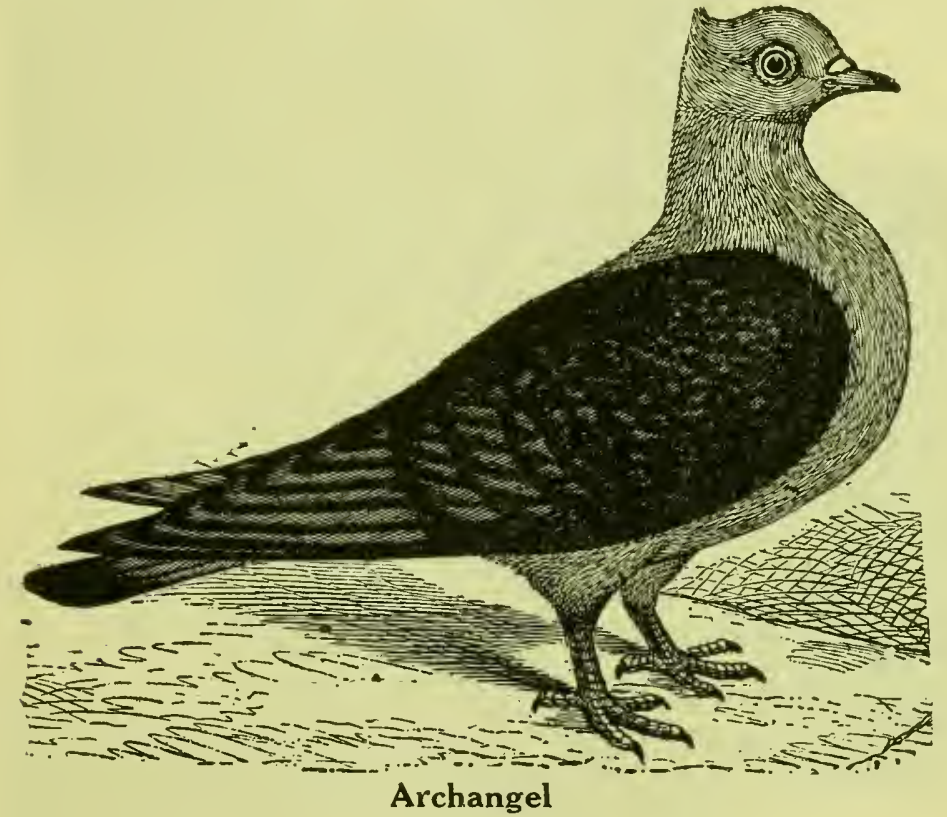

pearly eyes, long flights and tail, slim and tapering body and erect carriage make up the remaining properties of the fascinating. Jacobins.

\section{Archangels}

Of all the different varieties of pigeons with their great diversity of colors, none compares with the Archangel in richness. Just how they were named is a mystery, but there is a town in Russia by this name, and it is claimed they were originated there. In the Far East, where most of the varieties of fancy pigeons originated, the people are very devont, and we have many birds named after their teachers, such as Nuns, Jacobins, Priests, and hence it is presumed that they also named the Archangel on account of its richness in color. It is one of the most attractive varieties that we have, and they are bred to a high state of perfection. It has an upright car- 


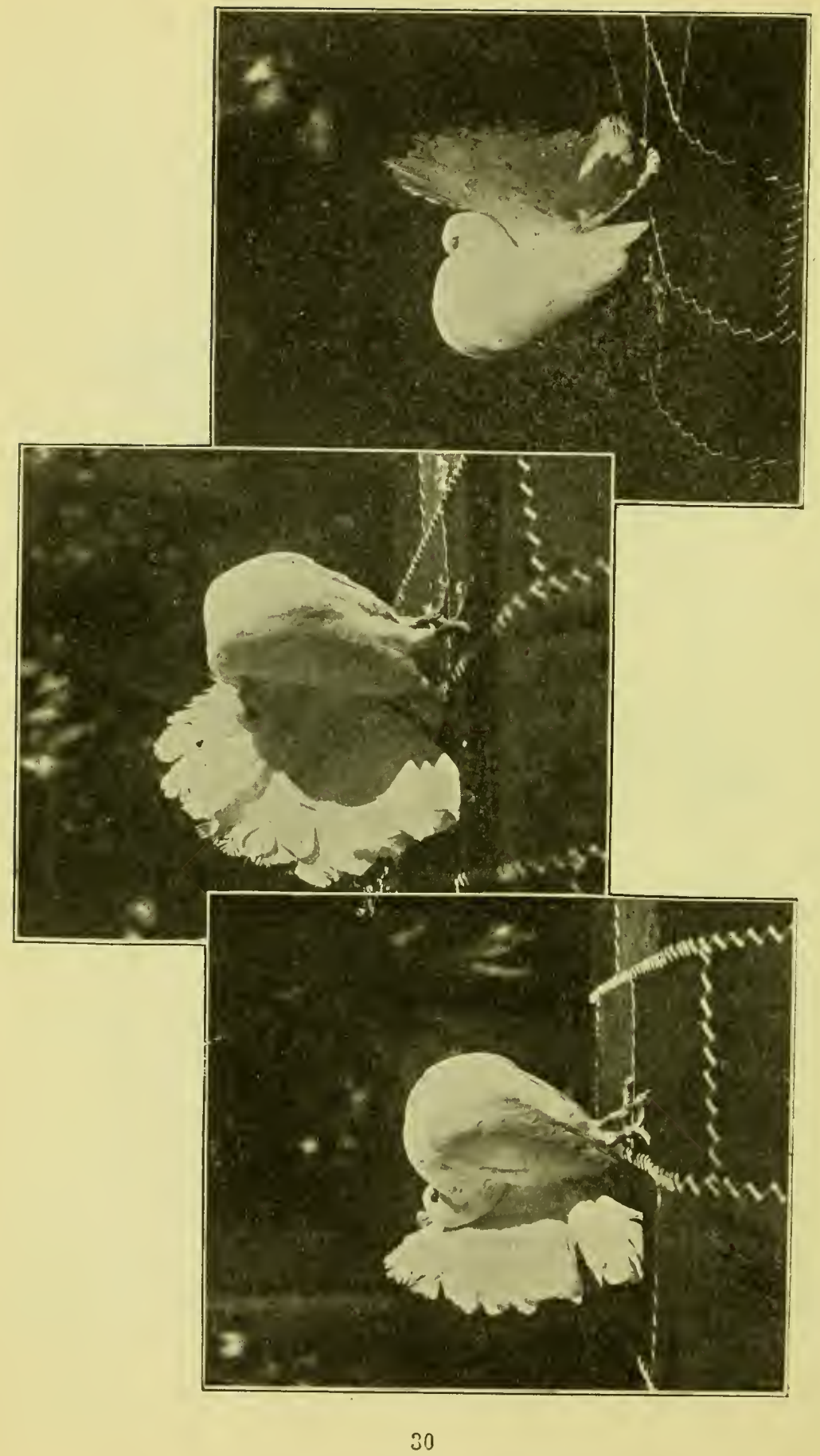


riage, long head, straight, slender beak. The wings are a dark brown while the neck, head, breast and bust are a rich bronze, giving them a burnished appearance.

\section{Fantails}

Of all the different varieties of pigeons possibly none attract the attention of the visitors at our leading shows more than the Fantails. It is conceded by all that this is one of the most interesting of all fancy varieties of pigeons. As we walk down the aisles of our different shows, we notice they are usually admired. Their aristocratic carriage, their graceful steps and that peculiar and striking motion of head and neck are their source of attraction and admiration. They

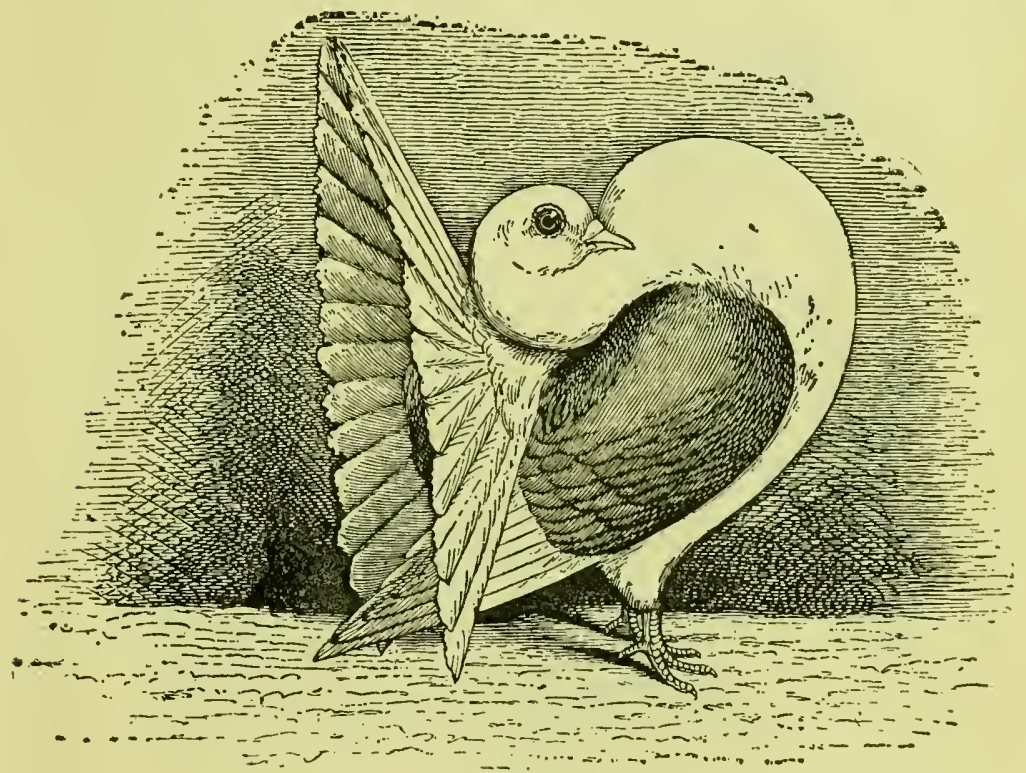

Fantail

constantly draw forth from the uninitiated the most amusing comments and remarks.

The Fantail, by nature, is not wild and this fact together with its peculiar characteristics makes it a general favorite. They are very easily tamed and quickly become attached to their owners. Another thing which helps to increase the popularity from an exhibitor's point of view is that one need not be a professional before being able to tell the good ones from the inferior birds and to pick out his show specimens. They not only please those who keep them solely for the pleasure of seeing them flying about their loft but they appeal strongly to all who take a delight in exhibiting and here the question may be asked, why? Because it is a variety that is not difficult to breed; that is to say, one need not serve an apprenticeship 
of several years by keeping the birds constantly before him in order to distinguish the exhibition birds.

The Fans are as a rule good mothers and fathers and so renuire 110 foster parents to rear their young, as is the case with some of the short billed varieties. Therefore the great expense of having extra lofts and retaining other birds to rear the young is aboliched. Contrary to much that has been said, the Fantail requires no faking for exhibition purposes. There are possibly many who will question this statement and ask. "What about their tails?" True enough, the tail of a Fan is often faked, but you need not resort to this method to get the good exhibition tails. The birds can be and are bred with tails that require no manipulation to enable them to win in fast com-

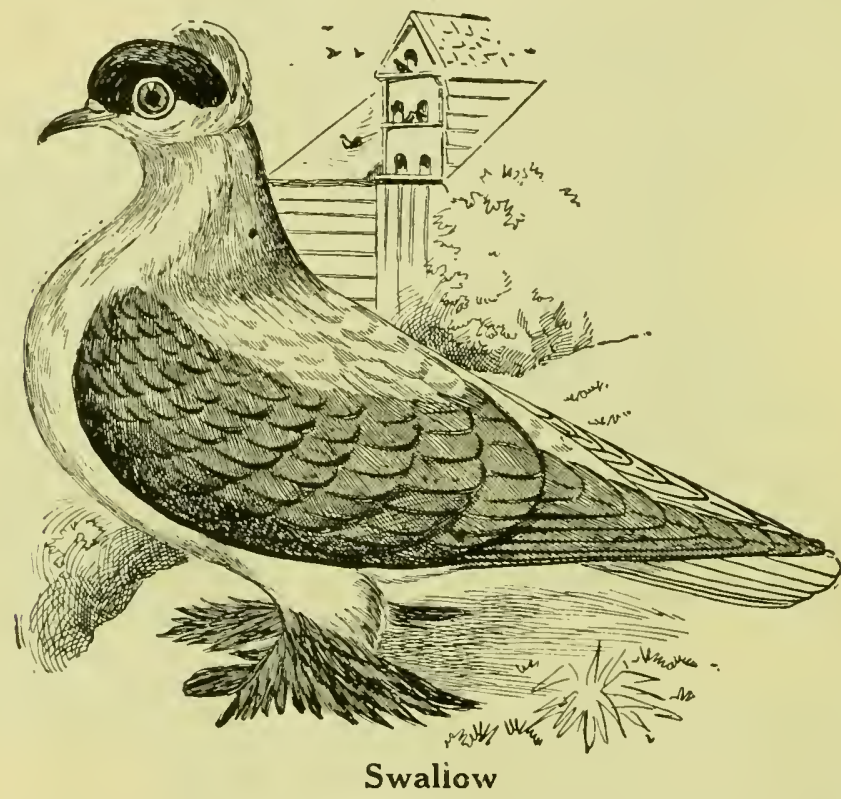

pany, and it is said that the bircls whose tails are not faked usually win over those that have been tampered with.

The novice may, therefore, venture to take up this delightiul breed with hopeful expectation of success, provided he uses juclgment in securing the parent stock and is careful with his matings. The training to get the required carriage of the Fantail is an art that you will very soon become acchstomed to and delighted with as well.

Fans are bred in many different colors, the most popular. however, being the Whites, Blacks, Blues, Reds, Yellow, as well as the Saddle Backs. 'The Whites, as usual, have maintained the leat and are posibly the largest class of any of the Fans at the larger shoms. 'They have been bred to such a high state of perfection that it is really difficult to find fault with many of the wimning specimens. The Blacks are not so popular as the Whites, but nevertheless the 
quality is not far behind. Blues, like the Blacks, are not bred very extensively, and the quality, as usual, is not that of the Blacks or 11 hites. Saddles are quite plentiful, generally having fair classes at the shows, with uniform quality but nothing in comparison with the 11 hite variety. The Reds and the Yellows have made no advancement in popularity for the past several years, and about the same size classes are seen at the shows and about the same interest taken as a number of years ago. It is claimed by some of the leading breeders that the Reds and Yellows are very difficult to breed. The widle-spread popularity of the Fantails makes them in demand. and the fanciers of any of the different varieties have little trouble in disposing of their surplus stock.

The Fantail should stand on tiptoe with its head back in a graceful manner resting on the cushion, chest upright, wing set fairly low

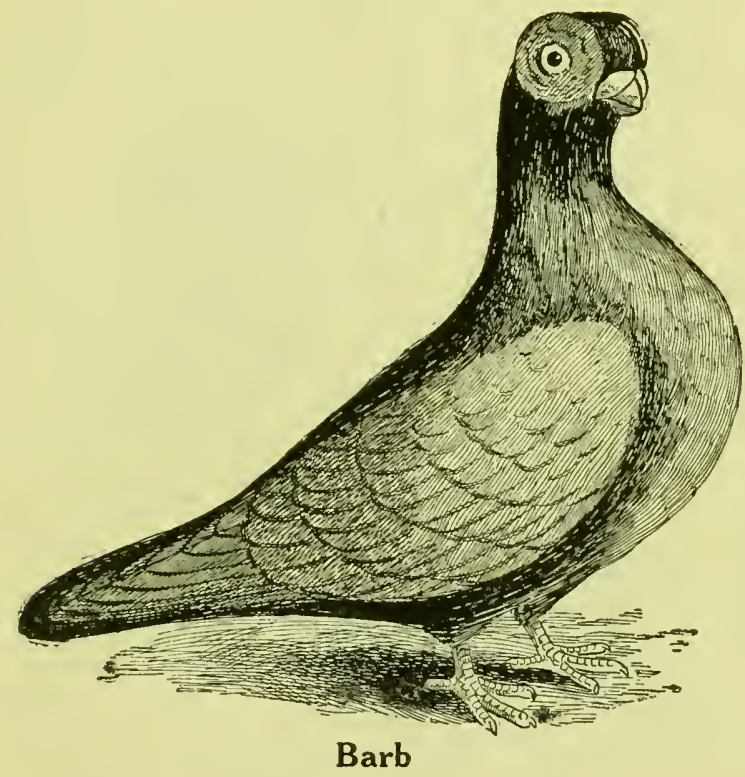

with the flights cleaving the lowest tail feathers. Tail should have thirty-six or more feathers overlapping each other. Should have a small round, compact body, the chest round like a ball.

\section{Swallows}

On account of their beautiful marking, swallows are very handsome birds; extensively bred and popular. They get their name from their close resemblance to the Sea Swallow. They have hazel colored eyes, long slender beak, shell crests and are heavily feathered on toes and legs.

Their body color is white with colored wings and toe feathers. 


\section{Barbs}

The Barb is by no means the prettiest of fancy pigeons. However, it is a hardy variety, a fairly good breeder and not at all isiticult to manage with reasonable care. One of the main feature- to watch in breeding Barbs is to prevent ulceration of the wattles, a disease to which all wattled varieties are subject. This can be prevented by sponging the wattles to remove the gummy exudation which is natural to all the wattled varieties. The main point in breeding the Barb is the head; the eye wattles are so large that it cannot see ahead or behind, thus making it an easy prey to its enemies.

They are bred in different colors; reds, blacks and yellows being, the most popular.

\section{Scanderoons}

While the Scanderoon has considerable contrast in its markings, it is not a very popular breed; very few being on exhibition in the

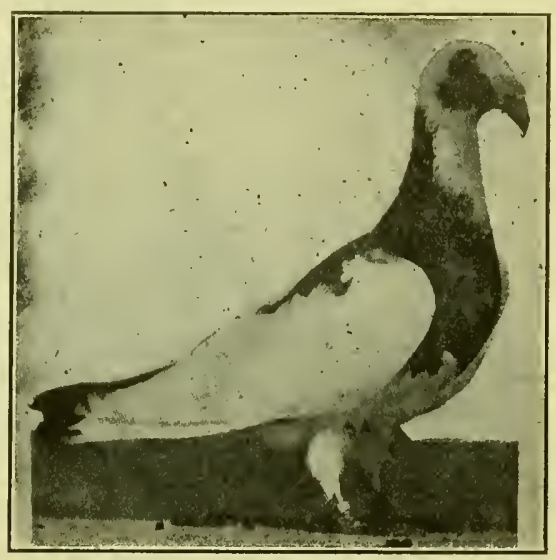

Scanderoon

show room. 'This is a very old variety of pigeon and is supposed to have originated in the Southern portion of Asiatic 'lurkey.

Mr. Harry M. Smith in the Feathered World says: "Scanderoonsthe hardiest of the hardy-rear their own youngsters well, so require no feeders, stand any amount of showing, and are always as fresh as fresh paint. Surcly this is the pigeon for the novice, for who can say he has not enough points to breed for?

"What a lovely contrast there is in the black pied, especially. when the black is really black and very lustrous-not the objectionable sooty-blue one sometimes sees-and the white, pure and of satin like lustre.

"We have birds with good curve of beak, but no substance. annl a scanderoon is little better than a Show Homer, without the latter. There must be substance of beak and a narrow skull-a very difficult 
conlbination to produce; some say impossible, and still breed from the old type of heavy skulled, duck shaped monstrosities with enough eye-cere and wattle to claim near relationship to the Carrier. These birds, too, as a rule, are long in feather, and so present a very unsightly appearance in the show pen.

"A good Scanderoon should be short in feather, have a bold, uprigint carriage, and a thorobred, racy appearance. Training in a pen. a few weeks before showing, will improve the carriage, but a bad croucher will never make a show bird-carriage is bred, not made.

"A long face, wattle of almond shape, and eye-cere of the brightest red-both fine in texture-are very necessary, especially as

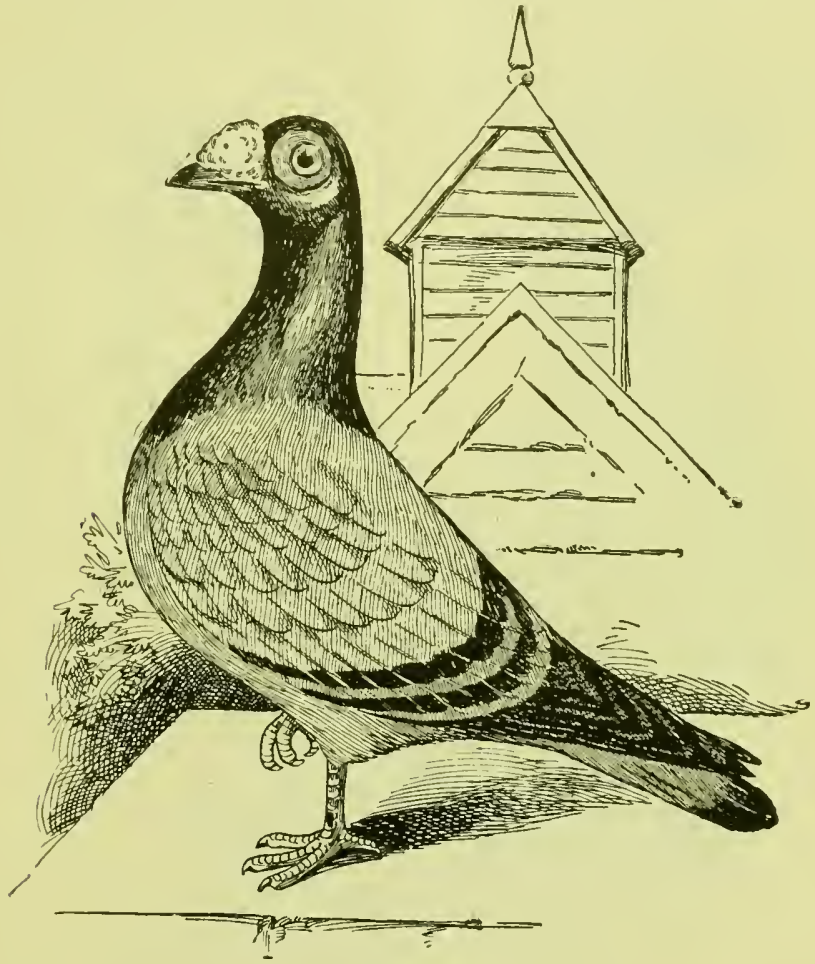

At Home

coarseness increases rapidly with age and shortens the successful show career of many an otherwise good bird.

"Perhaps the most difficult property to produce is that beautiful umbroken curve from the skull to the end of the beak, with both mandibles in unison and of almost equal strength. 'Faked as youngsters!' Perhaps; but such can easily be detected, as there alwars appears to be a sudden break in the curve of the nnder mandible, and the beak is more or less open, and sometimes crossed.

"Leave it alone; no good can come from such tricks. 'Striving' to better, oft we mar what's well.' 
"In spite of all that has been written against early breeding, I have practiced it with good results in Scanderoons. The early eggs have been fertile and I have a fair percentage of young.

"In conchusion, I would say, Scanderoons require very little attention, are as hardy as nails, and free breeders-once kept, never given "1p."

\section{Runts}

The Runt is the largest bird of the pigeon family. How it received the name of Runt is not mentioned by any of the early writers, not even by John Moore in I735 nor by Eaton, Brent or Willoughby.

Moore in his writings shows, by illustrations, first the Leghorn Runt-a large bird with an elevated tail. Even in those days few

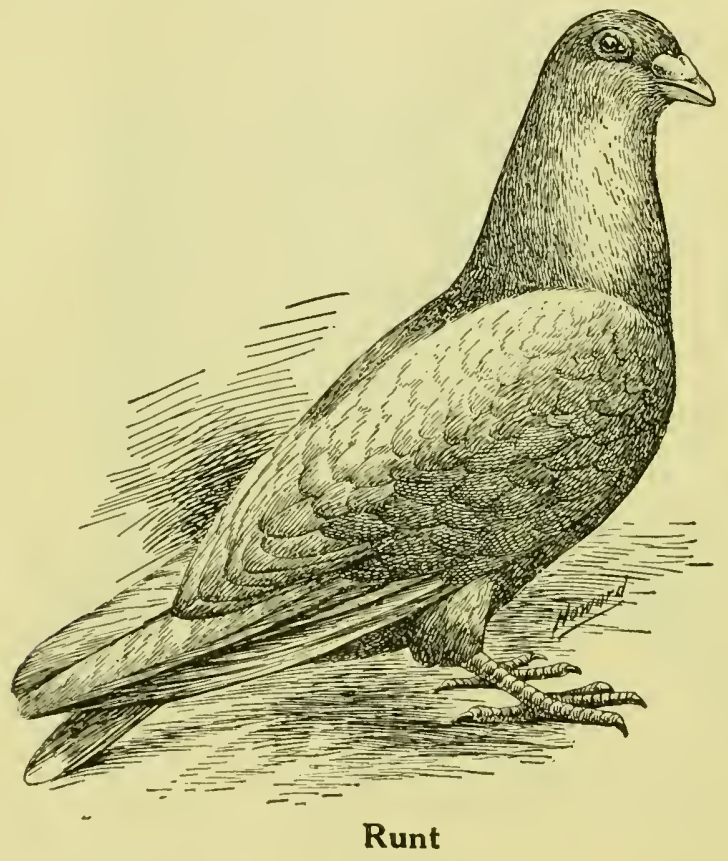

were exhibited that weighed less than two pounds each. 'These early' writers also mention a Spanish Runt. The illustrations are similar to the Leghorn, except the tail, which is not erect but nearly touches the ground. Lewis Wright states on page 195 of his book, that the Runt is simply an immensely large common pigeon and that prizes usually are given for weight alone.

VTe have seen them weighing two pounds nine ounces each. The colors shown are blue with black bars and silver with brown bars. By crossing them with common pigeons, a mongrel Runt has been 1) rinduced called by the French, "Pigeons Mondains." 
'The Runt most bred in the United States is the English Runt. At present there is a difference of opinion in regard to the color of the back. The English hold to the old color of the blues, that is, a blue with a white rump, while some Americans are striving for a blue rump. In fact, the writer saw some at Madison Square Garden Show having rumps of the same even blue found in good Dragoons and show Homers.

The Standard of Perfection by the American Runt Club calls for blue Rumps.

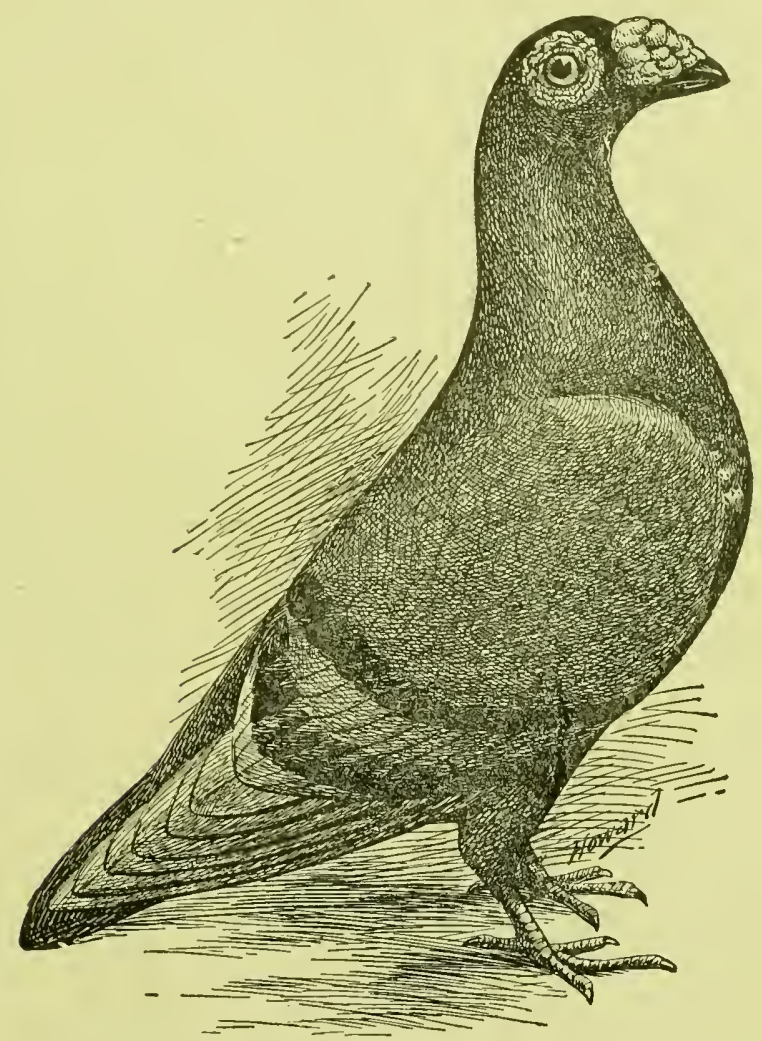

This is a heavy type Dragoon and is sometimes used for squabbing. The squabs are plump and larger than the Homers when the large cobby type of Dragoon breeder is used. 


\section{Utility Pigeons}

\section{Squab Raisers}

Ltility Pigeons are the large breeds that raise marketable squabs (young pigeons four weeks old) and plenty of them. Not only are they nsed as squabbers but are admired for their different types and markings, of which more are exhibited in the U. S. Shows than abroad. Some of the show types change hands at good prices, so the utility pigeon is a dual-purpose breed and has its standard as well as the strictly fancy breeds. This appeals to many engaged in pigeon keeping, because any young, lacking in type or color, can be eaten or sold fur eating purposes.

\section{Squab Raising as a Business}

Squab Raising has always been highly profitable, except during the Wurld War. Then pigeon raisers made overy little money. Wheat was in great demand; the price of feed advanced greatly; banquets were few: steamships, carrying tourists a rarity, and therefore the price of squabs dicl not advance in proportion to the adrance in feed. since the ending of the war, the price of squabs is considerably higher than ever before and all those engaged in the industry are making money and always have a realy market waiting for them. If they hate nu private trade, commission men are always anxions to get squabs. In fact, must of them are sold to commission men. Oi late years the straight breeds are used more than crosses. Why use crons. when there are so many straight breeds possessing everything any one can desire. The folluwing are a few of the breeds with the weight of the squahs they produce.

Homer:-6 to y pounds to the dozen.

Iolish Lymx-s to I 2 pounds to the dozen.

Carneaux-10 to It pounds to the dozen.

Maltese-ro to $1+$ pounds to the dozen.

Hungarians-il to 15 pounds to the dozen.

Austrian strasser:- 12 to 16 pounds to the dozen.

White Kings-1 2 to is pounds to the dozen.

Ir mdaines-1; to 2z pounds to the dozen.

hinnts-22 to 28 pumbls to the dozen.

The-e are only approximate weights, as some run higher and some lower than these figures.

'Ihe novice will ask which is the best? 'That question, answered by a pigeon man raisme Homers, will be, "Ilomers." While the man, rating Runts, will say, "Runts." lach is attached to his favorite. at a mother to her child-no baby is like hers. So the man raising suluas for market is attached to his particular kind of pigeon, the -inne as the fancier to his fancy birls. 
The variuns breeds will be described as we go along, but right here we will say the smallest birds mentioned breed the most squabs, while the largest birds mentioned breed the fewest squabs, which is nitivinal. Another point is the price, and here again the rule is, the smaller the bird the lower the price. Other points to consider"Shutd I buy the smallest breed when a medium size can be kept in the same number of nests and the same size house?" To this question we answer it is better to pay a little more for the larger size 1 breeders. For Ru11ts, you must expect to pay a good price and al-, ingure on more space to house them in, as they require plenty if $\mathrm{f} \cdot \mathrm{m}$.

The largest squal plants prefer the Carneau and keep more of then than of any other breed; claiming that the Carneaux never rice lark skinned squabs and run on an average of twelve pounds to the dozen. Hotel keepers do not wish to serve any larger squabs, as they would be obliged to charge such a high price, their patrons wuil not order them. It is claimed they will raise more pounds of $\therefore q\left(a^{1}\right)$ per pair of breeders than any other bird.

The Polish Lynx is admired for its markings as well as for its (wi) louild and the plump squabs it raises.

The Hungarian enthusiast claims for the bird that "it raises the guil las skin squab."

he Austrian strasser and Maltese are praised for their short. l,r.: iback, plump squabs.

ale White King is praised for its beantiful white feathers and larre:- -qualss.

The Mondaine is praised for larger squabs than the White King ani] : reeds more squabs than the Runt, of which blood it has a goo? sir. sling.

- lue Runt being the largest, produces the largest squabs but ver iev who raise Runts are selling squabs when they can raise then to breeding age and sell for breeders or slow purposes at a bis rice

Zaising squabs for market is one of the most fascinating, proficable and pleasant occupations one can possibly enter into.

The l'ditor of Leslie's Weekly, hearing so much about the squab indusry and desiring to give information to the public started to ges the real facts and learn something of the industry, first by going into the markes where he conld see money changing hands between the buter, selers and producers of squabs. He was surprised when he sair how cuickly squabs were sold, the high prices paid and the am mats sc promptly paid the slippers. After making inquiries iot informatior among the New lork commission men, relative to the indingry, he was directed to the author.

\section{A Few Points on Squab Raising}

Biy young mated birds from a squab raiser.

teep pigeons in standard houses.

I'1geons ay two eggs which hatch in serenteen dity. 
Squabs are ready for market when twenty-eight days old.

One pair of pigeons will raise six to ten pairs of squabs a year.

Pigeons raise squabs summer and winter.

The feathers bring a good price, including the flights.

The pigeons' droppings sell at good prices per hundredweight.

Mr. Howard Butcher, a veteran pigeon keeper at New Britain, Penna. has between four and five thousand utility breeders and receives $\$$ I.05 per pound for dressed squabs. Some squab raisers with special trade receive $\$ 1.25$ per pound in winter and a less price in summer. It costs $\$ 3.00$ to $\$ 3.50$ for grain to feed a pair of breeders a year.

Some large squab farms use $40 \%$ screenings, $40 \%$ whole corr, $20 \%$ Peas. Grit should be kept in a separate container.

Houses should be white-washed in August.

Nests should be cleaned when the squabs are removed.

Sloppy nests should be cleaned as soon as noticed and tlen should be sprinkled with air slaked lime; also sprinkle around them and wherever there is dampness.

Never have a clamp floor. Clean floors once a month. damp.

Double floors with special building paper between are sedom

Tar felt should never be used between double floors or mside of a building, because floors of this kind gather frost in winter thaw out in warm weather and cause dampness.

Remove a dead squab or bad egg as soon as noticed.

Do not use moldy feed.

Moldy feed will cause disease.

Pigeons, when properly fed and housed, contract few diseases.

Don't expect plump squabs when you feed late.

The earlier the feeding time the plumper the squabs.

Never take "peepers" away from breeders until they are a week old, as the old birds should disgorge all "pigeon milk."

Never raise the youngsters from young breeders until they have bred two or three pairs of squabs.

Never allow youngsters to grow up in the same lbuse with breeders.

Have a system by which you will know what every pir of birds is doing, the good workers as well as the poor ones.

Weed, weed, weed out the drones!

Don't neglect the bathing water. It is the birds' way of preventing lice.

Give them tobacco stems with which to build their hests: never hav, straw or anything hollow, to encourage lice.

Pigeons are not infested with lice as chickens are.

Pigeons build their own nests and feed their own young. 


\section{Thorobred Squab-Raising Homers}

Note the short thick legs, bruad breast and deep-keel, a cobby built Homer, the only type of Homer that should be used for squab production.

A point to remember is that flying pigeon men discard the heavy, deep-keel, short, cobby built Homers. These are just the kind the

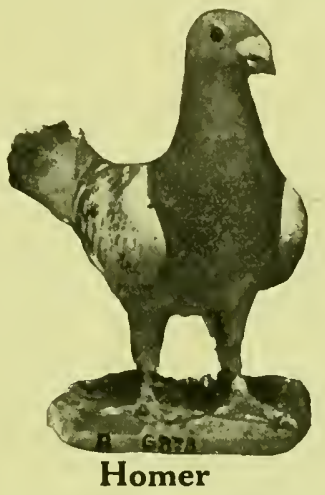

squab raser wants. Blues and light colored checkers are best suited for the purpose. They produce the big, meaty breasted squabs.

\section{Present Day Carneaux}

The Carneau is a par-excellent bird for both fancy and utility purposes and one never tires singing its praises. "If you do not care to show them, you can eat 'em," which cannot be said of many fancy birds as the latter are small or have dark skinned squabs, and do not pay for their feed when used for eating purposes; whereas a big fat Carneau that is off on feather color makes a good meal.

The present Carneaux bred in the United States are very appropriately termed "The American Beauties," due to the fact that the imported birds have been bred up to an ideal American Standard, improving the stock in size, symmetry, color and breeding qualities until the American type is far superior to the imported.

Name-Carnean (Carno). Plural-Carneaux (Carnose) is derived from the French. The French-English dictionary gives the following: Carmine (the red coloring principle of Cochineal) Carnation, natural flesh color, Carnu, S. M. P1. V. Carnal (t. of arts, Carne. 3; adj. of carnation color.) Carneaux. S. M. Pl. Red vent holes in a porcelain furnace. Cardinal Bird (Cardinalis) a beautiful bird of the Finch family, deep red in color. The French gave the name "Carneau" because the bird is mostly red. Words ending in "neau" and "eaux" are significant of the French. However, such words are now in common use in English speaking countries, and form their plurals by adding " $x$ ", which is the case in Carneau.

Origin-The best authorities we have are Brent and Willoughby; traced by Mr. Frank Lee Miles. Brent, in his writings, mentions a large prolific red pigeon also a golden yellow one. Willoughby mentions a smaller pigeon than the Runt but much more prolific and 
adept on the wing. France rightfully claims to be the first to give these birds prominence for their great squab producing qualities. The name CARNlidU finds its first use there. Belgium early bred the bird in great numbers. English wood-cuts over three hundred years ago show a large red and also a yellow pigeon closely resembling the Carnean. The first authentic record of Carneaux being imported into the United States was July 4 th, Igoo by Mr. George Hughes of Bridgeton, N. J.

Mr. Frank Lee Miles of Danville, Pa., organized the International Carneau Club and thru his efforts made it very popular as a show bird and also as a utility bird.

Show Carneaux-For show purposes it has been exhibited in the following classes: Red, Yellow, Red Rosewing, Red Mottle, and White-Sides, Yellow Rosewing, Yellow Mottles, White with orange eyes, Black and Dun. They are greatly admired at the leading shows by the general public.

Utility-For squab production they have proven to be the best. There are more Carneatux being bred in most squab producing plants thruout the comntry than any other variety of birds. Besides being a beautiful bird to look at, it is extremely easily handled. Being of a domestic nature, there is less quarreling among them and more attention is given to raising their young, feeding and fattening them to the limit, thus producing squabs of good flavor and firm meat in four weeks' time.

They produce more squabs per year than any other variety of its size and produce more weight, pound for pound, than any others. Its flesh is even better than the white squab, having a slightly yellowish tinge, which is looked upon with great favor-seldom, indeed, is a dark skinned squab seen. With proper breeding stock, squabs weigh, on an average, one pound each, which is the ideal high class restaurant-size squab. Half a squab is usually given at a serving. A half pound squab with other food is as much as the average man cares to eat at one time.

\section{Universal Carneau Standard}

\section{As Adopted by International Carneau Club, United Carneau Breeders Assn., Dixie Pigeon Association}

In judging all Carneaux it should be remembered that Carneaux are exhibition and "utility birds" used for squab-breeding purposes. They consist of three decided colors-red, yellow and white. They may be all red, all yellow, all white, or commingling colors of red and white or yellow and white.

\section{Points of Perfection, Type and Construction of all Carneaux}

Head-Prominent, strong and rounding from wattle to above eye, then gradually inclined to nape of neck. Broad between eyes, free from slender or snake-like shape; all parts in perfect keeping with the proportions of the body. Free from "Tumbler-like" appearance.

Eye-Large and prominent, located a little to the front of the center of the head.

Iris-Color, orange, shading to red.

Cere-Not too conspicuous, free from coarseness. Color, either cream, a flesh shade or red. 
Beak-Stout, medium in length, showing no ill shape. Color, light shade of cow-horn; may be darker at base, clear of all stain or black beak. (This must not be construed to legislate against dark color or pigment showing in beak of red, or red and white birds.)

Wattle-Smooth, V-shaped; free from coarseness. Color, cream or light flesh (epidermis) shade.

Neck-Broad across shoulders, straight in line to tip of tail.

Wings-Strong in proportion. Butts not prominent nor conspicuous. Flights carried over tail feathers and in keeping with body; not too long.

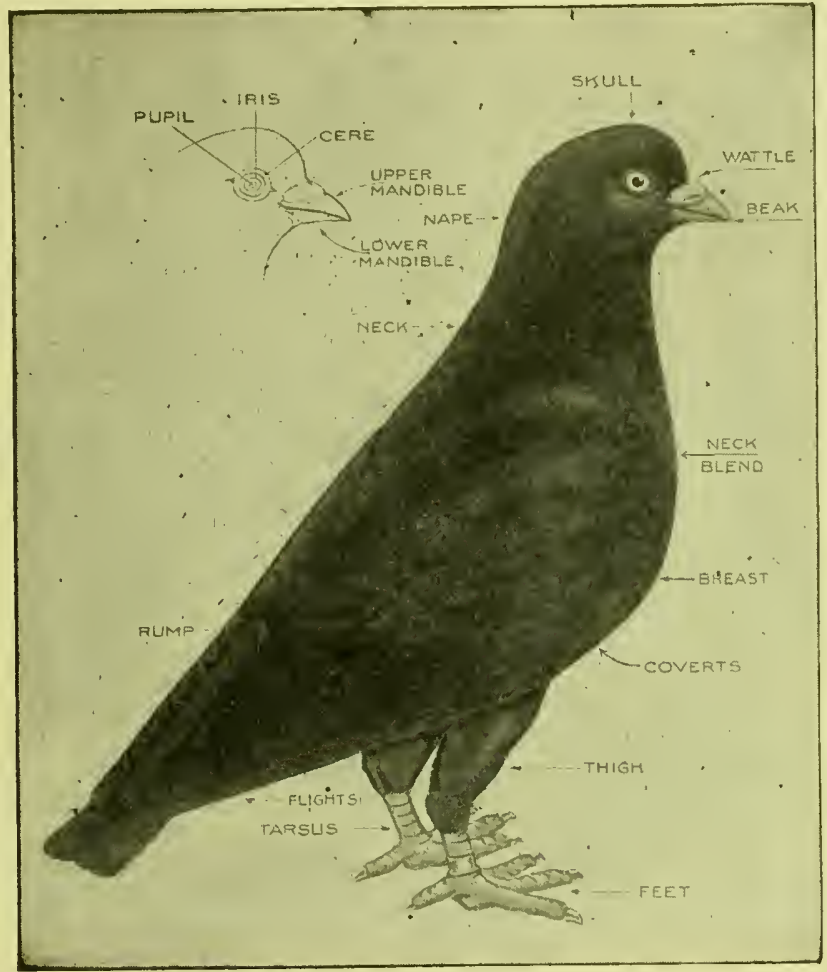

Standard Type Carneau

Tail-In keeping with body; not too long or "Runt-like;" extending not over an inch and a half beyond flights; nearly square at end (indicative of a broad back), free from pointed or wedge shape (indicative of a narrow back); carried in line with back.

Legs-Strong; length, in keeping with body, well up; straight, clear of feathers below the hock; standing well apart at keel, showing good open space; size, in keeping with body and symmetry, both in length and proportions; red in color.

Feet-Large, of good proportion; size and color in keeping with substantial tarsus.

Body-Solid, compact, deep in keel, round, corresponding with the well rounded breast, showing good, symmetrical proportions.

Flesh-Firm, solid, showing compactness. 
Carriage-Well up, haughty; free from squatty or crouch-like appearance, but well up on legs, carrying head in keeping; free from "down face," or tendency to bear beak in neck feathers.

Breast-Full, round and well developed; in full keeping with the symmetry of the bird.

Plumage-Close-fltting; must be positively free from conspicuous slate, blue or smut, or other off color. The deeper the under color, or fluff, the more valuable in points. Neck color shows slightly more luster and sheen, Weight: free from greenish or beryl shade.

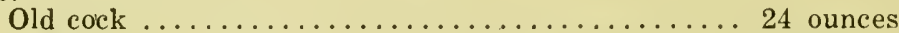

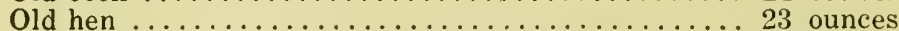

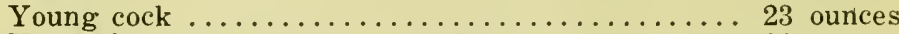

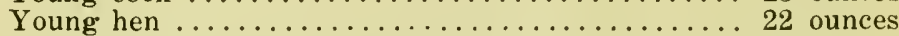

When judges are not thoroly familiar with the weight of the birds, they should weigh or satisfy themselves of the weight, judging by comparison with those in close competition.

Females-May be more feminine in general appearance, being a little more delicate and effeminate; the nearer, however, they correspond in type to the males, the more points they score.

\section{Solid Red Class}

To be judged by all points as above.

Color-Bright, deep red chestnut color, closely resembling the horse chestnut when ripe in the burr.

Decidedly deep red, free from off color. The deeper the under color or fluff the more valuable in points. Neck color showing more sheen and luster, free from green or beryl shades. The color similar to the "ox-heart cherry."

\section{Solid Yellow Class}

Same standard in type and all requirements, as in red class, except color, which should be a deep, golden yellow, showing sheen. Neck shading opalescent, blending with golden hues. Eyes, conspicuous. Iris, prominent, orange. Beak, cream in color. Birds of cinnamon color should be termed "off color."

\section{Red and White and Yellow and White Class}

Must be judged by the same type and all points as in the other classes, with the exception of color, which must have enough white feathers to exclude them from the red class or the yellow class. Birds eligible to either the red or yellow classification cannot compete with these birds.

Judges must guard against unfair competition in all classes. They must rule by points, also by comparison in keeping with show rules. When exhibited in pairs they must be judged by pairs and cannot compete against single birds.

\section{Rose Wing Red Class}

Same standard as in red class, except a limited number of white feathers in body of wing, forming a rosette in appearance, or ornamental design, not to extend beyond coverts, nor be too conspicuous in butts.

\section{Rose Wing Yellow Class}

Same standard as yellow class, except wing ornate, same as the rosewing red.

\section{White Class}

This class shall be judged by the same standard in type and all points as in the red and yellow classes, with the exception of beak and feather colors. Beak must be cream or clear white. Feathers shall be clear white, both exterior and under color, or fluff. All other feathers than white disqualify. Eye must be Carneau type and of conspicuous orange color.

\section{Black Class}

This class shall be judged by the same standard in type and all points as 
in the Red class, except feather color, which should be jet black, free from rustiness or dun appearance, showing a green metallic lustre with metallic green hackle.

Points of Scoring

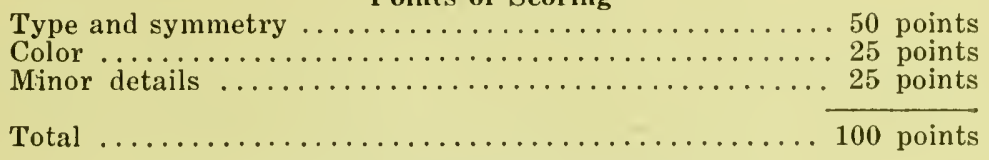

\section{Itemized Points of Scoring}

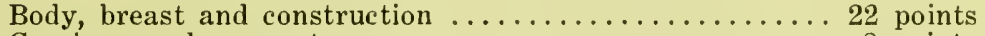

Carriage and symmetry $\ldots \ldots \ldots \ldots \ldots \ldots \ldots \ldots \ldots, 8$ points

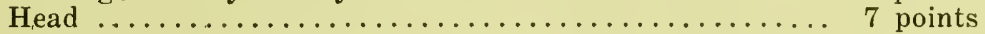

Neck ............................ 5 points

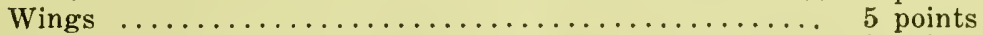

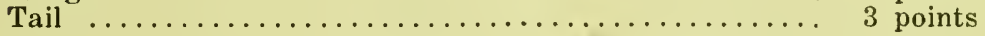

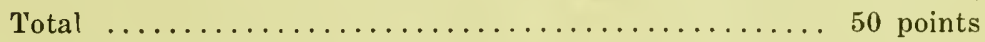

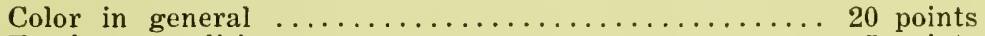

Feathers, condition $\ldots \ldots \ldots \ldots \ldots \ldots \ldots \ldots \ldots \ldots \ldots, 5$ points

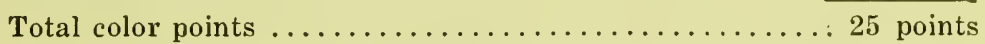

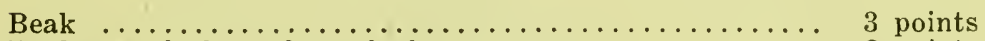

Beak, too dark or deep shade $\ldots \ldots \ldots \ldots \ldots \ldots \ldots \ldots \ldots 2$ points

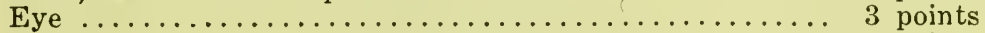

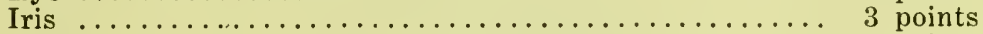

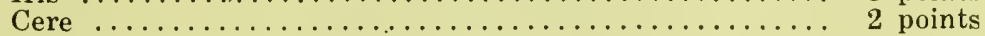

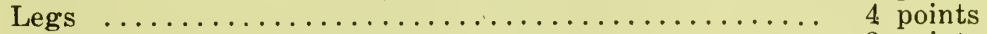

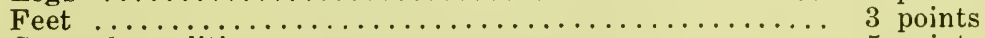

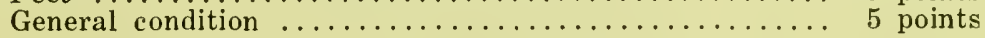

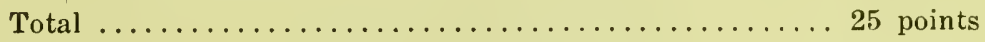

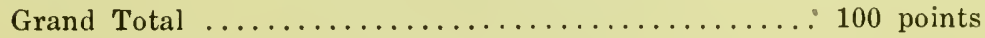

Judges must use the "Universal Standard" in judging all Carneaux, and, to be qualified to do so, must be in possession of and well acquainted with the standard; and when competition is close judges must judge all birds by points and comparison, and, when possible, exhibit and compare in walking cage.

In case of protest in regular form, the judge must furnish the committee with all points upon which he based his decision.

\section{Qualification-For All Classes}

All birds other than mentioned in standard shall be disqualified.

All birds showing conspicuous off-color in feather, especially such as blue, slate, gray or smut.

Birds with wry or uplift tails.

Birds carrying wings below tail, or hanging away from the body or with decided spread of wings.

Birds showing sickness or in bad condition.

Birds showing any "Runt" or "Hen pigeon" eccentricities or the "Tumbler head."

Birds showing any signs of having been tampered with, such as coloring, plucking, or any other indication of intended fraud.

Judges finding less than the regular number of tail or flights such as missing feathers shall cut or discount for same, or disqualify. 


\section{Carneaux Excelled in Quality at the National Show}

By J. W. Williamson, Judge, Secretary International Carneau Club.

The grand display of $22+$ American Beauties was a sight that will long be remembered by all who attended the first National. It was the best quality show of Carneaux ever exhibited. I never felt a keener love for these "l'he Pricle of My Heart" birds than when told, "Ready, go ahead and judge," for I was anxious to get right among them and I surely did. As I began handling, first one, then another, it seemed like gathering roses in a garden, going here and there for my selections, viewing them in the best light, picking a red, then a yellow, adding a white from one section and black from another until I had pictured in my mind a most lovely garden of living, breathing roses with their beauty ever increasing as the sun, at short intervals, threw its rays of light mpon them, enhancing their intrinsic value and by its illuminating power revealing all the beauty as it brought forth the irriclescent color effect more brilliantly at the breast and from the nape of the neck down the back to the tail. I never saw such excellent color effect in Carneaux before.

How greatly they improve from year to year-each year surpassing the previous one. The uppermost thought was "Is it any wonder so many fanciers raise Carneaux?" The Reds seemed to be the attractive flower of the garden, especially the plot assigned for the growing young cocks. When assembled in the walking cage they appeared as tho grown from the same seed pod. Quality here ran supreme. 'The dark red copper metallic sheen giving color effect and the beantiful red cere perfectly encircling the eyes were all that could be desired. 'The eye proper showed good size and bright, the iris shading from light orange to red. All were good specimens.

The type was close within the standard, for color without type must lose. The man who courts the flashily dressed lass and fails to notice the nicely molded model with beatity in face and form, gets fooled.

Only one bird went over standard weight and it weighed twenty-eight ounces. This bird and its mate were awarded first in stock pair class. It was also awarded a special by the International Carneau Club for the heaviest Carnean in the show.

One excellent colored yellow had to go down the line for showing too much Maltese. Very few showed Runt blood.

The Whites are coming stronger every year and good heads were found.

The Blacks were of good size and type except head; here they lack in forehead, which should be prominent. In profile, the rising should be perceptibly from the wattle. All black cocks were in poor condition, looking as tho they needed a good meal. Boys get the right head on your blacks or you will lose to the one who has them. 


\section{Maltese}

This variety has many admirers as a utility and show bird. It is sometimes called Maltese-hen, Henne or just Maltese. The ones selected for utility purposes have shorter legs, shorter neck, and a broader breast than the illustration below. The broal breasted ones have somewhat the appearance of Leghorn Runts.

It is a bird with quite a history, supposed by some to have originated from the Leghorn Runt. Eaton describes it as follows:"A stately, large pigeon, seven inches or more in the legs, close feathered and fast fleshed, extremely broat chested, he carries his tail turned up like a duck. His neck is longer than that of any other pigeon, and bends it like a goose or swan." John Moore, London, I735, quotes Willoughby as follows:- "This bird was originally bred at Pisae on the Duke of Tuscany's dominions or at Pisae in Peloponesus and from thence brought to Leghorn and so transmitted to us." The Burmese or Filorentine also originated from the Leghorn Runt, according to Brent in his writings.

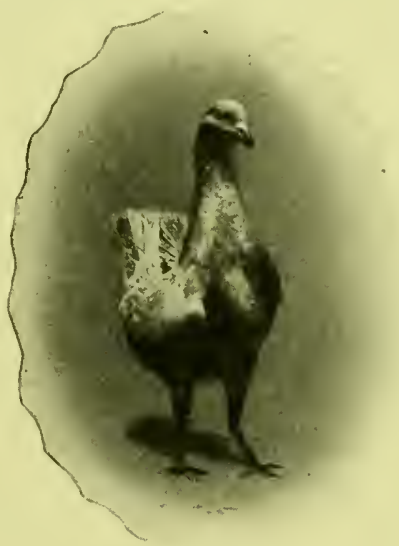

\section{Maltese}

Heavy blocky birds should never be placed in a show. There are several standards but the following is most frequently used for the Maltese.

\section{Maltese Standard}

Head-Long, well arched, carried high, finely curved from base of beak to back of crown, cheek bones flat, giving the appearance of a goose from side view. Measurements-Length, from the tip of beak to the back of the skull, three and one half inches. Width, from eye-cere, one inch, tapering to quarter inch above the mandibles.

Beak-Stout, long, forming a decided angle with the head; in black and blues, beak should be black. In all other colors beak should be flesh or light color. Measurements-of face and beak, one and three quarter inches, from the pupil of the eye to the tip of the beak.

Eyes-Not prominent. Whites, blue eyes, cere red; Blacks and Blues orange eyes, cere damson; Yellows, Duns and Silvers, pearl eyes, cere, flesh color; Reds, orange eyes, cere, flesh color. 
Neck-Very long and slender, carried erect, as nearly same thickness as possible, until approaching the shoulders. Measurements-Length from shoulder to top of skull, six inches.

Body-The breast to be broad, carried high, full and well rounded, projecting forward about half inch beyond the wing butt, straight breast bone, showing a moderate depth of keel. The back to be broad, short, horizontal and with slight elevation at the rump. Shoulders wide, slightly projecting, showing muscular power. Rump, well developed and very closely feathered, giving the body a symmetrical appearance. Measurements-Across the breast from inside of one wing butt to the other, three and one half inches. From breast to rump bones, six inches. Across back, including wing butts, four and one half inches or more.

Wings-Long in the joint, very short flights, lying close, carried well up, showing full length of thighs, and crossing or meeting on center of tail, wing butts prominent, projecting outward slightly at breast, giving a clean cut appearance. Measurements-From end of wing butt to tip of flight, eight inches.

Tail-Short, full, as nearly square as possible, carried upright, leaning slightly forward. Measurements-length not more than four inches, width not less than three inches and not more than three and one half inches.

Thighs-Powerful, long, and should show as much as possible, set well apart and in center of body, hanging straight down from wings, very closely feathered.

Legs-(Below the hocks) stout, very long, red; joint must not be bent, free of feathers.

Feet-Straight and long, toes set well apart; the toe nails of the same color as the beak. From the upper joint of thigh to the end of middle toe nail eight inches. From the hock joint to the sole of the foot should show about six inches. The leg from the wing to the sole of the foot should show about six inches. Across the breast, from the inside of one thigh to the other, two and one half inches. The breast should clear about five inches.

Condition-Hard and muscular thruout.

Color-White, Black, Dun, Silver, Red, Yellow, and A. O. C. Blacks. DunsDark even color thruout. Blues-A soft blue, sound and uniformly clear, a deep green luster on neck, and distinct black bar on wings and tail. Silver-Soft even color, and dark bar on wings. Reds-Dark red, even thruout, as lustrous as possible. Whites-Milk white, "satin like" lustre on hackle. Blacks-Should be lustrous black, showing a green sheen on hackle

Carriage-Erect almost perpendicular line existing from the ball of the eye to the sole of the foot, upright and stretching.

Action-Proud and graceful.

Remarks-The bird should be rather large, stand high, with short, hard, compact body, but not so heavy as to mar the elegance of its figure; it should carry its head high and when excited or driving should throw its head back almost to its tail; should be short in feather and fit very closely and compactly to the body, especially on the breast, shoulders and vent; giving the bird a very clean cut appearance and showing a muscular power. It should have a free, graceful action. An ideal specimen should stand fifteen inches high.

\section{Hungarians}

This is a bird of many interesting points that are not found in any other breed. 'The nearest approach to it is the Florentine in its markings. The type is that of the Maltese, but it is not so long in the neck and legs. 'The tail is longer and is not elevated so high. For utility purposes it is the "bird that raises the golden skinned squabs." 
The even tape markings in good specimens always attract attention. The markings are a deep even shade of black, red, yellow or blue as the case may be, with a tape marking consisting of an even, narrow, white stripe, starting at the center of the wattle and rumning over the crown of the head and down the back of the neck, widlening as it goes; thus forming a very pointed triangle at the base of the neck where it joins the back. The tape marking then passes in a narrow line just in front of the ends of the wing butts and comes together from both sides in an even curve in front and is merged into the white of the lower part of the breast, legs and thighs, meeting over the rump. The coloring which should be even and regular runs over the sides of the head including the eyes, then turns down by the ears and forms a deep pear-shaped bib on the breast. The wing bow, wing coverts and main tail feathers should be solid black. red, yellow or blue, as the case may be. of the same shade as the bib on the breast. Flight feathers should be white and free from colored feathers or mixture of colors. In the case of blue Hungarians, the wings when folded should show two distinct black bars, slightly wider in the center than at the ends, rumning a curved shape across the wing coverts. These bars should be three quarters of an inch or more apart at the lower edge of the wing and come together, or nearly so, as they approach the back where the wing folds against the back. The space between these bars should be the same shade of color as the rest of the wing bow. At the tip of the tail there should be one black bar of the same shade as those on the wings. The bar forms an even edging when the feathers are in their proper place.

Credit for the drawing up of the Standard is due Mr. D. M. Green and also credit for other services rendered for the good of the breed.

\section{Hungarian Standard}

Disqualifications-Solid black beak, knock knees, absence of tape marking, bib color joining that of wings on both sides, drooping wings or solid colored rump. (See general disqualifications.)

Standard Weights-Old Cock 26 ounces; Old Hen 24 ounces; Young Cock 24 ounces; Young Hen 22 ounces.

\section{Shape}

Head-Rather long with finely curved rounding skull giving a trim and neat appearance.

Beak-Moderately long, stout and tapering with a slight downward curve as it approaches the tip end.

Wattles-Small, neat and smooth.

Eyes-Round, of moderate size in proportion to the size of head.

Eye-Cere-Neat and fine in texture.

Neck-Long, erect but of good proportion, showing fullness where it joins the breast.

Wings-Short, carried well up and close to the body; wing butts rather prominent giving the body a strong heavy appearance.

Back-Short, broad and straight with exception of slight elevation at rump. Shoulders should be wide, showing strength and fullness. 
Tail-Should be about one inch longer than wings, of moderate width and should be carried at an angle of forty-five degrees.

Breast-Broad, full and well rounded, signifying an abundance of breast meat.

Body-Rather short, very compact, well rounded, and carried high off the ground, When standing erect a male bird should measure fourteen inches and a female thirteen and one-half inches from the ground to crown of the head, but not more as excessively long, slender neck and legs are undesirable. A large compact, heavy-bodied, close feathered bird of moderate height with stout legs and well developed neck and shoulders is much more desirable and should always be given the preference over a very tall, stilty, smaller bodied specimen with extra long neck and legs.

Shanks and Toes-Long, of good size and free from feathers.

Beak-Flesh color.

\section{Color-Black Hungarians}

Eyes-Orange.

Eye-Cere-Red.

Shanks and Toes-Red.

Plumage-A rich glossy black with a tape marking consisting of an even narrow stripe starting at the center of the wattles and running over the crown of the hearl and down the back of the neck, widening as it goes until it comes within about one half inch of the top edge of the wing butts on each side, then narrowing again very rapidly to form a pointed angle at the base of the neck; the point extending toward the back. The tape marking then passes in a narrow line about one half inch wide just in front of the wing butts and comes together from both sides in an even curve in front and is merged into the white of the lower part of the breast, legs and thighs, meeting over the rump. The black markings should be even and the edges regular and well defined, should run over the sides of the head including the eyes, then turn down by the ears and form a deep pear-shaped bib on the breast. The wing bow, wing coverts and main tail feathers should be solid black thruout and of the same shade as the bib on the breast. The primary feathers of the wings, also the rump and thighs, should be pure white and free from colored feathers or mixtures of colors.

Beak-Flesh color.

Color-Red Hungarians:

Eyes-Orange.

Eye-Cere-r.Red.

Shanks and Toes-Red.

Plumage-A deep even shade of red with a tape marking consisting of an even narrow white stripe starting at the center of the wattles and running over the crown of the head and down the back of the neck, widening as it goes, until it comes within about one half inch of the top edge of the wing butts, on each side, then narrowing again very rapidly to form a pointed angle at the base of the neck; the point extending toward the back. The tape marking then passes in a narrow line about one half inch wide just in front of the wing butts and comes together from both sides in an even curve in front and is merged into the white of the lower part of the breast, legs and thighs meeting over the rump. The deep red color, which should be even and the edges regular and well defined, runs over the sicles of the head including the eyes. then turns down by the ears and forms a deep pear-shaped bib on the breast. The wing bow, wing coverts and main tail feathers should be a solid red thruou: and of the same shade as the bib on the breast. The primary or flight feathers of the wing's and also the rump and thighs should be pure white and free from colored feathers ox mixtures of colors. 
Beal-Flesh color.

\section{Color-Yellow Hungarians}

Eyes-Orange.

Eye-Cere-Red.

Shank: and Toes-Red.

Plumage-A deep even shade of yellow with a tape marking consisting of an even narrow white stripe starting at the center of the wattles and rumning over the crown of the head and down the back of the neck, widexing as it goes until it comes within about one half inch of the top edge of the wing butts on each side, then narrowing again very rapidly to form a pointed angle at the base of the neck; the points extending toward the back. The tape marking then passes in a narrow line about ore half inch wide just in front of the wing butts and comes together from both sides in an even curve in front and is merged into the white ci the lower part of the breast, legs and thighs meeting over the rump. The deep yellow color, which should be even and the edges regular and well defined, runs over the sides of the head including the eyes, then twrns down by the ears and forms a deep pear-shaped bib on the breast. I tre wing bow, wing coverts and main tail feathers should be solid vellow thruout and of the same shade as the bib on the breast. The primary or flight feathers of the wings, also the rump and thighs, should be vare white and free from colored feathers or mixtures of colors.

Beak-Flesh color.

\section{Color-Blue Bar Hungarians}

Eyes-Orange.

Eye-Cere-Red.

Shant: and Toes-Red.

Plumes-A soft even shade of blue with a tape marking consisting of an $\mathrm{A}=\mathrm{n}$ white stripe starting at the center of the wattles and running over ... crown of the head and down the back of the neck widening as it $\approx=s$, until it comes within about one half inch of the top edge of the wis butts on each side, then narrowing again very rapidly to form a inted angle at the base of the neck; the point extending toward the ack. The tape marking then passes in a narrow line about one half in. in wide just in front of the wing butts and comes together from both s. 2 e in an even curve in front and is merged into the white of the lower $2 x \mathrm{rt}$ of the breast, legs and thighs, meeting over the rump. The soft ae color, which should be even and the edges regular and well defised, runs over the sides of the head including the eyes, then turns dwn by the ears and forms a deep pear-shaped bib on the breast. The wha bow, wing coverts and main tail feathers should be a soft even s.tade of blue of the same shade as the bib on the breast. The wing: wen folded show two distinct black bars, slightly wider in the center then at the ends, running in a curved inverted V-shape across the wing -rits. These bars should be three-quarters of an inch or more apart st the lower edge of the wing and come together, or nearly together, a: they approach the back where the wing folds against the back. The ace between these bars should be the same shade of color as the rest if the wing bow. There shall also be one black bar of the same shade as those on the wings at the tip end of the tail; the bar forming an even scing when the feathers are in their proper place. The primary or fight feathers of the wings, also the rump and thighs, should be pure wivie and free from colored feathers or mixture of colors.

\section{Scale of Points-Hungarian Pigeons}

In scoring Hungarian pigeons, or judging them by the score card syslem, Wre consideration must be given to the evenness and accuracy of the tape marking as required in the different sections as well as to the depti. ano $e v e n$ shade of color. The tape marking is a special feature that dis- 
tinguishes the breed, and a distinct even edging of the color section where it joins the white is particularly desirable.

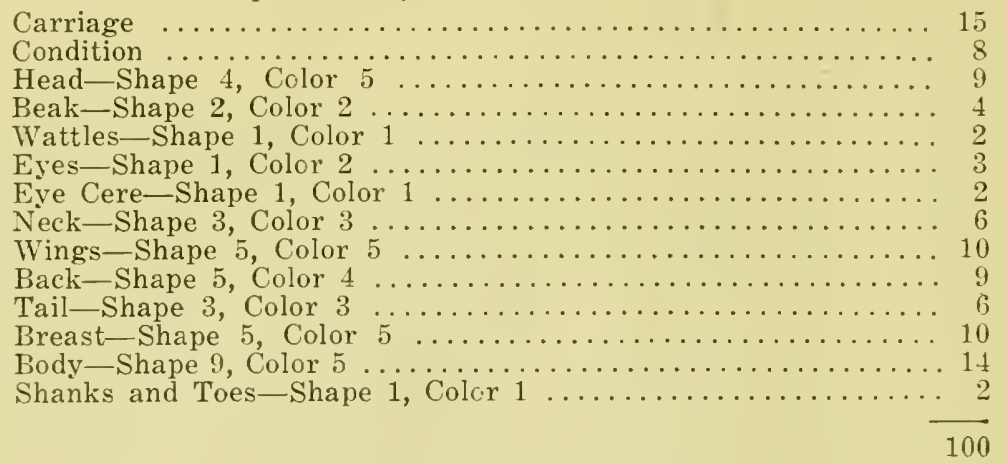

\section{White Kings}

This bird was originated by Harry Troth of Millville, N. J. The illustration below is of one of the early type and was consiclered a

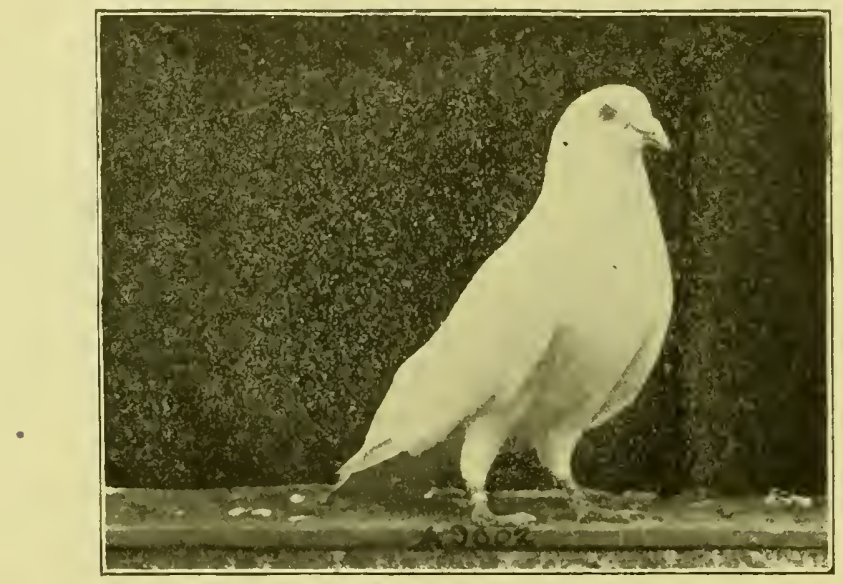

\section{White King}

good one. The latest types are birds of the same blocky appearance but the tail is carried parallel to the ground. The White King appeals to the squab raiser on account of its size, its white feathers and white meated squabs.

\section{Official Standard For Kings \\ As Adopted By American King Club}

1)isqualifications-Color other than white or creamy white in any part of plumage of White Kings, and color other than silver or silvery blue in any part of plumage of Silver Kings; any feather or feathers on shanks or toes; deformed beak or toe; wry or split tail, or any radical deformity.

Standard Weights-Old Cock, 26 ounces; Old Hen, 24 ounces; Young Cock, 24 ounces; Young Hen, 22 ounces. 


\section{Shape}

Head--Moderately large, with round skull and prominent forehead.

Beak-Stout, of medium length.

ivattle-Rather small, smooth in texture.

Eyes-Prominent, large, keen.

Cere-Perfectly round, of medium size, (about 1-16 inch wide); fine in texture.

Neck-Moderately long, symmetrically blending into broad shoulders and breas:

iWings-Comparatively short, well folded, ending about three-fourth inch in front of and on the tail; fronts well covered by breast feathers.

Back-Medium length, straight, very broad from shoulders to tail.

Tail-Rather short, broad and level its entire length, carried parallel to the ground and on a line with the lower portion of the body.

Breast-Prominent, broad, deep and well rounded.

Body-Medium length, broad, deep, well rounded, carried horizontally.

Feel-Straight.

Shanks and Toes-Shanks: Stout, of medium length, straight, free of any indication of feathers, set well back under the body and well apart. Toes: Straight, of medium length; well spread.

Plumage-Close feathered; any tendency to long or loose feathering or elevated tails or wings should be discouraged.

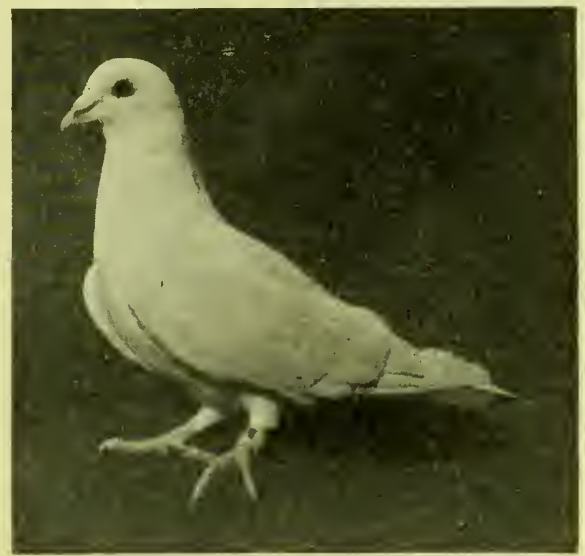

\section{Latest Standard White King}

\section{Color-White Kings}

Beak-Pinkish white.

Wattle-White and frosted.

Eyes-Brownish black.

Cere-Beet red.

Shanks and Toes-Bright red.

Plumage-Pure white.

Beak-Horn color.

Color-Silver Kings

Wattle-White and frosted.

Eyes-Pearl.

Cere-Flesh color.

Shanks and Toes-Bright red.

Plumage-A silvery blue tending to fawn color in all sections of body including rumps with as little contrast as possible in shade of back, breast, wings and tail. The neck should be a darker shade of rich fawn color with a brilliant metallic luster, wings when folded to show two sharp 
well defined bars slightly wider in the center and at the ends running in a curved inverted $V$-shape across the wing coverts. The bars should be wider apart at the lower edge of the wing and come together or nearly so as they approach the top when the wing folds against the back. The space between the bars should be of the same shade of color as the rest of the body. There should also be one dark bar of the same shade as those on the wings at the tip end of the tail, the bar forming an even edging when the feathers are in their natural position.

\section{Scale of Points}

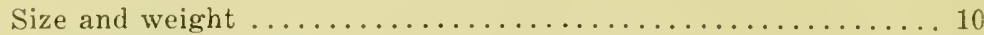

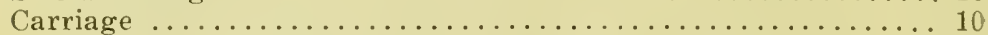

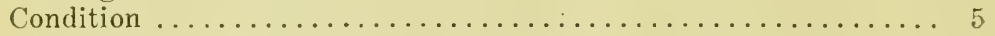

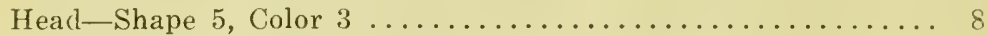

Beak-Shape 2, Color $1 \ldots \ldots \ldots \ldots \ldots \ldots \ldots \ldots \ldots \ldots \ldots \ldots \ldots \ldots \ldots$

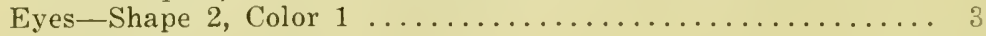

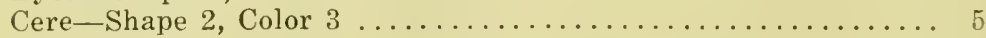

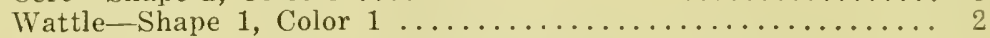

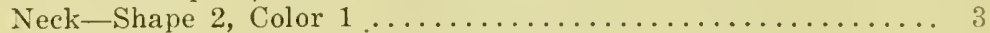

Wings-Shape 5 , Color $3 \ldots \ldots \ldots \ldots \ldots \ldots \ldots \ldots \ldots \ldots \ldots \ldots \ldots \ldots \ldots \ldots \ldots \ldots$

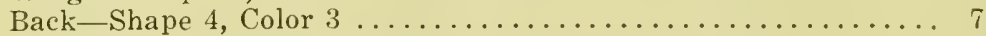

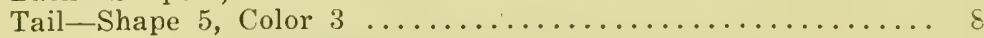

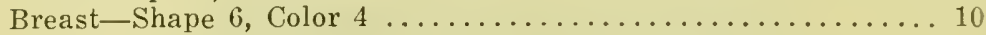

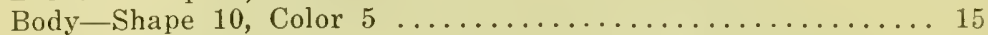

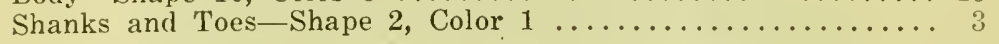

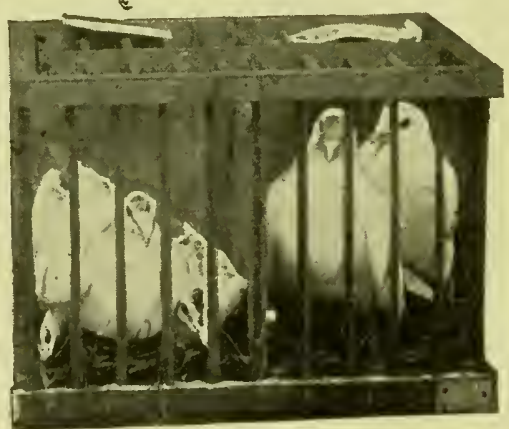

Two Pairs of Large White Kings, Showing the Method of Shipping Where the Distance is not Great.

\section{Mondaines}

The Mondaine has the general type of the small Runt. which many claim it to be, while other groups of fanciers clain it originated in Switzerland and is a distinct type. Mondaines come in several colors as do the Runts, but the favored color in America is white. The Swiss Mondaines, which are considered good breeders of large white squabs, being white feathered, some prefer them to the dark colored birds.

The following Standard is the one adopted by American fanciers and which the atuthor has judged by: 


\section{Swiss Mondaine Standard}

Disqualifications-Color-Any other color than white, blue, silver or their combinations. Type-Short keel, perpendicular neck, crouchiness, drag to wings, hump breast or any radical deformity. Condition-Seriously impaired or diseased.

Standard Weights-Old Cocks, 27 ounces; Old Hens, 24 ounces; Young Cocks, 24 ounces; Young Hens, 21 ounces.

\section{Shape}

Head-Medium size and length with moderately full frontal, the eyes being set about three fifths forward of the base of the skull. Should be slightly oval at the rear of the skull and the highest point should be immediately above the eye. Objections-Elliptical, round, long back skull, flat or pinched, eye too far forward.

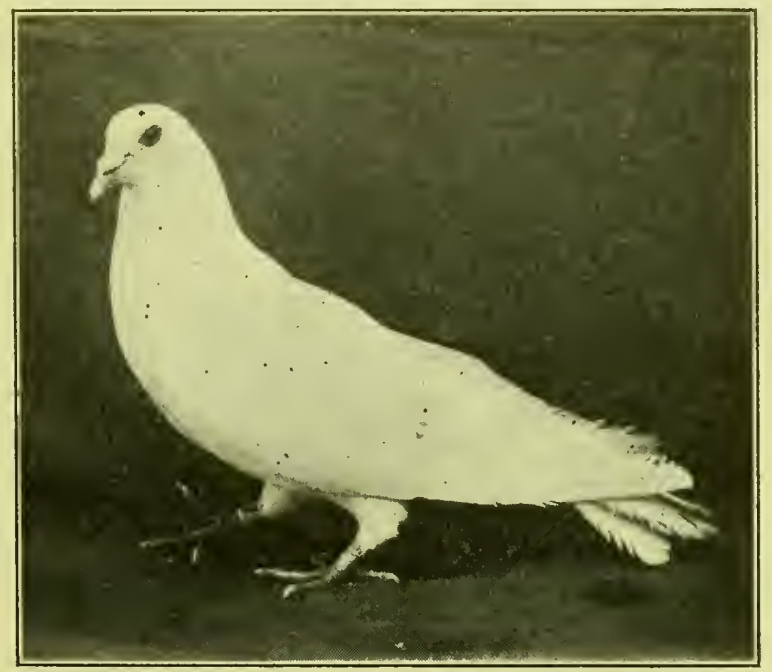

\section{Mondaine}

Beak-Strong and of medium length, the upper mandible curving slightly downward as it approaches the tip end. Objections-Pinched, hooked oz short.

Wattles-Rather long, medium size. Objections-Unequal in size, coarse, large.

Eyes-Round and full. Objections-Beadiness, sunken, lack of lustre.

Eye-Cere-Regular in shape, rather wide. Objections-Irregular, coarse.

Neck-Long, carried forward and up, gradually tapering from a full breast. Objections-Coarseness, short, swan-like.

Wings-Long, well up and snug to the body. Objections-Shortness, droopiness, narrowness.

Back-Long, tapering to the tail, the widest point being well below the shoulders. Objections-Pronounced shoulders, quick taper, especially at the rump.

Tail-Long, fairly well spread and so joining the back as to make a pleasing appearance. Objections-Up-tilted, dragging, narrow, short.

Breast-Long, to accompany the long body, full and well rounded. Objections -Short or double breast, narrow. 
Shanks and Toes-Strong and of good length, clean preferred, feet of generous proportions. Objections-Too short or grouse legged.

Feathers-Long and close. Objections-Looseness, too short or too narrow.

\section{Color for White Swiss Mondaine}

Beak-Flesh colored, free from stain.

Eyes-Very dark hazel.

Eye-Cere-Red.

Shanks and Toes-Pinkish red.

Plumage-Pure white in all sections, with a satin lustre on neck, no yellowish tinge.

Undercolor-White.

Scale of Points for Swiss Mondaine Pigeons

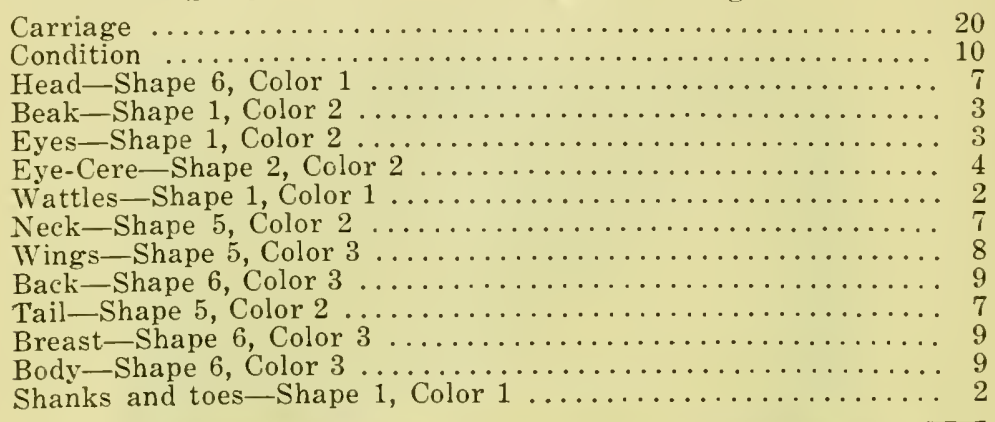

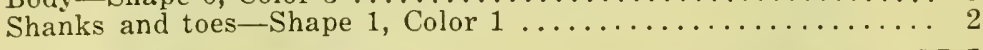

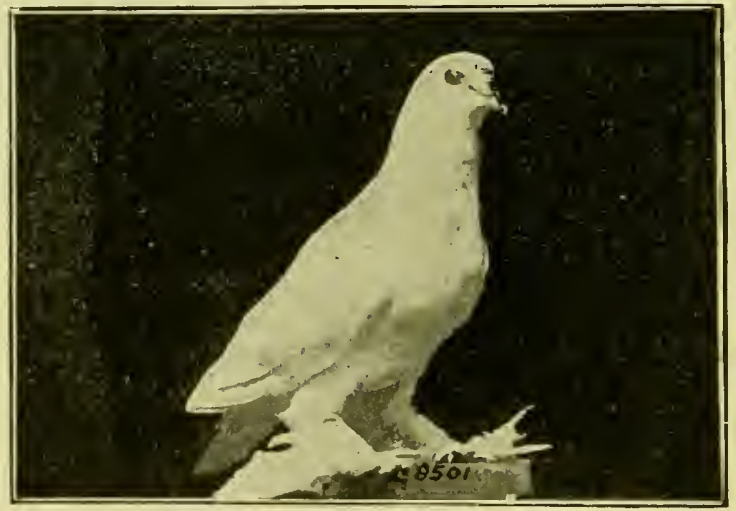

Duchesse

\section{Duchesse}

The Duchesse is a bircl that was used for both fancy and utility. purposes. In the fancy, the better booted they were, the more highly priced, while the squab raiser tried to avoid the heavily feathered legs. The Duchesse is larger than the Homer and a good breeder, but few are used for squab purposes as the feathers are an objection to pickers and the squabs have not the neat appearance when plucked, as the clean, bright, red foot squab. 


\section{Squabs}

\section{Their Rapid Growth}

The peepers shown in the cut below weighed one and one half ounces when two days old. The other egg is cracked and ready to release its prisoner, weighing three quarters of an uunce. The peepers are helpless, being entirely different from young quail or pheasants, which run as soon as hatched. The peepers remain in the nest until four weeks old, unless there is an unusual disturbance. They are tiny little things, blind at birth and can only say "peep." While

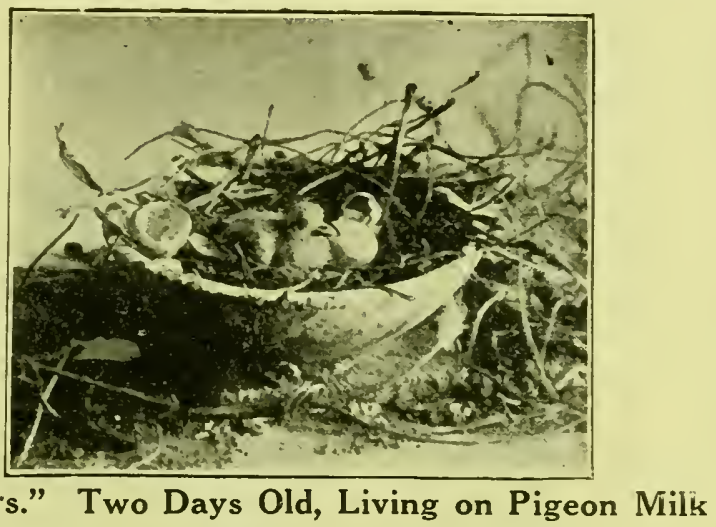

they seem very lifeless, yet they are hardy, and will withstand the heat and cold where a young chick would die in an hour's time. As far as heat and cold are concerned they are tough as nails.

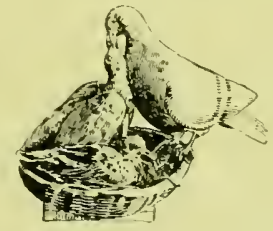

\section{Lunch Time}

l'igeon milk is found in the crops of both of the parent birds during the periol of incubation. The milk forms in the crop about three Cays before the peepers are hatched. In the majority of cases the peeper is out of the shell in eighteen days. Some writers state the pigcon's milk is white in color; others will say it is yellow; and still others, a light brown.

MY experience in dissecting birds has shown it to be of various: colors. I have also noticed that it is the feed that governs the color. 
If the birds are fed principally on corn, the milk will be yellow; if on wheat and kafir corn, it will be white; and if darker grains, such as buckwheat, hemp, rape, etc. are fed it is often of a darker color. So the one who so positively states it is white, is correct, as well as the one who claims it is of a darker color, but that is as far as they seemed to go, as none ever gave reasons why the color is as it is. However, squab breeders are not particular about the color as long as it does the work. It is very hard to find a substitute for pigeon's milk. Soaked bread, crackers or anything else will not have the nourishing qualities that God has provided in the nature of the birds.

When a squab is rolled out of a nest or injured, the best way to feed it artificially is to soak some peas and feed one at a time. I have seen people take such a squab and feed it by placing the bill in their own mouths, similar to the way the parent birds do.

\section{Raising Squabs}

Raising Squabs for the market is one of the most fascinating. profitable and pleasant occupations a man, woman, boy or girl, can

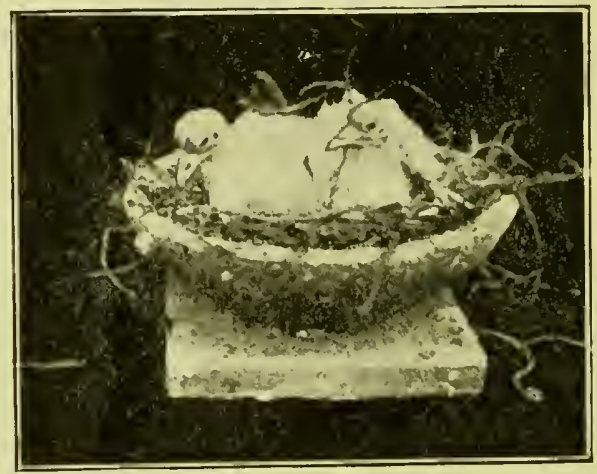

\section{"Squeakers." Two Weeks Old, Living on Soft Feed}

possibly venture'into-the work being light, has caused many to enter into it whose health would not permit them to do inside work or very laborious outside work.

With ordinary care breeders should raise fat, plump squabs in sufficient quantities to make at least $\$ 1.50$ per pair a year from each pair of breeders, which many claim they are doing, and experience will teach many things that will increase the profits year by year. It is one of the industries that is not overcrowded, and has many advantages, with less drawbacks, than any other business along the same line.

Any old breeder will tell you that it is not hard work but that you must have the right kind of stock, give fresh water twice each lay, keep it from the sun, and feed no one grain continually, but vary the food from day to day.

squab farming, as it is termed, does not require a college edu- 
cation to insure success, altho many college bred people are engaged in the industry. 'There is no keen competition; no being shut up in office or store. The markets are always eager for your squabs, as they are never fully supplied and prices grow better continually. squab eating is a luxury. No meat can be compared with it, as it is far superior to wild game, and has no trace of the wild game flavor. I squal) is the most toothsome morsel of meat man can possibly eat. fairly melting in the mouth and very nutritious. "Quail on toast" cannot be compared with "Squab on toast." They contain no gun shot wounds and are a greater luxury, also they are plumper and heavier from which they derive the name "Squab." In the markets the prices are always above the price of quail, as will be noticed in the commission merchants' quotations.

The breeding birds breed very rapidly, laying two eggs at a sitting, but before the squabs from the first sitting, are four weeks old. at which time they are ready for market, two more eggs have been laid in another nest and incubation continues. This is why two nests are necessary for each pair of breeders. 'Twenty-five pairs of breed-

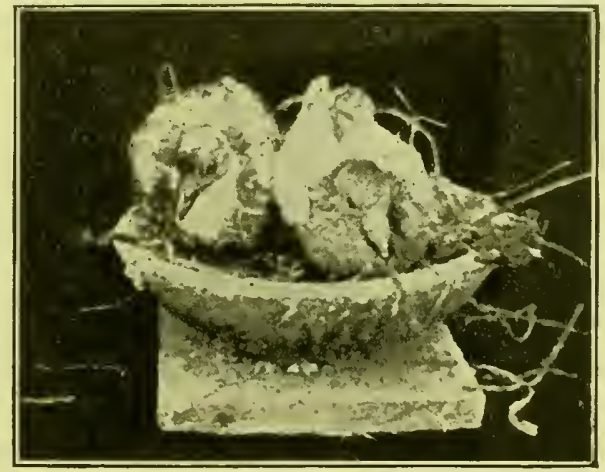

\section{“Squealers." Three Weeks Old, Living on Coarse Food}

ers will more than supply an ordinary family with squabs and the surplus can be sold to pay the feed bill.

The eggs of pigeons hatch sooner than the eggs of any other domestic bird requiring only eighteen days and in four weeks the squabs are ready for market. It requires hen's eggs twenty-one days to hatch, guinea-hens, twenty-six days, pea-hens, twenty-eight days. ducks, twenty-nine, turkeys, twenty-nine and geese, thirty days. If you have bred any of the above, count the time required before they are ready for market and the cost of the feed, then compare with the time and cost of getting squabs to market in four weeks.

The question is often asked, "Will the business soon play out?" For thirty or more years this old question has been asked, but while some have been asking the question, others have been increasing their business from year to year.

There are men, who, when they fail in business, blame the bus- 
iness, but it is not the business that's a failure, but the man back of it. We find some few in the squab business. who become greedy and buy the cheapest feed they can, and perhaps start in with cheap, common birds. For instance, in order to make a try-out, a man will start on the cheap plan. He continually feels cracked corn. His birds are apparently doing all right, but such feeding soon tells oil the birls and they do not feed their squabs so well. Their water has been neglected; their nests are deep boxes the grocer gave him and are hard to keep clean. Consequently they become excellent breeding places for vermin. He wonders why his neighbor's birds do so well and his so poorly and finally he decides to sell his birds and quit, saying, after his ruined birds are sold, "The squab business is no good for I tried it."

A proprietor of one of the largest plants in the southern part of the State of New Jersey started twenty-eight years ago with a few pairs of the best birds he could purchase. With the start from these.

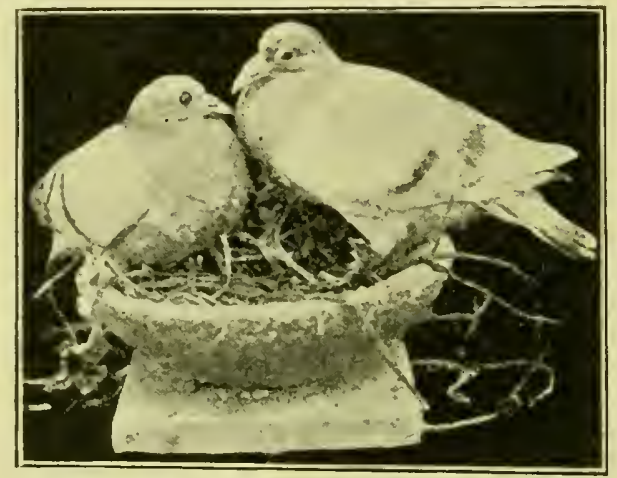

\section{Squabs Four Weeks Old, Living on Hard Food, Showing their Rapid Growth from One Day to Four Weeks.}

he now has one of the best equipped plants in the State and claims his birds alone built up the business and have paid for all the buildings, besides netting him a neat income. A business that will give such sure and safe returns should have the best of treatment, as the margin of profit is sufficient to warrant the very best of everything. 


\section{Feeding}

The method of feeding pigeons is somewhat different from that of feeding poultry. 'The various mashes, cut clover, ground bone, beef scraps, egg foods, green stuffs, etc., which are fed to poultry should never be fed to pigeons. A little green stuff can be ted and dues no harm, but is not necessary.

Pigeons are very fond of pepper-grass, lettuce, cabbage and pea leaves but care must be taken in feeding these things so that the pigeons do not get too much. Chickens can eat a great many articles of food that will kill pigeons.

Pigeon food is the more simple of the two, as their variuus grains can be counted on the fingers.

When there are only a few coops of birds, peas can be planted within the flies, oblong frames made of six inch boards with poultry netting tacked over them. As the peas grow the birds eat them thru the netting. This method prevents them from eating too much.

\section{How To Feed}

A great many people throw the feed in the flies. I have seen men who have thousands of birds feed in that manner and evidently they did not know any better.

'They claim they give only sufficient feed for the birds to eat up clean. As far as eating up clean is concerned, it is the proper way to feed, but the feed should not be given in the fly, as it is not an easy titsk for the beginner to give birds exactly what they will eat up clean, and at the same time have sufficient to fill the crops of each squab in the nests. It is better to have a little left over than not enuugh. My guide is the crops of the squabs. If their crops are full, they have had enough, and the breeders have had enough. An hour after feeding, examine the squabs and you will soon gauge to a nicety the amount of feed needed. Three quarts of feed will be plenty for fifty pairs of breeders and their squabs.

If the feed be thrown in the fly and any of it remain over-night, the dew in summer will cause it to sour, in winter it will lie in the snow and in rainy weather it will mold.

Another bad feature of feeding in the fly is that the sparrows will fly to your coops as regularly as you go to feed.

No one can estimate the exact amount of feed required for a coop of breeding birds. The amount of feed the breeders require for themselves is small compared to the feed they pump into the squabs. The old birds can get along with, very little food, but when fifty pairs of breeders are feeding fifty pairs of squabs, which in four weeks should weigh as much as the breeding birds. it is quite evident that a large amount of feed is necessary to develop that amount of flesh, 
as at every feeding time the breeders cram crops of the squabs full. In some cases, when squabs are two weeks old, the crop is as heavy as the squab. The better breeders and feeders your birds are, the more feed they will consume.

\section{Automatic Feeders}

Never use automatic feeders. They are used on very few large squab farms. However, they are very convenient for pigeon dealers, who are buying and selling breeding stock and do not make a practice of raising breeders for sale. One objection squab raisers have to them is the fact that the birds will eat all of the dainties and leave the corn and wheat, but the principal objection is that the breeders become less active; will not eat regularly nor feed the iquabs regularly, when feed is continually before them and conseiuently do not produce big, plump squabs.

Major Frank M. Gulbert who was one of the ablest pigeon judges in this country, said, "I am firmly opposed to any sort of feed hopper that will keep the feed continually before the birds. It is all very well to say that when they want it you want them to have it, but, I ask, 'How long could a man keep his appetite if his food was where he could see it all the time?' He would soon loathe the sight of it."

\section{Time To Feed}

The hours at which to feed during the winter should be between 6:30 and $7: 30 \mathrm{~A}$. M. and at $3: 00$ P. M. In summer, between 6:00 and $7: 00 \mathrm{~A} . \mathrm{M}$. and at $4: 00 \mathrm{P} . \mathrm{M}$.

The regular time for the last feeding should be strictly observed, as it is the time the cock bird leaves the nest and the hen takes his place.

The hen should have food before going to the nest. Another important feature is that feeding at the above stated time gives the breeders plenty of time to feed before night-fall. A half hour or so will not make so much difference in the morning feeding, altho the morning feeding should be as carly as possible, owing to the fact that the squabs crops are nearly empty. After the feeding time is set, remember that regularity should be strictly observed. The birds will be expecting you. If you are regular, the breeders will be regular in feeding their squabs.

\section{What To Feed}

Red wheat and corn are the two main articles of food for pigeons, but for pigeons to continually eat wheat and corn is like a man continually eating ham and eggs-he soon tires of them. Canada field peas, hulled oats, kafir corn, millet, buckwheat, rape seed, hemp, rice, sunflower seed and table scraps, from which all meat and grease have been taken, should be added to the wheat and corn. Stale bread, if not moldy, is very good if soaked in a little water, but don't give too much of it nor too much green food.

Farmers who have an over-supply of seeds, such as radish, tomato, etc., can feed them but must do so sparingly, the same as mil- 
let. Wheat screenings are guod if you can secure a good quality, but mills, as a rule, place little of this on the market, as they make more out of it by grinding it up and putting it in other products. There was a time when good screenings could be procured and still can be, at a few mills, but since the use of improved machinery in many mills, screenings are a scarce article and what is offered for sale contains so much chaff and dirt that it pays better to buy wheat. Never feed many green peas, much green stuff or mushy meals as it gives the birds diarrhoea. What they need most of is well-seasoned hard grain, and plenty of grit to grind it; viz.-charcoal, salt and crushed oyster shells, which should be kept before the birds continually and should be renewed each week.

All grain that is to be fed to pigeons should be well-seasoned. New corn and wheat should not be fed until about October or November, and I would advise continuing to buy the old corn and wheat until that time. Some buy large quantities of wheat in July and August, because it is a little cheaper just after being threshed, but there is no economy in such buying, even tho it is cheaper, as grain shrinks considerably in the hardening process.

Wheat, from the time it is threshed, will shrink two quarts to the bushel, or six per cent in six months. One hundred bushels of corn will be reduced to eighty bushels in the same length of time.

Cracked corn should never be purchased in large quantities. Never keep on hand a supply that will last over a week, as it is very heating, and will sour and become moldy. Always feed a rariety.

After you have your squab plant working systematically it will surprise you how quickly the work can be done, and with certaintr. as there is no guess-work or worry over what should be done next. Get out of the old style of "any old way" and move along with improved methods.

Birds require different food at different seasons. During the summer feed about the following proportions:-Two buckets of wheat to one of corn, and in winter two buckets of corn to one bucket of wheat. Then add the dainties, using more of them in winter than in summer; altho when the birds are molting use about the same proportions of sunflower seed and hemp.

Then feeding give more corn and wheat than anything else. Next in quantity, Kafir corn, peas, hulled oats and buckwheat, millet. rice, rape seed and hemp. Sunflower seeds should be fed sparingly, as they are expensive and are used as luxuries. If you find it more convenient to purchase and use other grains, arrange to suit your locality.

Then peas are cheap, use more of them and less wheat. When Kafir corn is cheap do not use so much cracked corn. As a rule the two mentioned (peas and Kafir corn) are usually lower in price during the summer months.

\section{Kafir Corn}

Kafir corn is becoming quite popular with squab raisers, and 63 
takes the place of Indian corn to a certain extent. While its properties are not equal to Indian corn, yet at the same time it makes a nice change, and is not a great deal below in the rich fats and protein found in Indian corn, nor is it as loosening to the bowels as wheat. For pigeon food, I class it between Indian corn and wheat.

It derives its name from a South African tribe known as Kafirs.

It was first grown in the United States in 1886 . There are a great many varieties. The most common seen in the markets are the white and red, which are grown all over the United States where Indian corn is raised. Most of it is raised in the western states, between the Mississippi River and the Rocky mountains. Kansas and Nebraska produce more of it than any other states, from which states eastern feed merchants draw their supply of feed. Farmers in the western states claim they can grow it with greater success than Indian corn, as it withstands the blight better. There is but little difference in the nourishing qualities of the white and red. but the latter is the better grower. It is about the size of hemp seed and round in shape. If kept in large quantities and too long, it will hecome musty and if fed, will cause trouble.

\section{Indian Corn}

When buying corn the purchaser usually asks for yellow corn. or poor man's corn (the white variety), but of these two grains. there are over 272 yellow varieties and 217 white.

For feeding animals and birds it does not matter very much which particular variety is used, as there is very little difference in the amount of proteins and fats. The yellow varieties, however, are mostly used.

The corn used for pigeons should be Sifted Cracked Corm. If the cracked corn is not sifted there is considerable waste as the fine meal will not be eaten by the birds.

\section{Whea:}

There are as many varieties of wheat as there are of corn, and when purchasing same, you are apt to get one variety one time and mother variety the next time, and yet not know the difference. In fact it does not make any difference so far as feeding is concerned, but a wide difference in its being prolific and profitable to the farner. Under this heading all the varieties will be classed in two groups. the same as the Kafir corn-red and white-but the latter should not be used regularly. When it is used, mix in other hard grain: also, when using new red wheat, mix in hard grain and watch the squabs. If too loosening to the bowels, reduce the amount. Rice will be found very good to feed along with new grain.

\section{Wheat: Screenings}

These are very good, provided you can secure good screenings. If you can you will find them a most excellent pigeon food; containing besides wheat, various other grains and seeds, which are very healthful for pigeons. Be careful to avoid a poor quality. 


\section{Scorched Wheat}

This should never be fed to pigeons.

Cause of Scorched Wheat-Several years ago in the month of August I was in a position, the experience of which taught me considerable about wheat. The work was that of fitting up the holds of large grain-carriers. These vessels are built in compartments, and carry grain from one port to another. A tight floor is made of scantling and hemlock boards stripped with plastering lath. When repairing damaged floors, considerable damaged wheat is found and wherever there is dampness the wheat has sprouted, especially in a leaky boat or one encountering high seas. A great deal of this wheat gets into large granaries and damages other grain. It is then put thru a heating process and the sprouts are scorched off, after which it is sold as feeding wheat. You need never be deceived by this wheat, as it has not the fresh appearance it should have, but is somewhat darker and if bitten into, has a moldy or burnt taste to it. Wheat remaining a long time in granaries and not properly ventilaterl so that air can pass thru it will also sprout.

\section{Stale Bread}

Stale bread that is not sour nor moldy, when slightly dampener makes a nice noon-day meal, with some hard grain fed at the same tim $\therefore$

Bakers will be glad to sell it, and it makes a cheap food, but when only 50 to IOO pairs of birds are breeding, the scraps from the table will be plenty, as too much soft food should not be fed to pigeons.

\section{Fea}

There are quite a number of varieties of peas, but only one should be fed to pigeons as a regular feed. This is the Canada Field Pea. It is a very small pea, perfectly round and smooth, of a light yellow color, always very hard, and can be used shortly after being: taken from the vine. Pigeons delight in eating them, and they bring their squabs along in fine condition. They are grown the same as ordinary garden peas, and have the advantage of a longer season than the garlen pea. They can be grown anywhere the garden peas can be grown and will stand even a colder climate than the garden pea.

\section{Rice}

There are over one hundred and sixty varieties of rice. It is an excellent food for pigeons, to be fed with wheat. It is raised principally in the southern states, where rice can be purchased at a reasonable price. A great deal of it can be used for feed, especially when lots contaning a little chaff, which makes it unfit for table use, can be bought. Pigeons do not take to it at once but after a few meals they like it.

\section{Hulled Oats}

Oats are very nourishing. The price is the main draw-back to using them, but when they can be secured at a reasonable price. they 
should be fed, as nothing will bring along squabs as rapidly as hulled oats. Oats that are not hulled should never be fed.

\section{Bariey}

This is another good food. It is sometimes used with the hulls on. It then resembles oats and somewhat resembles un-hulled oats when it is un-hulled. I would not advise using it with the hulls on as the chaff is injurious to the squabs.

Those who do use it with the hulls on, do so merely because it is cheap, but cheap foods should not play a part in squab raising, as it means cheap squabs.

\section{Buckwheat}

Buckwheat, either the dark brown or gray, is used by many squab-raisers, but should not be fed in large quantities, and not much of it in summer, as it is very heating. Mix it with wheat, if mixed with corn, both grains being very heating, will cause bad results. It is a good, hard grain and is excellent to mix with white wheat or with new red wheat, when the old wheat happens to be scarce.

\section{Hemp}

Hemp is very fattening and stimulating, and should not be used separately. The best variety is the Russian Hemp. Birds are very fond of it, but they should not be fed too much of it. It is excellent during the molting season. Too much hemp will cause liver trouble.

\section{Sunflower Seed}

This should be used the same as hemp; it is even richer in protein than hemp. A small quantity goes a long way. Birds do not like it so well as they do hemp. It, too, is excellent during the molt, gives a good lustre to the feathers, and is an aid in shedding the old feathers.

\section{Mille?}

Millet is used as a stimulant. Birds breed better when a small quantity is used with the other food. There are a great many varieties. It is used very extensively as human food in Japan, India and China. It is grown all over the United States, the most of it in states west of the Mississippi River. It is sown broadcast.

Golden Wonder Millet is the variety used most in squab production, but nearly all of the varieties are used.

\section{Rape:}

Rape seed is a very small, round, brown seed, somewhat the size of millet. Pigeons are very fond of it. It is used as a dainty.

\section{Lentils and Vetches}

Lentils and Vetches are somewhat similar, and grow like peas. The former is mostly used in soups for flavoring. The pods contain only two flat round seeds. The lentils are mostly imported, but some 
are grown in Arizona and Mexico. They are high in price and are used only as dainties in squab-raising.

\section{Salt}

Neither salt nor Rock Salt should be used in any way except in a properly proportioned grit mixture. Picking at Rock Salt bends the beaks of young birds like a hook, or causes crossed beaks. Then when they become breeders they cannot feed their young properly.

\section{Grit}

Grit is one of the essentials pigeons should never be without. You would naturally think a man foolish if he owned a good set of artificial teeth and yet sat down to the table without them and tried to eat. The pigeons have no teeth. So nature has provided pieces of grit, such as sand, gravel, broken stone, small sea-shells, crockery, or anvthing gritty to take the place of teeth.

The crop of a pigeon takes the place of the mouth of the human being. The teeth of the human being grind the food, and by the aid

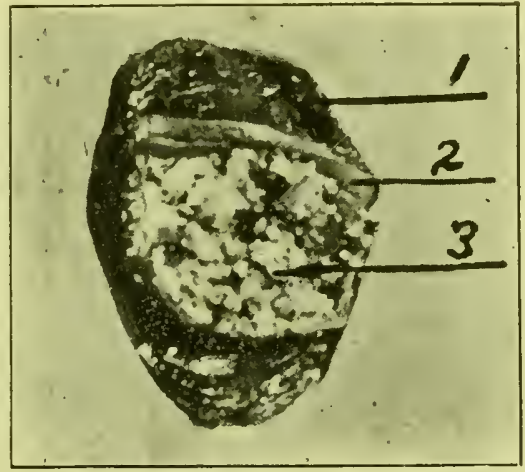

\section{Dissected Gizzard Showing Many Small Gritty Particles}

of the saliva furnished by certain glands, the food is softened anc: masticated, which is the first form of digestion, then it passes into the stomach. In pigeons, food lies in the crop until softened somewhat with the juices similar to gastric juices in the stomach, when it passes into the gizzard; the grit along with it. This organ is very thick and firm, and keeps the food and grit in constant agitation. Without grit to properly grind the food, pigeons will become sickly, due to indigestion, get thin, become mere skeletons and die. When a fowl or pigeon is being prepared for the table, examine the gizzard and notice the great amount of grit it contains, and the varietiesfrom a piece of broken glass to broken pieces of flower pots-all made smooth by the action of the gizzard.

I have learned more of the needs of pigeons by opening their crops and gizzards than in any other way.

The grit has another office to perform besides grinding the food. It regulates the digestion by assisting in the assimilation of 
the food, provides shell material for the eggs, and keeps the birds healthy.

\section{Charcoal}

Charcoal sweetens the crop and absorbs the injurious gases which collect. It is a most efficient purifier and disinfectant, acting upon the bowels and driving out the impurities-in this way cleansing the whole system. While using it you scarcely ever see a dark squab, as dark squabs are due in a measure to birds with liver disorders. The charcoal, acting on the liver, helps it greatly in performing its work. By cleansing the system it acts as a regulator and appetizer. It is not a drug but nature's own purifier, and is therefrire a gond preventive of disease. It also gives lustre to the plum1age.

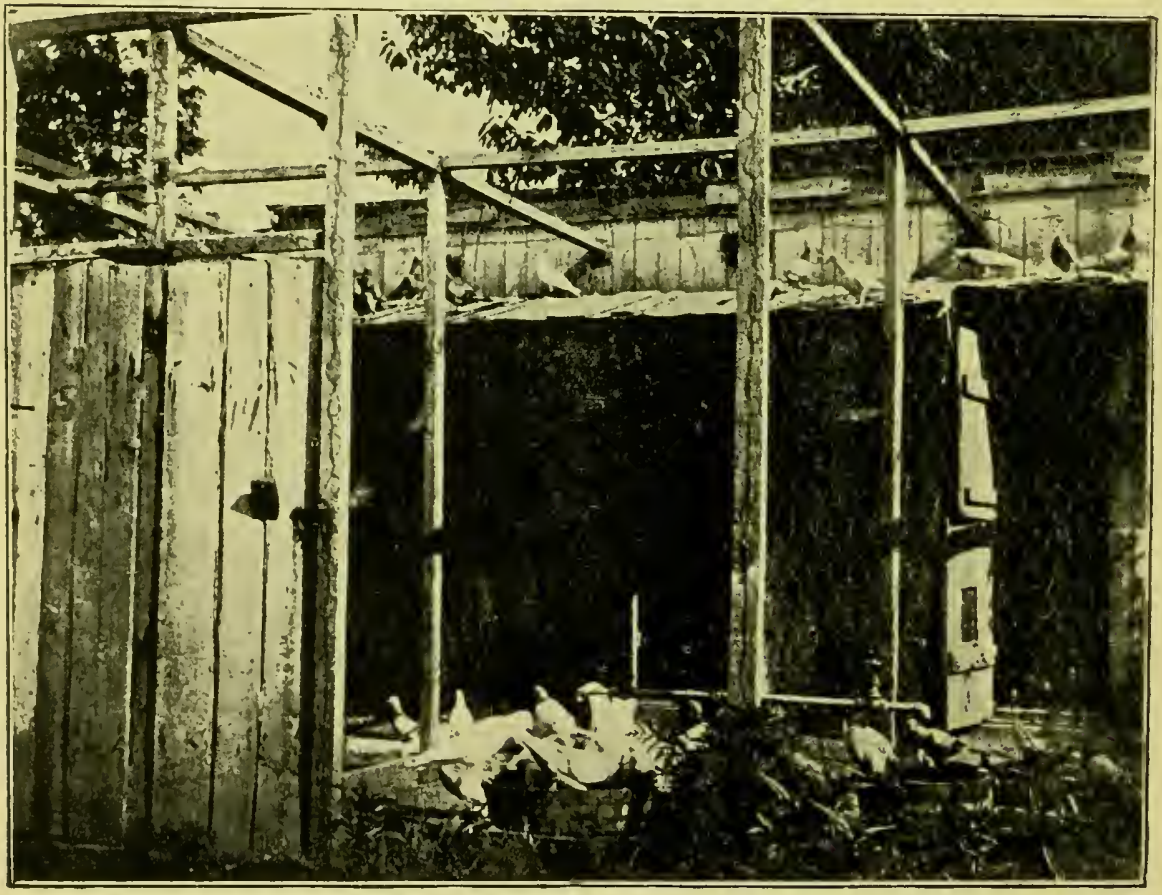

Taking The Morning Bath 


\section{Sanitation and Health}

\section{Sickness}

There is not much sickness among pigeons, if they are properly cared for. Good food, grit, and that one ounce of prevention, are better than ten pounds of cure.

Some people get careless and neglect their pets, allowing them to drink filthy water, eat moldy food and do not keep them supplied with grit. They think more of how to cure than how to prevent sickness, and will tell you of the great success they have in curing pigeons. I have noticed that some of the most careless make excellent doctors. The careful class will feed the best and use their best judgment to keep their stock in the pink of perfection, but

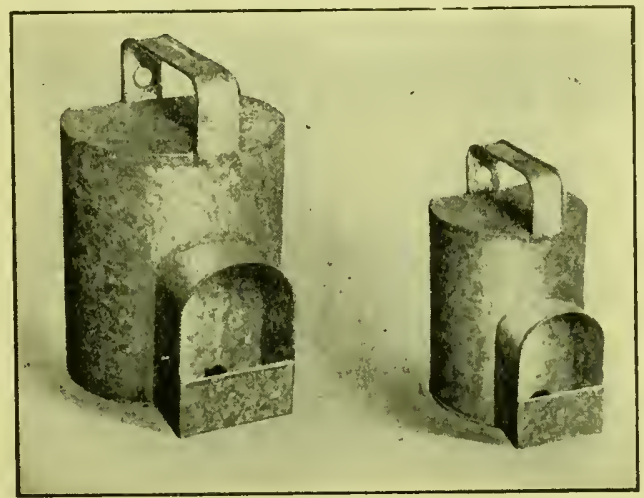

Drinking Founts

should anything go wrong, the careful one will call in the careless one to do the doctoring. It seems we all have a niche to fill.

Do not feed mixed feeds with high-sounding names. They are usually composed of a large amount of inferior grains that cannot be sold separately, or contain a lot of waste pop-corn from large confectioneries, who sell it by the barrel. While some recommend it, I would not, as I find the birds do not care for it.

If you clo not care to mix your own feed, you can purchase good mixtures from advertisements in any of the reliable poultry and pigeon journals.

\section{Water}

Water is one of the freest gifts of God to man. Yet man fails to use enough for himself and fails to judiciously supply his birds with it. Pigeons are great lovers of water, always drinking after a meal and between meals. They will bathe frequently if given the proper facilities for loing so. They enjoy bathing at all times. 
Give drinking water twice a day in the flying pen, and in freezing weather place it in the houses. If there is no shade at the end of the flies, place the drinking founts in a box turned on end with? back toward the sun. I find sunflowers make an excellent shade and the seeds can be fed to the birds.

Give bathing water at least twice a week, and empty it after the birds have bathed. Always give the bath water in the morning.

Pigeons should never be given water in receptacles made of tin or in anything that has contained posionous matter, grease or acid. Rusty cans used as water containers are very detrimental to the health of the birds. This rust is entirely different from the rust of iron which is beneficial. When birds molt use iron in the drinking vessels for a tonic. The iron can be supplied by using a large spike.

Never use kegs that have contained paint, no matter how thoroly: they may have been cleaned. White lead will kill pigeons.

For drinking purposes use receptacles made of galvanized iron, crockery or wood that can easily be cleaned.

\section{Water System}

If you have no water system, have a one-inch galvanized line of pipe running to the houses and laid two feet under the ground.

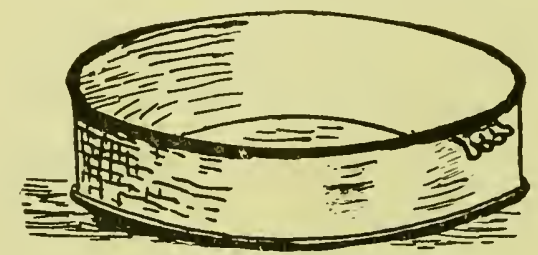

Bath Pan

At the end of each fly have a valve to turn the water on and off. At the extreme end of the pipes is a cistern eight feet deep. During the winter the water is turned on by a valve and when all of the houses are supplied shut the water off at the valve. The valve is then opened at the cistern and the pipes are drained dry. In this way water can be supplied and yet there will be no trouble with frozen pipes.

At nearly all large squab farms where pipes are not used, the water is conveyed in a barrel on two wheels. Farms of one thousand to fifteen hundred birds are watered in this manner. When only a few hundred birds are kept the water is carried in a bucket, while others have the flies built to a small stream of water, or over it.

Same have a wind mill, while others use a force-pump, and some have a hydrant centrally located, and attach a hose. Others have piping running thru the flies.

\section{Whitewashing}

Coops should be whitewashed at least once each year. It is a pleasure to enter a newly-whitewashed coop. Everything seems to be so sweetened and the air is so pure. 


\section{A Good Whitewash}

If you want to do it right, place the lime in a tub, box or whatever is the handiest for you. Then pour water around the edge of the lime so that it will nearly cover it. As the lime begins to slake, stir with the paddle and add only sufficient water to keep the lime from burning. After the lime is all slaked it should be like a stiff putty. Now add a little more water and allow it to remain this way for one week. This is the way plasterers make what they call "putty." Then take some of the putty and add water to it until it is like new milk. To prevent the whitewash from turning yellow, place in it a little washing blue. To keep it from rubbing off, place in some powdered alum. To make it work easily like paint, put in a little soft soap, or use soap powder. To prevent any possible chance of lice add a little crude carbolic acid. If you have more lime than you need, keep it ; it will air slake and you can throw it in the nest bowls when you clean the nests.

\section{The Proper Way to Clean}

The parent birds, while hatching the eggs, which requires from seventeen to eighteen days, do not soil the nest, but when the squabs

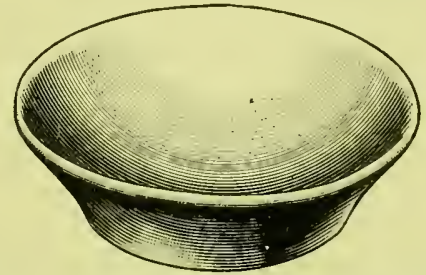

\section{"Nest Bowl." The Kind to Use are Round on the Inside so Egg Will Lie in Center.}

are two weeks old the nest is quite dirty around the edges and should then be cleaned by taking it from the nest bowl with a trowel; placing the manure by itself, as it should be saved and sold, then shaking out the stems, placing about half back in the nest bowl. 'Two weeks later the squabs are four weeks old, and ready for market. Then the nest is cleaned again and air-slaked lime should be thrown in the nest bowl. Be careful when using lime that none gets in the birds' eyes. The birds have already built a nest in the adjoining bowl and very likely have eggs or peepers. The nest bowl just cleaned is all ready for their nest-building. It will be noticed that there is no special time for cleaning, except that nests should be cleaned twice, once when squabs are about two weeks old and again when they are four weeks old. The floors may be cleaned whenever you wish to do them.

\section{Cleaning Houses}

The advice that some writers give on cleaning sounds ridiculous to many old squab raisers. Some advise cleaning the house once a week; some twice a week; every month; every six months; every year, etc. 
It is the nests that must be kept clean. Clean the floors once a month. Some men with thousands of pairs of breeders, clean floors only once or twice a year. It is advisable to clean the floors at least once a month, and then you will seldom be troubled with mice or rats. Mice will build right in the nests with the birds and rats will burrow on the floor, if houses are dirty or full of litter.

A fancier complained about his birds leaving their nests, and the eggs getting chilled. I answered, "It must be caused by mice. Clean your nests more frequently." The reply was that there was not a mouse on the place. The man, living near. I went to his place and he took me to his houses and showed the nest of chilled eggs. As soon as I saw the nest with fine stems in the corner I knew the cause. I asked, "Have you a cat?" He said, "yes," and got her. I told him the first thing the cat would do if he was not careful, would be to catch a squal), and if she did, to box her ears, and take the squal) from her. This she did and he did as I had told him. He now carried her to the nest of chilled eggs, lifted the nest and found a mouse nest but no mice. He then took the cat to the next house and as he lifted a nest, out jumped an old mouse and three half grown ones. In fifteen minutes the cat had caught them all. I now told him he had not followed my directions in cleaning nests; but he insisted they were clean, and not dirty. "Yes, but you did not clean as directed, as I believe I know something about the length of time it takes mice to build nests and rear young that are half-grown, as well as about squabs. Train the cat to catch them and you will soon be rid of them." It is these small things that count in squab-raising. Soon after this my friend called, stating that his birds were doing nicely, and the cat well broken in: that she caught fifteen mice in one day, and that he can honestly state now that there is not a mouse in any house or he would find some trace of them when cleaning the nests.

\section{Training Cats to Catch Mice}

When training cats to catch mice and not to catch squabs, it is best to teach a young one. A cat will follow you to the houses like a dog. However, you will not find any mice nests if you keep the squab nests clean, as a mouse cannot build and have young from the time the nest is cleaned to the second cleaning time. If the cat has spiecl a mouse and cannot catch it, let her remain all night, and usually she will come running to you in the morning with a mouse, as proud as a boy with a tin watch.

When cleaning, the only tools needed are a spade, a trowel and a strong shovel or short scraper. Do not use a lot of long handled tools, such as a hoe, scraper, etc. Enter your houses slowly, so that the birds that want to fly out to the fly may do so without being frightened. Some of the birls will remain on the nest during the whole time of cleaning, and you will be obliged to lift them off, while wthers will keep flying in and out. Never whistle nor make an uproar in the house. Clean each nest as quickly as you can, so as to allow the birds to cover their eggs, talk in low tones to your birds. Cet acquainted with them. If one sticks to its nest and coos angrily 
at you, allow it to strike your hands, but be careful when lifting the eggs, if the bird gently slaps you, that it does not knock the eggs from your hand.

\section{Shifting Nests}

When shifting a nest, it must be done very slowly. If the nest is on the floor don't disturb it until the eggs are three to five days old; or the birds will leave it. To move it, first place it in a nest bowl; the next day place a couple of bricks or blocks under it : keep raising it two or three inches for three or four days then increase the distance until the nest is where you want it. I have changed them in this way from one side to another and from the floor to the top row of nesting apartments.

Never take a pair of breeders, their nest of eggs or squabs from one house to another, for in nine cases out of ten they will leave them.

\section{From Egg to Market}

About two weeks after birds are mated, the hen will lay an egs about four o'clock in the afternoon, but will not sit very regularly. She skips a day and lays the second egg. She then covers the eggs and gives them better attention. The longer incubation continues, the closer she nestles the eggs and if watched closely, it will be noticed that both birds turn the eggs quite frequently with their bills. The cock covers the eggs from ten o'clock A. M. until about four P. M. when the hen takes her turn.

The weight of a Carneau egg, that will produce a squab weighing one pound, is one ounce. The day after it is hatched the peeper will weigh one ounce more, and continue gaining one ounce till seven or eight days old. 'Then the increase lessens to about three quarters of an ounce per day and some days there is scarcely any difference noticeable, altho many will gain considerably during the last week. depending on the feeding qualities of the breeders.

The first egg laid is about one eighth of an inch larger than the second one and the first peeper, when hatched, has a day's start of the other egg. Many writers claim the reason for this is because the cock birds are larger than the hens, but in many cases I have had both squabs hatched the same day and the cock bird always turned out to be the larger bird. As a rule, the cock bird of a pair of nestmates is always the larger.

I do not attribute this to the size of the eggs or that one hatches before the other, but as is natural with all birds and animals, the larger is the male. In chickens the cock of the same breed is always larger than the hen, even tho the eggs are all hatched the same day.

Like a great many squab raisers, I always imagined a squab matured more rapidly during the last week of its maturity, but squabs are very deceiving at this age, as I have proven by weighing them repeatedly from the egg until they are full-grown and ready for market. During the last week they stand up on the nest when approached, and because they take on feathers so rapidly, it seems to be the age at which they gain the most flesh. However, it is only an abundance of feathers, and feathers are not heavy. 


\section{Diseases and Their Remedies}

On previous pages of this book we have endeavored to help the pigeon breeders to keep and care for their birds in such a way as to keep them in good health, but diseases will come, and sometimes when almost ideal conditions surround the birds, and when they do come you naturally want to know a remedy that has been tried and true.

\section{Canker}

Canker is a disease that will oft times make its appearance in the best regulated lofts. It attacks a bird sometimes in the ear, nostrils, mouth and throat. The disease in any section is a very contagious one, and it is hardly worth while doctoring the specimen unless it be a valuable bird. The same treatment used for mouth and throat canker will not effect a cure for canker of the ear, and a bird that recovers from an attack is not a good specimen to breed from, as it often makes its appearance in the squabs and oft times the whole loft is polluted and the breeder wonders how his birds contracted the disease. Canker inside the mouth and on the tongue can be cured by scraping it off until the blood comes and burnt powdered alum sprinkled on. This is one of the most effective cures for canker. Canker in the ear is not so easily cured as canker in the mouth, and the ear washed gently with a solution of bicarbonate of soda and water daily will effect a cure if taken in time and the bird is given the proper attention.

\section{Pigeon Pox}

A common and contagious disease caused by filthy conditions, moulding food, filthy drinking water, etc., is pigeon pox. It first makes its appearance like a little pimple and develops into a warty growth. When pulled off small root-like threads come with it and a quantity of pus and a watery fluid which has a very disagreeable vdor. The only cure known is to cut around the growth in such a way so that when the wart is pulled off the roots will come with it. Then wash the wound with a solution of carbolic acid and water and then apply a healing salve. The disease is curable, but remember very contagious.

\section{Going Light}

Going light is the curse of the pigeon world. Whole flocks have been cleared out, and on account of this disease many hundreds of fanciers gave up the business in despair and disgust. When it makes its appearance quick action is necessary to prevent it from spreading. It is sometimes caused by birds getting chilled coming or going to shows. Tuberculosis can, in almost every instance, be 
traced to dirty food, water, filthy houses and runs or some other neglect on the part of the owner. From appearances to the unexperienced the bird seems well but in a few days dies, having wasted to a mere skeleton. The disease starts with diarrhoea, and in the course of a few days the bird becomes so weak that it is unable to fly. When a bird so afflicted is found I would advise to take it out of the flock and kill it. While there are a number of remedies that in some cases will cure, yet I do not think it advisable to give any here. As stated above, when it is first discovered, kill the specimen, clean up, disinfect and eradicate the cause which in nearly every case you are able to do.

\section{Leg Weakness}

Sometimes this is due to injury of the spine, but more frequently to rheumatism. Injury to the spinal cord does not give much encouragement in effecting a cure, for in many cases the paralysis will become complete. For leg weakness caused by rheumatism remove the bird to dry, comfortable quarters, feed sparingly of strong food and the bird will usually come around alright. 


\section{Pigeon Houses and Equipment}

\section{The Standard Nesting Equipment}

'The ready made strle has four of these double nests to a section.

Ready made standard Houses and Equipment-up-to-date and sanitary-are the most economical.

They are a great boon, not only to the marketing squab-raiser but are ideal for Fancy Breeds and Racing Homers. For the latter the fly pen is not used (except for a house of untrained birds to exercise). The regular signal bolting traps are placed at the overhead shutes, which are so arranged that on a race day when a bir.l homes

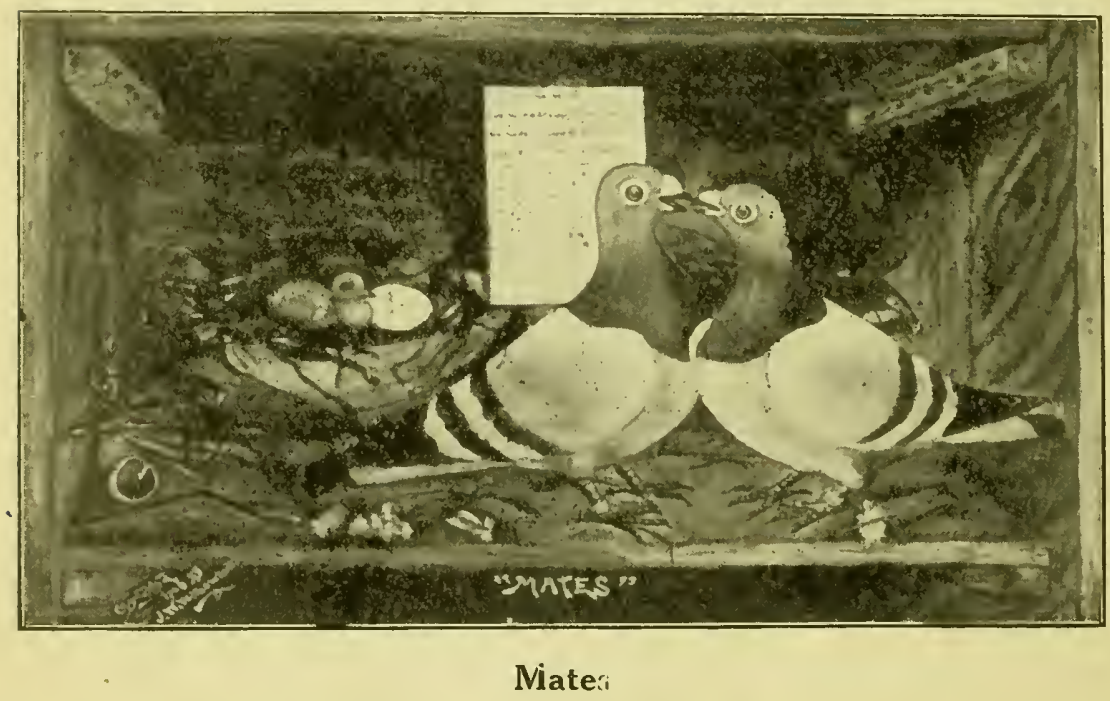

and rings the signal bell the bird can be caught in the overhead shute in the alleyway, its counter band can be promptly removed and placed in the time clock quicker than by any other method in use.

One of the greatest essentials in keeping pigeons to derive the most pleasure and profit, is proper equipment. Fou can no nore be highly successful with a make-shift house, than you can do a good jol) with poor tools.

At the post-war price of labor and lumber you cannot build even a make-shift as cheaply as you can buy some standard ready-made house. Even after you pay the freight bill, a standard will be cheaper. You can put them up one day and place your birds in the next day.

\section{Description}

Standard houses are built in sections of well seasoned, tongued 
and grouved boards on sides and ends. Doors and windows are already in. Strong frame and good roofing naterial are used, size is eight by fourteen feet. Seren feet elevation in front; eight feet to the gable and six feet rear with a four foot alleyway in front, between the nesting room and the fly pen where the most light enters and the birds have better light to eat out of the feed-troughs that are in the alleyway than when the passageway is in the rear as it is in the old style houses. A wire netting partition with a door in it divides the alleyway from the nesting room. There is a door in the front elevation with wire cloth and windows of same material in the rear, so constructed as to give a large volume of light and ventilation without drafts on the birds. A new feature is a wire partition running from the edge of the top row of nests to the ceiling.

To erect the house you merely bolt it together with a wrench and place the roofing material on. After it is bolted together rou can move it anywhere you wish. If you want to add more units you need only to minfasten your bolts, remove the end and fasten to the next house and so on, continuing with a row of houses. It is adrisable to purchase two or more if you are engaged in Squab Troduction, four is the most economical number to buy. Birds breed extra fast in these houses. When saving youngsters for breeders you lieed extral houses.

When the youngsters start to mate, trap them with an atutonatic trap and place them in a breeding house.

\section{The Interior}

The interior of the houses, with their apartment nest boxes, keeps the birds mated where you want them and keeps them tame. Every pair has a home to themselves for nesting, but the birds can all be together when feeding or in the fly pen.

The feed and grit are placed in special troughs in the alleyway (not the nesting room). This saves opening a great number of doors which causes a waste of time and continually tracks in dirt to the aisle.

The special feeding troughs are so arranged in the aisle that the birds can put their heads thru the lattice work to eat and do not scatter the feed in the nesting room or aisle.

It is a pleasure to walk thru a clean alleyway and show your birds to advantage in standard houses and equipment, and point ont every double nest box with contented working birds. When each pair has a home of their own, they do not fight.

Figeon keepers who do not have standard nest boxes usually have three times as many nest boxes as birds, which means a lot of wasted room and requires a house one third larger than the standard house.

With a three nest idea, birds are continually changing nests and fighting for possession; soiling, breaking eggs, killing peepers, and knocking squabs out of the nests. The price of a few of the squabs thus lost would pay for a section of standard rests. 
With standard double nest equipment all of the birds are peaceably at work and raising more and better squabs.

They cannot fight with their neighbors, as the partition extends out from the landing nest board. Every apartment nest box being occupied, saves one third on the cost of nests, which is quite an item coupled with the one-third cost of the building.

If a pair of breeding birds are sold, their nests are closed up until occupied by another pair. If a breeder dies, say, in apartment number ten, a young bird of mating age of the same sex should be taken from a youngster's house and placed in number ten to mate up. A leg band of the same color as the band on the other bird, should be placed on the opposite leg of the new bird (cock-right leg; hen-left leg.) Close them in with a mating screen and let the screen remain till the birds are mated.

The mating screen is another good invention, and when it is in place, a pair of birds must work where they are mated, for all the other nests are occupied or closed up. They will not build nests on the floor as there is too much light on the floor. They cannot build above the nest boxes as the wire partition runs from the top row to the ceiling. At night the hen is on the nest and the cock is in the adjoining nest or on the landing board. He cannot roost over a door or window, because the way in which these places are constructed prevents him from doing so, and he must roost near liis mate all night.

Standard mating traps are made four to a section, are placed against apartment nests in a youngster's house and work automatically. Birds can go in and out at will, but when a pair is noticed "billing" or "driving" find out the nesting place number (every nesting place should be numbered) then set the trap and leave it for a time. Upon your return you will find they have automatically trapped themselves. If a cock is noticed in a nest box cooing for a mate, set the trap, even tho he does fly out before it is set; he will return and a hen with him. These traps can be used to advantage in a breeding house where the birds are not all mated. Having four traps to a section, they fit any standard nesting equipment and you will soon have every pair mated, will know what they are doing and can weed out the drones.

Fly pens should be eight feet wide or as wide as the houses, should be twelve feet in length and should be six and a half feet high. If higher, the birds would be out of reach. Alighting boards are placed around the sides and against the house. A good grade of two inch mesh galvanized netting is used; one inch can be secured at a higher price. If you have an old house and need only doublenest equipment, you can secure any number desired. If you are breeding Racing Homers your needs will be bobs, bell with sufficient wire, insulated staples, switches, etc. 


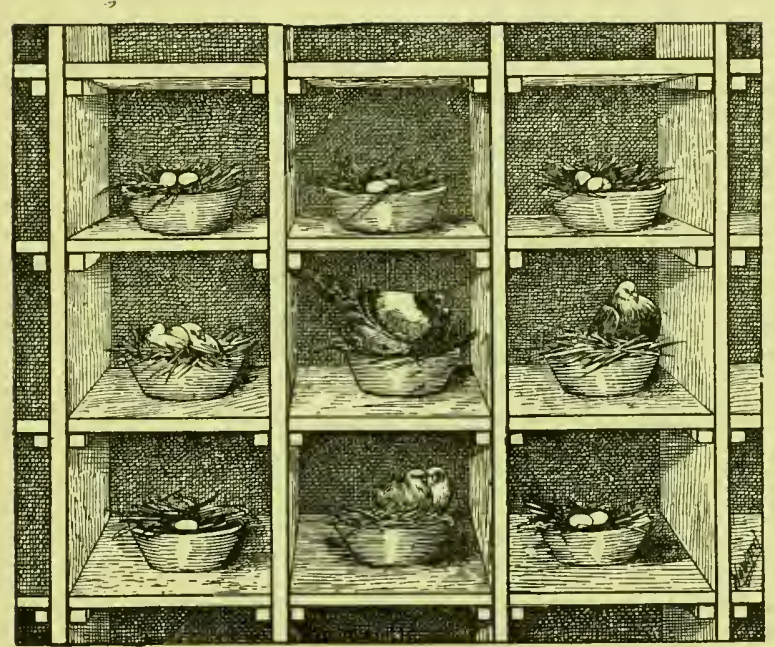

The Old Style of Nesting Equipment

This style cell arrangement is fast disappearing as the birds are too close to each other and fight for each others nests. At times because of this, some of the pairs are delayed a whole season before getting down to work. 


\section{Mating}

When buying birds be sure to buy from a reliable breeder. Your birds should all be mated and ready to go to work. But nearly every beginner wants to raise some youngsters and must mate them when they are old enough. The time depends on the birds themselves. A small number may show sigus of mating when they are four months old, and even sooner, while the majority of birds will not mate until they are five months old.

The hens always show signs of mating before the cocks, and many breeders make a great mistake by mating to an old cock bird, a young hen three or four months old, before it has gained the proper vitality. It is not wise to mate birds too soon. When it is desired to mate only a few pairs now and then, take them from the house you are rearing the youngsters in, and put them in a breeding house where you want them to work, using the mating screen. Some birds will mate in a day or two, while others will be a week or two. To mate, place a bird in each apartment, using the spindle partition between them. If they are agreeable the cock will begin to coo and walk about, spreading his tail and making advances toward the hen, lowering and raising his head and waltzing all the way round, nearly on tip-toes, continuing his "wow-wow, wackity-coo;" in a very deep tone. The longer he keeps up the flirting the more he lengthens out the coo.

The hen at first acts very shy and apparently pays very little heed to her ardent wooer. But his constant, earnest cooing soon wins. The hen finally giving up to the artfulness of Cupid's wiles. nods her head in approval, blinks her mild eyes and struts about wit? wings partially extended. She then swells out her throat, showingr an irridescent lustre of bright feathers, and after making a low coo takes the decisive step up to the partition and watches the cock go. ing thru his ardent wooing. For a moment she places her head back under her left wing, and the cock does likewise. After this part of the ceremony the cock places his head thru the partition, and takes the bill of the hen in his (taking bills) and with long affectionate kisses they love each other as only doves can love. Their union is sealed and you can now rest assured these devoted birds will live its peacefully as doves. Don't keep them separated any longer. Take out the partition and throw in a few stems, that they may go to housekeeping and go on with their domestic affairs. For convenience we will call the cock, "Dick," and the hen "Bets." You will now observe that Dick goes to one corner and calls to his bride. Bets follows and gently picks over his head. Dick, in pigeon language says:"Here we will make our home." And Bets sits in the nest bowl while Dick gathers stems, testing each in his bill before laying them at Bets' feet. It is Dick's duty to find a suitable home and material for the nest, and Bets' part is to build the nest, which she sets about 
doing. Now this deserving pair should be registered. The first thing to do is to record their leg-band number, if the band be seamless and then place on open bands; the same color band on the right leg of the cock and on the left leg of the hen. You can now tell all materl birds at sight.

\section{The Register Card}

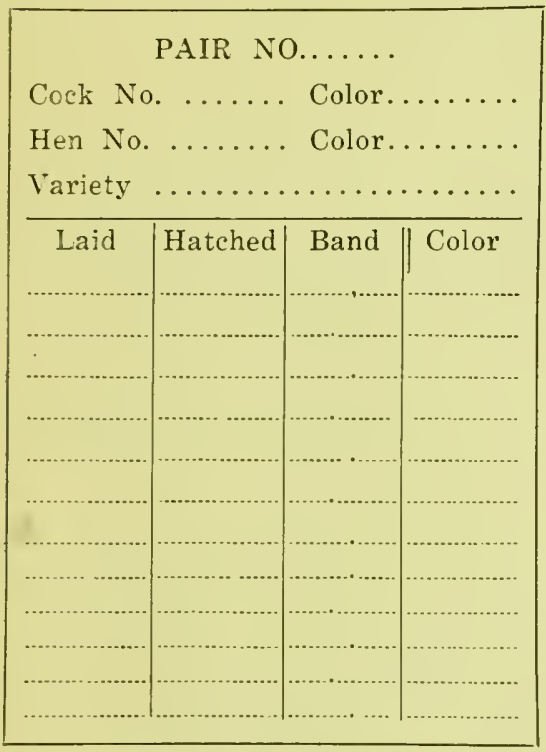

This is a sample of the card, reduced in size, that should be used on every pair of nests. To tell all the knowledge gained by using these cards would fill quite a book.

By certain marks you will learn the qualities of each individual pair. You can tell by the card how soon the birds started to work.

Any birds and youngsters that do not grow up to a good size can be culled out and shipped to the squab market.
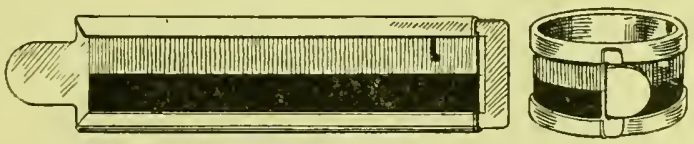

Color Bands

The cock should have the same color band as the hen, riz: Pair I, Red bands, Cock right leg, hen left. Pair 2-Blue bands, etc. In this way you can tell mates without catching them to read numbers.

The home is now ready for Dick and Bets to start as pedigreed breeders. The card will tell how well they succeed. Bets, as she flies about will be followed by Dick, who will continue driving her (driving to nest), picking her on the head and driving her to the nest. Old style nests may cause the whole coop of breeders to be in an uproar and swear vengeance against these young intruders. Some (if the bold fellows will want to take Dick's mate, but he keeps close at her heels. There are several empty nest boxes from which Dick (an choose, but he will probably take a fancy to a nest that is occufiect by an old pair of breeders with eggs, or squabs, and after a 
scrimmage lasting a couple of weeks, the eggs will be destroyed and the old breeders driven from the nest. But they are not inclined to seek another nest but will continue to fight with the new pair. Finally, they get in trouble with other pairs and thus for a month or more eggs and squabs are destroyed all on account of just one pair of birds being thrown in a coop to shift for themselves.

For two months, I had two pairs of birds fighting for the same uest. When I thot one pair was settled, the other would cause trouble, so, finally, I placed one pair in another coop.

I then determined to remedy this evil and succeeded by the improved nests and the methods mentioned in this book.

Do not be deceived into thinking that fifty cocks and fifty hens placed in a coop will mate in a week's time, or that if a bird die, all you need do is to throw in an extra bird to mate. It will mate, no doubt, and will probably break up more than one pair by doing so. A loss in eggs and squabs follows and do you know whether the bird that died was a cock or a hen?

My advice is to take the old bird out of the breeding house if possible, or it will cause trouble. If you are rearing youngsters, place it in with them, as an odd bird should never be permitted in a house of regular breeders.

Some breeders mate different colored birds together, claiming it gives more stamina and that the birds breed better. My experience with many matings has been that the color of the pigeons makes no more difference than would the color of a man's clothing. This proves the method of mating, as given in this book, to be superior to any other method. The reason some claim they get better results with birds mated to different colored birds, is due to the fact that they are more apt to be birds that are not nest-mates, but by the methods herein stated, you are doubly sure of not mating nest-mates. One advantage of mating up different colored birds is, that a person with a small flock can more readily keep track of mates that are not banded, which accounts for the success some have over others who do not know their birds.

It is surprising how soon a person can become familiar with a flock of birds, and point out the different mates. But all this is not necessary when you buy properly mated and banded birds, or band your own birds with colored bands as they mate.

\section{How To Tell The Sex}

The best way to determine the sex of pigeons is to watch their actions. One of the surest signs, we have noticed by close observation, is that the cock bird when flirting will occasionally turn all the way round, but have never noticed a hen turn more than half way. The cock is usually larger than the hen, and its head is rounder, its neck thicker and coarse, while the crown of the head of the hen is, as a rule, slightly concaved. But the shape of the head cannot always be relied on.

The eyes of the cock are bold and clefiant, while the hen has a 
miller expression. The vent bones of the cock are closer than those of the hen. The older the hen, the wider apart the vent bones. This is due to laying.

The latter method is most relied on by breeders and dealers, but it is not always a sure sign, as we have had cocks, whose vent bones were wider apart than those of the hens. Again this rule cannot be depended upon in the case of young birds, as it is only the laying of eggs that distends the vent bones of the hens. Another method is to ieel the end of the breast-bone, which will be found to extend further back in the cock than in the hen. A method I used when a boy was to take the feet of the bird in the right hand and the bill in the left hand, and stretch it. If the bird was a cock, the tail would drop or lie even with the body; if a hen, the tail would be thrown above the level of the body. I have often followed this old rule. but as I became more familiar with the birds and their actions, I did not test by this method but was guided more by their actions and the expression of their eyes. When you get a doubtful bird and have tested it by all the methods you know, place it in a mating coop with a good vigorous cock bird and you will soon be satisfied as to its sex.

To tell the sex of a dead bird when you wish to re-mate the other one, disesct it by cutting it down the back, which will positive1v reveal the sex.

The study and rearing of pigeons will be found very interesting. You can learn something every day by closely observing everything, which makes it a very interesting as well as profitable business.

\section{Marketing Squabs}

\section{How to Tell When Squabs are Ready for Market}

Never pick cherries until they are ripe and never pick squabs until they are plump. If squabs are not plump at five weeks, don't lieep them any longer, as they usually get thinner between five and six weeks of age, do not take on flesh again until two or three months old, and do not attain their full growth as pigeons until one year old. They are then as large as they ever will be, except a few which may put on extra fat. If a squab is firm and the pin feathers are a quarter of an inch long, no matter what age it is, it is ready for market. Experience will teach just how far to let them grow. Remember, the longer they grow and take on flesh the better for the squab-raiser.

If, after examining one, you think it will take on more flesh, let it continue. If it is feathered sufficiently and appears to have its 
growth with tail feathers about three inches long, don't let it go another week for it will lose flesh.

\section{Prepare Squabs for Market}

If you propose shipping on Monday, go thru your coops on Saturday and notice how many squabs will be ready. If it is about the same number you had the previous week, get boxes or barrels ready to accommodate the required number. Have your shipping tags, tubs and everything in readiness and early Monday morning, before feeding, gather the squabs-not in a box, or you will have some of them smothered before killing time, unless the box is ventilated on both sides.

\section{How Squabs Are Picked}

Let us presume your picker or pickers have filled a tub half full of water, and placed in it two handfuls of salt, while you were gathering the squabs, and also have the knives ready. Now comes the part that is done in various ways - the killing of the squabs. Some chop the heads off, others get the feathers off by scalding them the same as chickens are treated in the West, and then wonder why eastern poultrymen and squab-raisers get more for their goods.

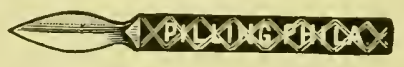

Knife

Still others ship them with the feathers on. Without going over the various ways, which are wrong, let us get to the manner in which the eastern and good western trade demands them, namely:--feathers plucked, head and feet left on, and the entrails not drawn. IIarkets that demand squabs dressed, they should be, what is termed "dry picked." Suspend the squab from a noose tied to its feet, then hold the squab by the wings and head and thrust a knife in the mouth, to the back of the jugular vein, then draw it up into the brain. This causes the feathers to loosen. You can now pick and not get soiled if you hold the wings right.

This is a more humane way of killing than by cutting the heads off. As soon as the blood flows readily, pull out the wing feathers, then the tail, then the feathers on the crop. This is where you should be careful, so that you will not tear the skin. If several are picking, one should do the roughing and sticking and the rest pick the pin-feathers. After a little experience squabs can be picked in two or three minutes. Some pickers work faster by placing a bag on their laps, sticking and picking while the squab is on the lap. If it is a rough bag, be careful not to skin the squab.

Do not become hurried and begin picking a squab before it starts to bleed. If you do, it will turn out to be a very dark red bird. This is the cause of a great many dark squabs. Pick off all the feathers but the ones on the head. Some leave a few feathers in the wings like squab ducks. But squab pigeons are not squab ducks; nor squab broilers, altho the latter are picked the same as 
squabs. As soon as the squab is plucked it should be thrown into the tub to further plump it. If a squab slould be a little dark the brine will tend to whiten it.

After the squabs have been in the first water half an hour or an hour, wash them and place in another tub of clean water without salt, allowing them to remain the same length of time. Then suspend them on a rack where two eight penny wire nails are driven in every five inches, one quarter of an inch apart. Or you may take them out of the tub and pack immediately after drying them with a cloth. If you find any still dark, place then in a bucket of water to which has been added a half teaspoonful of baking soda.

\section{Packing}

Never pack a warm squab, the animal heat will cause it to turn green. In summer time place a layer of cracked ice about the size of walnuts in the bottom of your box or barrel. If you use a box. lay them in rows breast down. When half full, place another layer of ice, then more squabs, and top off with ice. Write on a slip of paper the number of squabs and the weight. While your picker is getting the squabs ready you should be attending to your mail. Be sure to tell your expressman to call in time for a certain train. You do not deliver the squabs; the expressman calls for them, and gives you a receipt for them, which you should keep on file. The agent places them in the baggage car adjoining the passenger coaches, and when they reach their destination they are delivered by the express company. There is no extra charge for calling for or delivering them at the other end. You can pay the expressage, or the commission men will deduct it when they make your returns, which should be the same or the following day.

Let us go now back to where we finished packing:

After the lid is nailed down good and tight, tack on the tag the commission man sent you, and write your own name and address, or stamp it on, which is better. Now mail a postal card or letter saying: "Shipped you today 50 lbs. squabs," or what ever the weight may be, as squabs are now mostly sold by weight.

Squabs are cooked by the same general rules used for cooking poultry and wild game birds; but must not be cooked so long, as squabs are very tender and their fine, mild flavor should not be destroyed by over-cooking. Squabs have the finest flavor when they are four weeks old. They are then at the right age, plump and weil filled out. 


\section{Recipes}

Fried Squab on Toast-After cleaning, split down the backs, place in a frying pan with a little water. Add pepper and salt; then cover. After steaming a few minutes, put some butter in the pan, and fry until a nice brown. When fried, toast bread, nice and crisp, and lay half a squab on each slice, pour over this a little of the broth you have saved from the steaming after you added butter and serve hot; sprinkle with a little celery salt.

Roast Squab On Toast-Draw the squabs and wipe with a damp cloth; do not wash. Cut off heads and feet and sprinkle with pepper and salt. Fasten thin slices of salt pork over the breasts; place in a roasting pan with a little water. Baste every five minutes. A few minutes before taking up lay a slice of toast under each squab to serve it on. Brown coarse bread crumbs in butter and pour over each squab. Boil the liver and pound to a paste with butter; salt and pepper and spread on the toast on which you serve the squabs.

Roast Squabs With Oyster Dressing-Remove heads and feet from a dozen squabs and after cleaning, dry with a cloth, then make the dressing of stale bread seasoned with salt and pepper and a lump of butter. Put a pint of oysters in the dressing. Tie the necks of the squabs and stuff them; then place in a roasting pan, with water, laying the squabs in rows with breasts up. Bake until a nice brown, basting frequently. Make a gravy by adding water, then thicken with a little flour and milk.

Roast Squabs Stuffed With Chestnuts-Roast same as in recipe number one. Prepare stuffing as follows: Remove the sinew's from one pound of lean veal, and the strings from the same weight of leaf lard. Chop together until well blended, moisten with one half pint of broth, add one teaspoonful of salt, one salt spoonful of pepper, one pint of chestnuts blanched and boiled. Fill the squabs. One cup of the cooked chestnuts may be reserved, mashed, sifted and used to thicken the gravy. This should be lightly browned, not to destroy the chestnut flavor.

Squabs a la Cendre-Dress as many squabs as there will be covers. Dry them and put the livers inside again with a little salt and butter. Wrap each squab in a thin bairde of salt pork, tucking a leaf of sage under each wing. Wrap again in well buttered paper (white) and roast half an hour in hot wood ashes, as you would potatoes with their jackets on. Remove the paper and serve with maitre d' hotel sauce. 
Maitre d' Hotel Sauce-Add to one cup of fresh drawn butter, the juice of one lemon, chopped parsley, minced onions, thyme, cayenne pepper, and salt. Beat while simmering.

Mint Sauce-If unable to procure the prepared sauce, make as follows: Three tablespoonfuls white vinegar, two of mint, one of sugar, and one of salt; mix at least ten minutes before using:

When properly prepared they are fit to set before a king.

"Four and twenty white squabs

Baked in a pie,

When the pie was opened,

The squabs began to sing,

'Is'nt this a dainty dish

To set before the King?" " 


\section{Inciex to Illustrations}

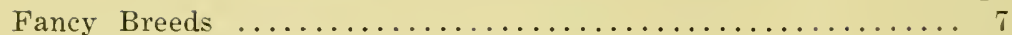

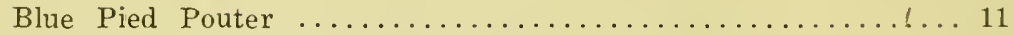

English Carrier ................................ 14

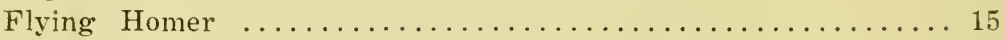

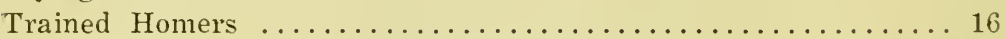

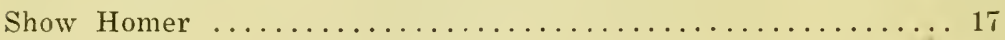

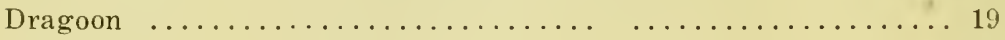

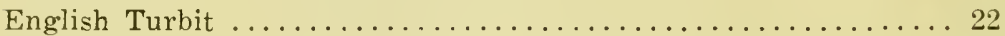

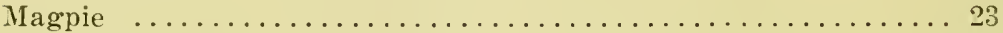

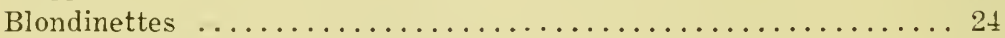

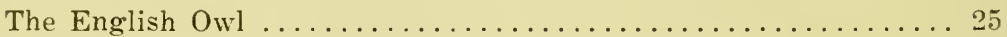

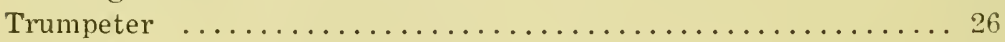

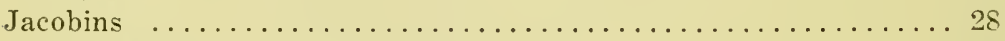

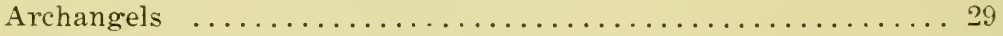

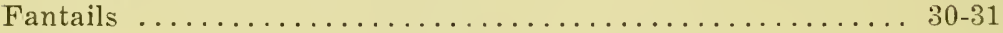

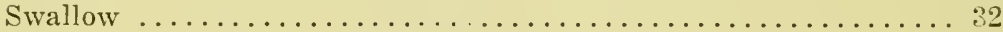

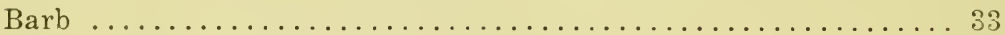

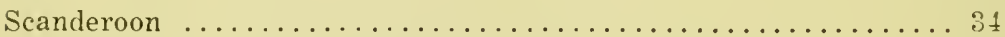

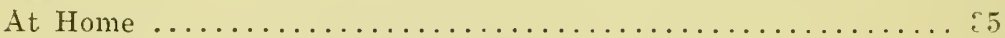

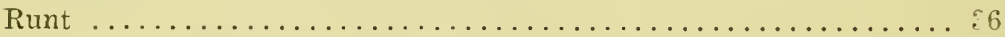

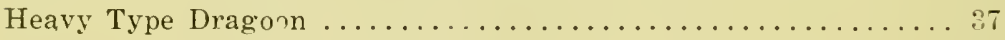

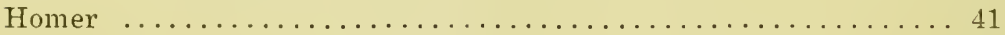

Standard Type Carneaux ....................... 43

Maltese ................................ 47

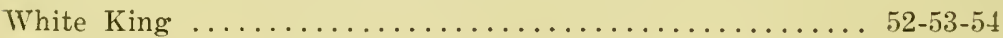

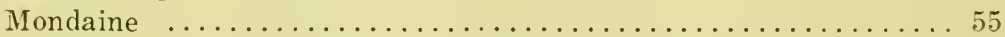

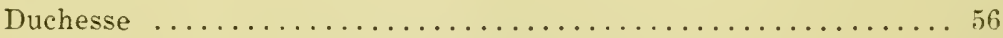

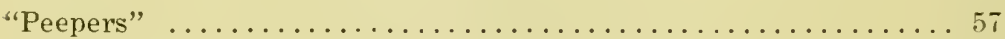

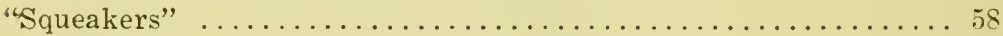

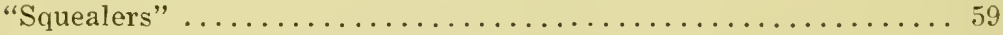

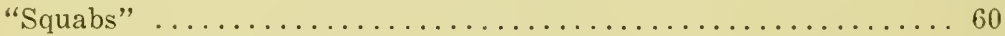

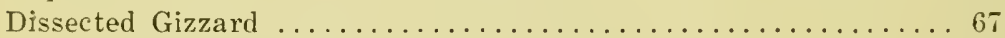

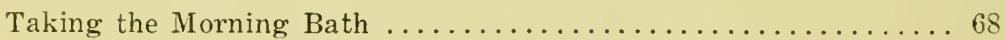

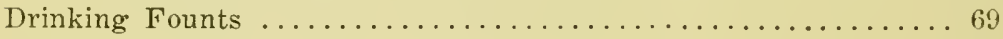

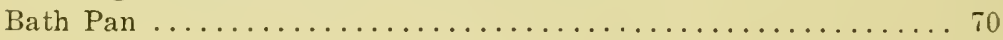

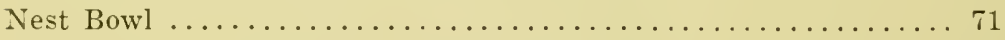

Mates .............................. 6

The Old Style of Nesting Equipment ............... 79

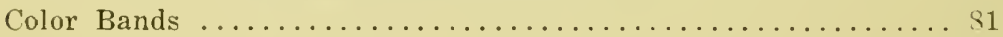

Knife ................................. 84 


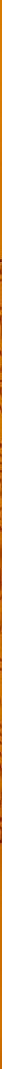



